4 nordon 



\section{Final report from the NORAP Priority Setting Workshop}

9-10 June 2009

Sigtuna, Sweden 
Final report from the NORAP Priority Setting Workshop

9-10 June 2009

Sigtuna, Sweden

TemaNord 2010:553

(C) Nordic Council of Ministers, Copenhagen 2010

ISBN 978-92-893-2084-9

This publication is available as Print on Demand (PoD) and can be ordered on

www.norden.org/order. Other Nordic publications are available at www.norden.org/en/publications.

$\begin{array}{ll}\text { Nordic Council of Ministers } & \text { Nordic Council } \\ \text { Ved Stranden } 18 & \text { Ved Stranden } 18 \\ \text { DK-1061 København K } & \text { DK-1061 København K } \\ \text { Phone (+45) } 33960200 & \text { Phone (+45) 3396 } 0400 \\ \text { Fax (+45) 3396 } 0202 & \text { Fax (+45) 3311 } 1870\end{array}$

www.norden.org

\section{Nordic co-operation}

Nordic co-operation is one of the world's most extensive forms of regional collaboration, involving Denmark, Finland, Iceland, Norway, Sweden, and three autonomous areas: the Faroe Islands, Greenland, and Åland.

Nordic co-operation has firm traditions in politics, the economy, and culture. It plays an important role in European and international collaboration, and aims at creating a strong Nordic community in $c$ strong Europe.

Nordic co-operation seeks to safeguard Nordic and regional interests and principles in the global community. Common Nordic values help the region solidify its position as one of the world's most innovative and competitive. 


\section{Content}

Preface

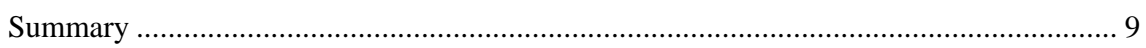

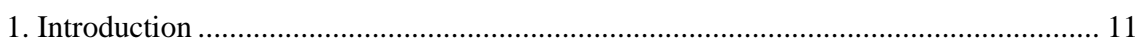

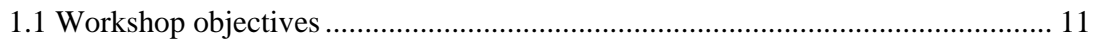

1.2 Introduction to the background document ........................................................ 12

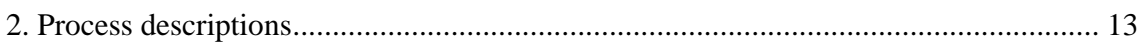

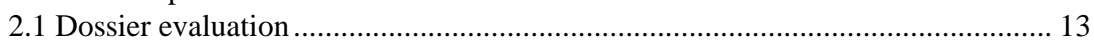

2.1.1 Examination of testing proposal......................................................... 13

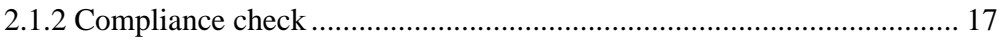

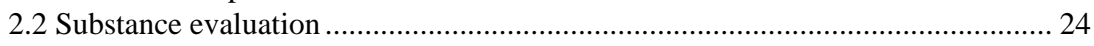

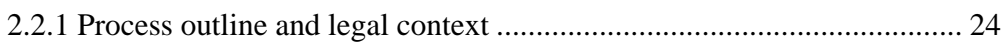

2.2.2 Work performed at MS CA related to the process................................... 29

2.2.3 Influencing factors for the process ........................................................ 31

2.2.4 Sources of information ........................................................................... 32

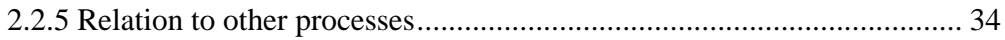

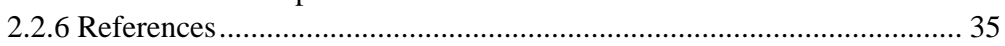

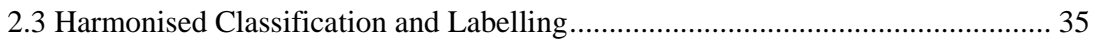

2.3.1 Process outline and legal context ........................................................ 35

2.3.2 Work performed at MS CA related to the process................................... 38

2.3.3 Influencing factors for the process ..................................................... 40

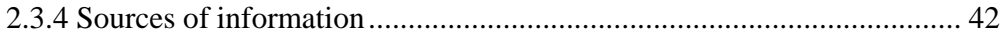

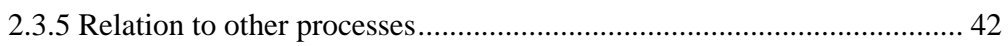

2.3.6 References ............................................................................................. 42

2.4 Identification of Substances of Very High Concern (SVHC) for the

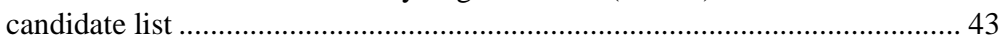

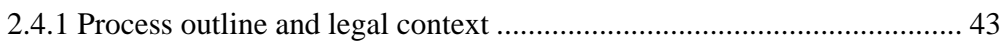

2.4.2 Work performed at MS CA related to the process................................... 44

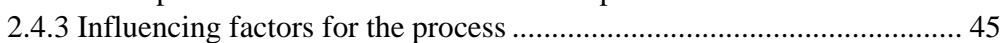

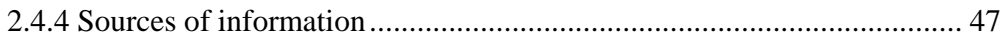

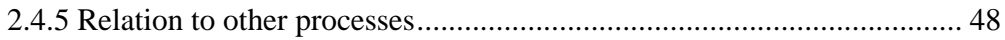

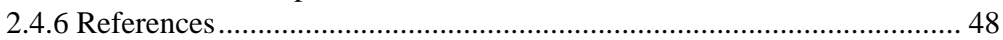

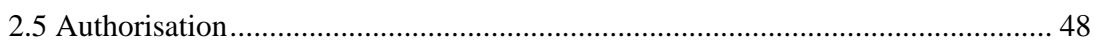

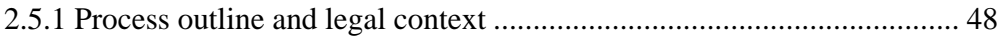

2.5.2 Work performed at MS CA related to the process....................................... 51

2.5.3 Influencing factors for the process ........................................................ 52

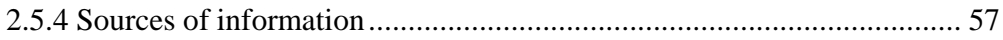

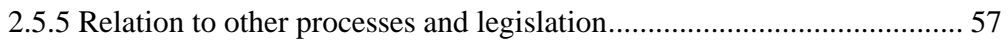

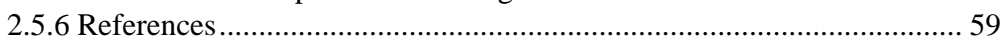

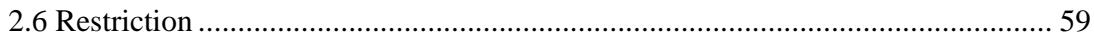

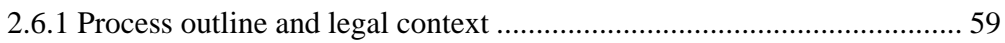

2.6.2 Work performed at MS CA related to the process.................................. 61

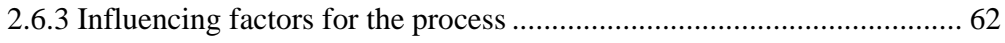

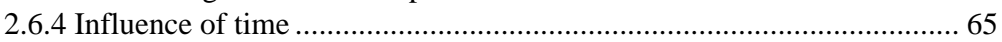

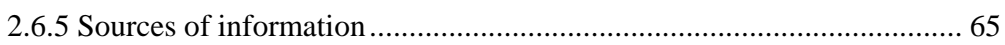

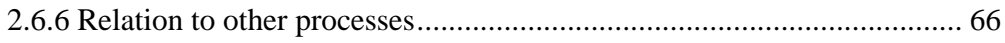

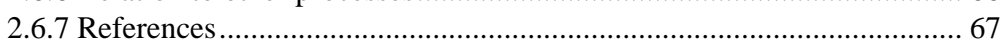


3. Considerations of different risk management options ......................................................69

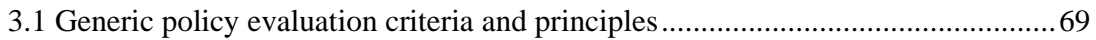

3.2 Authorisation vs. Restrictions, deciding on the route............................................ 70

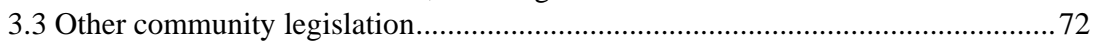

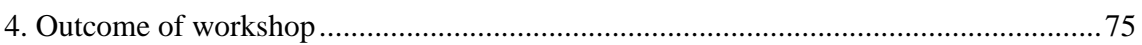

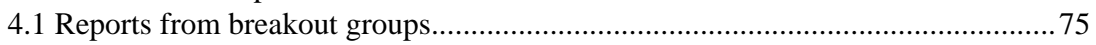

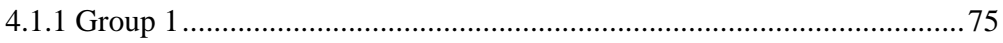

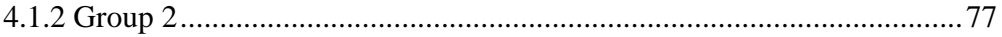

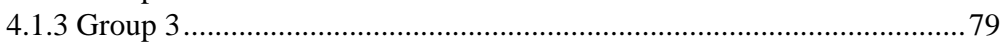

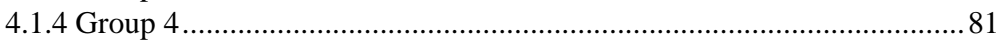

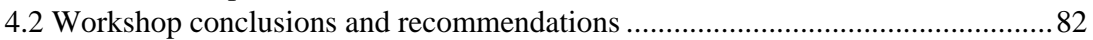

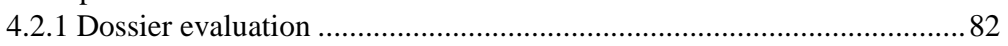

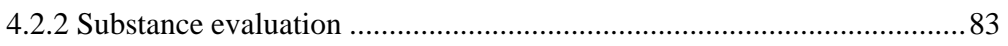

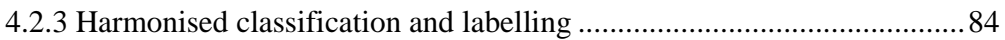

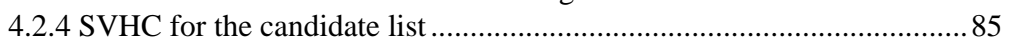

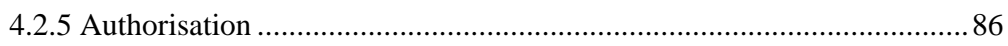

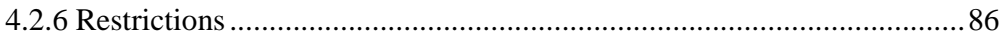

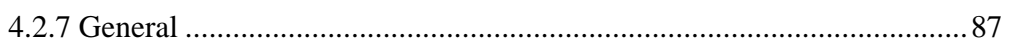

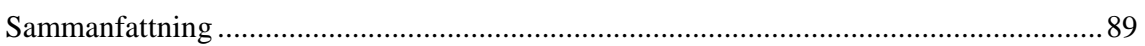

Annex 1 - Issues for discussion in breakout groups........................................................ 91

Annex 2 - Examples of further information that can be requested under substance evaluation

Annex 3 - Detailed tasks and responsibilities of the Member State

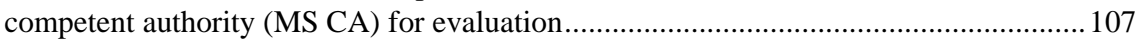

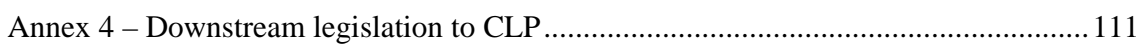

Annex 5 - Examples of existing Community legislation under

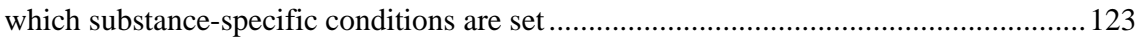

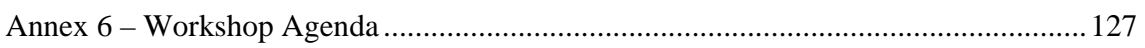

Annex 7 - Tasks for consideration and discussion in the breakout groups at the Workshop

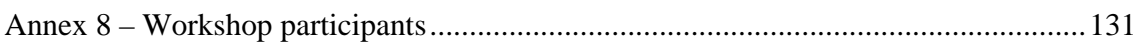




\section{Preface}

A Nordic workshop on priority settings within the context of the new working fields under the REACH regulation and the regulation on Classification, Labelling and Packaging (CLP) was organised in Sigtuna, Sweden on 9-10 June 2009. The main aims of this workshop was to increase the Nordic authorities' understanding of the processes involved, improve their competence in the priority setting of substances within these processes, as well as increase their awareness of the relevant factors influencing such decisions.

The workshop addressed priority setting for work under the processes which form the general basis and context for the main part of the work of Member State Competent Authorities (MS CAs) in relation to the European Chemicals Agency (ECHA) and its Committees. The outcome of the workshop is intended primarily for use by the Nordic countries in national priority setting, but could be used as well for national input in contribution to further developments in these processes under ECHA's responsibility. In particular, this would be appropriate for the development of risk based criteria for substance evaluation where ECHA is required by the REACH legislation to cooperate with the Member States.

This final report from the workshop contains both a background document (describing the main processes in REACH and CLP regulations) and conclusions from discussions that took place in the breakout groups during the workshop.

This report has been prepared with funding from the Nordic Chemicals Group of the Nordic Council of Ministers. The report has been written by; Jörgen Henriksson, Elisabeth Karlsson, Anna Wik, Alicja Andersson, Ivar Lundbergh and Lolo Heijkenskjöld at the Swedish Chemicals Agency.

The work has been guided by a Nordic Steering group, with the following members from the Nordic authorities: Katarina Lundberg and Ivar Lundbergh representing the Swedish Chemicals Agency, Sweden; Jon Birger Aarnes, Marianne van der Hagen and Marianne Tvermyr Holmen representing the Climate and Pollution Agency, Norway; Marie Louise Holmer and Henrik Tyle representing the Environmental Protection Agency, Denmark, Jaana Heiskanen representing the Finnish Environment Institute, Finland and Outi Tunnela representing the National Supervisory Authority for Welfare and Health, Finland; Sigridur Kristjansdottir representing the Environment Agency of Iceland. 



\section{Summary}

The Reach and CLP regulations have created a new working context for the Member States Competent Authorities (MSCA). The regulations have also introduced new processes aimed at regulating and informing about substances on the market (e.g. registration, the candidate list and authorisation). In addition, new working procedures are developed, in which the newly formed European Chemicals Agency (ECHA) has received a central role. In order to achieve the goal of effective chemicals management, the new system requires active participation of the MSCAs in the REACH/CLP processes and a close cooperation with ECHA.

In order to use their resources efficiently and to meet the new legislative requirements the MSCAs have to set their priorities. The MSCAs have to decide what substances to select for which processes, taking into account a variety of factors, both those formally expressed in the regulations and those important for their own national goals.

In order to understand the factors that may influence prioritization under Reach and CLP, a workshop on priority setting was organized and a background document prepared. The document describes the REACH/CLP processes that require MSCAs involvement, the legal context, the role of the MS Competent Authorities and the work implications such as tasks and resources required; factors influencing the priority setting; influence of time and especially the REACH registration stages; sources for information, and finally, relationships between the processes.

The list of identified factors was discussed at the workshop and completed by the workshop's participants. The conclusions and recommendations from the workshop may serve as a basis for setting the national priorities in the work with REACH and CLP. 



\section{Introduction}

A Nordic workshop on priority setting within the context of the new working fields under the REACH regulation and the regulation on Classification, Labelling and Packaging took place in Sigtuna, Sweden on 9-10 June 2009. The workshop was arranged by the Nordic Risk Assessment Project (NORAP) based on funding from the Nordic Chemicals Group (NKG) of the Nordic Council of Ministers (NMR).

The workshop addressed priority setting for work under processes which form the general basis and context for the main part of the work of Member State Competent Authorities (MS CAs) in relation to the European Chemicals Agency (ECHA) and its Committees. The relevant processes are for example substance and dossier evaluation, harmonised classification, development of dossiers for identification of substances of very high concern (SVHC) and their subsequent risk management through authorisation requirements, as well as proposals for restrictions on marketing and use.

The outcome of the workshop is intended primarily for use by the Nordic countries in national priority setting, but could be used as well for national input in contribution to further developments in these processes under ECHA's responsibility. In particular, this would be appropriate for the development of risk based criteria for substance evaluation where ECHA is required by the REACH legislation to cooperate with the Member States.

Workshop participants were staff from Nordic authorities experienced in either hazard and risk assessment or risk management of chemicals as well as invited experts from RIVM, Netherlands.

\subsection{Workshop objectives}

The objectives of the workshop were to increase the Nordic authorities' understanding of the processes involved and their competence in the priority setting of substances within these processes, and awareness of the relevant factors influencing such decisions. The outcome is the conclusions and recommendations based on breakout group discussions of the descriptions of the processes and discussion topics for each process. This may extend to developing criteria or even elements for priority setting strategies that may be further developed nationally by the Nordic countries. However, the background document and workshop were not intended to include the development or discussion of ranking procedures for these processes. An additional aim was also to provide a starting point for Nordic cooperation on developing background material that could be used for later national input to the prioritisation processes under the responsibility of ECHA. In particular, this 
would be appropriate for the development of risk based criteria for substance evaluation.

\subsection{Introduction to the background document}

This background document, developed for the workshop, covers the relevant processes that were discussed at the workshop. This document was circulated in advance of the workshop describing the various processes for priority setting and influencing factors etc. Furthermore, the background documentation includes suggested discussion topics that were subject for discussion in the breakout groups at the workshop. After the workshop this background documentation was developed into a final report also including the outcome from breakout group discussions and conclusions or recommendations (lessons learned) from the workshop.

Several processes in REACH and their issues for priority setting were considered for discussion at the workshop. The following processes/areas are included in the background documentation report:

- risk-based criteria for prioritising substances for substance evaluation on the Community Rolling Action Plan (CORAP);

- national priority setting of activities related to draft decisions emanating from dossier evaluation of registration dossiers;

- priority setting in choosing substances for proposed harmonised classification;

- priority setting of substances for identification as Substances of Very High Concern (SVHC) for the Candidate list, e.g. for Authorisation requirements;

- priority setting among such candidates for recommendation for the authorisation system; and

- priority setting for proposing substances for EU-wide restrictions.

For each process the background document covers a number of issues like: the legal context and relevant articles in REACH and CLP governing each process; the role of the MS Competent Authorities and the work implications such as tasks and resources required; factors influencing the priority setting; influence of time and especially the REACH registration stages; sources for information, and finally relationships between the processes. Discussion topics for the breakout sessions of the workshop are included as an Annex. 


\section{Process descriptions}

The different processes described in this report are not placed in order of importance or in order of sequence.

\subsection{Dossier evaluation}

Evaluation under REACH (Title VI of the REACH Regulation) defines the assessment of registration dossiers (examination of testing proposals and compliance check of registrations) and substances.

\subsubsection{Examination of testing proposal}

Process outline and legal context

The main objective of the examination of testing proposals is to investigate whether the information requirements according to REACH are fulfilled, and if the proposed studies are appropriate and will increase the knowledge of the dangerous properties of chemicals in order to protect human health and the environment, while at the same time preventing unnecessary animal testing and costs.

According to Article 40 all proposals for tests specified in Annexes IX and $\mathrm{X}$ submitted as part of registrations or in downstream user reports have to be examined and a decision drafted by ECHA.

Testing should only be necessary when information on the dangerous properties is needed for compliance under REACH, i.e. when the registrant considers it necessary to obtain additional information to allow them to assess and document that risks are adequately controlled. Consequently Annex $\mathrm{XI}$, as well as specific adaptation rules in Annexes VII to X, has been developed with a view to keeping animal testing to a minimum.

Two main aspects in relation to examination of testing proposals can be identified.

- Whether the proposal complies with the standard testing requirements.

- Whether reasons for proposing additional testing for endpoints beyond the standard testing requirements are appropriate.

Depending on the outcome of the examination of the testing proposal ECHA shall draft one of the following decisions (Article 40(3)): 
- a decision requiring the registrant(s) or downstream user(s) concerned to carry out the proposed test and setting a deadline for submission of the study summary, or the robust study summary if required by Annex I;

- a decision in accordance with point (a), but modifying the conditions under which the test is to be carried out;

- a decision in accordance with points (a), (b) or (d) but requiring registrant(s) or downstream user(s) to carry one or more additional tests in cases of non-compliance of the testing proposal with Annexes IX, $\mathrm{X}$ and $\mathrm{XI}$;

- a decision rejecting the testing proposal;

- a decision in accordance with points (a), (b) or (c), if several registrants or downstream users of the same substance have submitted proposals for the same test, giving them the opportunity to reach an agreement on who will perform the test on behalf of all of them and to inform ECHA accordingly within 90 days. If ECHA is not informed of such agreement within such 90 days, it shall designate one of the registrants or downstream users, as appropriate, to perform the test on behalf of all of them.

For non phase-in substances a decision shall be drafted within 180 days of receiving a registration or downstream user report containing a testing proposal. For phase-in substances the deadlines are substantially longer. ECHA shall draft a decision within 5.5, 9 and 15 years for those dossiers which have been submitted within 3.5, 6 and 11 years respectively after entry into force of REACH.

All testing proposals have to be examined and decisions drafted within the above deadlines. Priority will be given to substances which have or may have persistent, bioaccumulative and toxic (PBT), very persistent and very bioaccumulative (vPvB), sensitising, and/or carcinogenic, mutagenic and toxic for reproduction (CMR) properties, or substances produced and/or imported in quantities above 100 tonnes per year, classified as dangerous and with uses resulting in widespread and diffuse exposure (Article 40(1)).

The final decision will be taken in accordance with the procedure laid down in Articles 50 and 51 and will take at least 30 days to allow for any comments by the registrant or downstream user. The procedure can take up to more than 6 months in cases where MS-CAs proposes to amend the decision drafted by ECHA. The Commission will take the final decision if the MS Committee fails to reach unanimous agreement within 60 days of the referral. For this procedure no fixed deadline is set.

The ECHA decision should take into account an appropriate time frame when setting deadlines. The registrant should be pro-active and inform ECHA in time if he cannot meet the deadline set. If the test requested by the final decision is not submitted within the specified deadline, ECHA has to decide whether a new decision should be taken or the enforcement authorities will be informed to consider possible further action. 
Work performed at MS CA related to the process

Role of the MS CA in the process: The obligation of the individual Member State Competent Authority is to:

- examine, and if appropriate, to propose amendments on draft decisions made by ECHA resulting from the examination of testing proposal

A detailed description of the tasks and responsibilities of the MS CA for dossier evaluation is included in Appendix 1.

Work required throughout the process: The examination of testing proposal is performed by ECHA, however the process as such will still result in draft decisions on testing proposals, made by ECHA, which need to be examined, and if appropriate to propose amendments on.

Influencing factors for the process

According to information presented at the MSC meeting (MSC-7) in April 2009, ECHA estimates that they will perform approximately 100 dossier evaluations 2009 and in the order of 600 during 2010. As a consequence of this, the number of draft decisions for the MSCA to examine will likely be considerable, which will require the MS CA to prioritise which to examine and which not to examine. Below are a number of influencing factors (not listed in any order of priority), separated between legal and others, that may be used when making prioritisation between which draft decisions to focus resources on and which not.

- Legal:

An influencing factor specified in the REACH legislation that may influence the prioritisation of which draft decisions to focus on (if too many to examine them all) is:

- If the test is prioritised according to Article 40(1)

- Other:

Examples of factors that may influence the prioritisation of which draft decisions to focus on (if too many to examine them all) are:

Type of test protocol, standard test or not

- If the substance is a so-called "difficult substance” (e.g. low water solubility, highly volatile, ...) which may require specific considerations as regards test design and interpretation of the test results

- If the test protocol used may have influence on how other tests may be designed ("setting of precedence") 
- Available non-testing data for a substance, which are considered reliable enough, that can be used instead of the data resulting from the proposed test

- Available non-testing data for a substance, which are considered reliable enough, that indicate that other tests are required (e.g. fish early-life stage (FELS) test proposed but non-testing data indicate the need to also test for bioaccumulation)

- And of course resources available and country specific political instructions etc. (from government/departments)

\section{Additional influencing factors identified at the workshop}

Additional influencing factors that were recognised for examining testing proposals were:

- information on use via product register data;

- substances with high political focus (e.g. endocrine disrupters).

\section{Sources of information}

Registration dossier and testing proposals.

\section{Relation to other processes}

In general, the three evaluation tasks (testing proposal and compliance check within dossier evaluation, and substance evaluation) are to be considered independently. However, certain links are evident, and results and information obtained in the different tasks should be used and linked in an intelligent manner, particularly to avoid any duplication of work between ECHA and MS CAs.

There is no automatic link between the examination of testing proposals and the compliance check of registrations which are the two parts of the dossier evaluation. In fact examination of testing proposals and compliance check are two separate processes. However, a dossier can be evaluated for testing proposal(s) and also be selected for a compliance check. In addition, the examination of a testing proposal could result in a check on some relevant sections of the CSR or different studies included in the technical report. Hence, all the steps undertaken during the examination of testing proposals should be properly documented in order to avoid any duplication of this work if the dossier is selected for a compliance check.

The same links that can be made between the examination of testing proposal and compliance check can also be identified between testing proposal and substance evaluation. Indeed, during the stage of testing proposal examination, a partial check of relevant parts of the CSR and/or the technical report might be performed. Consequently, to avoid unnecessary duplication of work, it is important that any remark on the quality of parts of the registration dossier made during the evaluation of testing proposal is reported via 
annotations in IUCLID 5 and is taken into account by the MS-CAs in their substance evaluation.

\section{References}

The following documents have been used for the compilation of this section on the examination of testing proposal.

- ECHA "Guidance on priority setting for evaluation” (available on http://guidance.echa.europa.eu/)

- ECHA" Guidance on Dossier and Substance Evaluation” (available on http://guidance.echa.europa.eu/)

\subsubsection{Compliance check}

Process outline and legal context

The purpose of checking a registration dossier for compliance is to ensure that the legal requirements of REACH are fulfilled and the quality of the submitted dossiers is sufficient, the safety assessment is suitably documented in a Chemical Safety Report (CSR) as required in the REACH Regulation, the proposed risk management measures are adequate, and that any explanation to opt out from a joint submission of data has an objective basis. ECHA may request further information from registrants in case the information submitted does not comply with the requirements of REACH.

According to Article 41(1) ECHA may examine any registration in order to verify any of the following:

a) that the information in the technical dossier(s) submitted pursuant to Article 10 complies with the requirements of Articles 10, 12, and 13 and with Annexes III and VI to X;

b) that the adaptations of the standard information requirements and the related justifications submitted in the technical dossier(s) comply with the rules governing such adaptations set out in Annexes VII to $X$ and with the general rules set out in Annex XI;

c) that any required chemical safety assessment and chemical safety report comply with the requirements of Annex I and that the proposed risk management measures are adequate;

d) that any explanation(s) submitted in accordance with Article 11(3) or Article 19(2) have an objective basis.

The compliance check differs from the completeness check that is carried out by ECHA under Article 20(2). Within the compliance check ECHA has to determine whether the information submitted in the technical dossier or in the CSR is adequate and corresponds to the requirements of REACH, by taking into account the tonnage and rules for adaptations of standard information requirements. In contrast, the completeness check is an automated 
process that does not include an assessment of the quality or the adequacy of any data or justifications submitted.

If the dossier does not comply ECHA shall prepare a draft decision requiring the registrant to submit any information necessary to bring the dossier into compliance with the requirements. It can therefore be regarded as a control tool to ensure the quality of the registration dossiers. This draft decision will follow an adoption process (Article 50/51 procedure) to ensure that the registrant and downstream user, as well as the MS CA and the members of the MS Committee, can comment and agree on the proposal.

In the context of Article 41(1)(a) to (c) ECHA should check the adequacy and the interpretation of the information presented in the registration dossier(s).

In the context of Article 41(1)(d) ECHA should check if the explanation(s) for separate submission of information have an objective basis. According to Article 11(3) or Article 19(2), the manufacturer or importer may submit information separately if:

a) it would be disproportionately costly for him to submit this information jointly; or

b) submitting the information jointly would lead to disclosure of information which he considers to be commercially sensitive and is likely to cause him substantial commercial detriment; or

c) he disagrees with the lead registrant on the selection of this information

It should be borne in mind that the results obtained from the compliance check shall be used when carrying out other activities, i.e. by MS CAs for the purposes of substance evaluation (Articles 45(5)), identification of substances of very high concern (Article 59(3)) and restriction (Article 69(4)) and by ECHA for the purpose of developing criteria for substance evaluation (Article 44) (cf. Article 42(2)).

ECHA may select any registration dossier for a compliance check and may not necessarily check all parts of the registration dossier. Within 12 months from the start of a compliance check, ECHA may prepare a draft decision requiring the registrant to submit further information within adequate time limits. When a decision is taken and the information required is submitted, the procedure ends. If there are reasons to check the dossier again at a later date, the dossier can be selected for another compliance check. However, multiple decisions on one and the same dossier shall be avoided where possible.

The task of ECHA with regard to selecting dossiers for compliance checking will be to:

- apply specified criteria (Article 41(5)) and random selection; and

- define new criteria from the experience gained. 
To ensure that the registration dossiers comply with the Regulation, ECHA shall select a percentage of these dossiers for compliance checking, not lower than 5\% of the total received by ECHA for each tonnage band.

Where registration dossiers are to be selected for a compliance check in a non-random manner, the Regulation specifies some criteria for dossier selection. Article 41(5) explicitly states that priority for compliance check shall be given to dossiers meeting at least one of the following criteria:

a) Information in the technical dossier on the following parts was submitted separately in case of a joint submission:

- classification and labelling, Article 10(a)(iv);

- study summaries, Article 10(a)(vi); and/or

- robust study summaries, Article 10(a)(vii).

b) The dossier for a substance (phase-in and non-phase-in) manufactured or imported in volumes above 1 tonne per year does not meet the full requirements of Annex VII.

For phase-in substances that are manufactured or imported in volumes between 1 and 10 tonnes per year not meeting the criteria of Annex III, the registrant is not obliged to fulfil all the requirements of Annex VII and is allowed to submit only the physicochemical properties mentioned in Annex VII.

c) The dossier is for a substance listed in the Community rolling action plan.

Duplication of work should be avoided as much as possible and ideally the results of the compliance check(s) should be available prior to or in the first stage of substance evaluation. It is highly recommended that ECHA performs the compliance check(s) of the registration dossier(s) relating to a substance on the Community rolling action plan as soon as the substance is known to be on the Community rolling action plan.

However, these priority criteria are not exclusive. Additionally, information submitted by third parties shall be considered when selecting dossiers for a compliance check (Article 41(6)).

Besides the criteria for dossier selection mentioned in the Regulation and cited above, a compliance check may be performed on dossiers selected by using one or a combination of trigger criteria listed below. Some of these criteria could be used as a trigger for a targeted compliance check as well. Guidance on selection criteria for a compliance check is given in the ECHA "Guidance on priority setting for evaluation" and in Annex 3 in this guidance are the following supplementary criteria proposed:

- Dossiers containing waiving statements.

- If a testing proposal is submitted for a test quoted in Annexes VII or VIII. 
- The information submitted by third parties as suggested in Article 41(6) is contradictory to information in the dossier. In any case, the adequacy of the information received from third parties needs to be checked first.

- Dossiers highlighted by Member States (e.g. during preparation of an Annex XV dossier or from enforcement activities of REACH) or ECHA itself (e.g. during examination of testing proposals or preparation of an Annex XV dossier), identifying poor quality or gaps in registration requirements.

- The dossier has been flagged because of non-compliance of data used in a category or read across approach.

- Specific physicochemical properties of the substance which make testing difficult may require an in-depth quality check (e.g. substances of low solubility, volatile substances).

In order to save time and reduce the workload a compliance check might be performed only on specific parts (e.g. human health endpoints) of the dossier. ECHA may target the compliance check by checking specific sections of the registration dossier. This involves:

- targeting specific parts of the technical dossier and CSR; and

- identifying new criteria for targeting the compliance check

Whenever targeting a compliance check, a stepwise approach is considered useful. Thereby part of the dossier will be checked for compliance, and if this is found to be non-compliant then checks on further parts of the dossier may be carried out.

Work performed at MS CA related to the process

- Role of the MS CA in the process:

The obligations of the individual Member State Competent Authority are to:

- examine, and if appropriate, to propose amendments on draft decisions made by ECHA resulting from the compliance check

- send in any available information on substances registered where the dossiers do not contain the full information, especially if enforcement or monitoring activities have identified suspicions of risk

A detailed description of the tasks and responsibilities of the MS CA for dossier evaluation is included in Appendix 1.

- Work required throughout the process:

The compliance check is performed by ECHA. The obligation of the MS $\mathrm{CA}$ is to send in available information on substances registered where the 
dossiers do not contain the full information should be performed before a substance has entered the process of compliance check.

The process as such will also result in draft decisions made by ECHA which need to be examined, and if appropriate to propose amendments on.

\section{Influencing factors for the process}

According to information presented at the MSC meeting (MSC-7) in April 2009, ECHA estimates that they will perform approximately 100 dossier evaluations 2009 and in the order of 600 during 2010. As a consequence of this the number of draft decisions for the MSCA to examine will likely be considerable, which will require the MS CA to prioritise which to examine and which not to examine. Thus, even though the prioritization of substances for compliance check is done by ECHA only, the process as such will most likely result in considerable work for the MS CA, work that will require prioritisation. Below are a number of influencing factors (not listed in any order of priority), separated between legal and others, that may be used when making prioritisation between which draft decisions to focus resources on and which not.

- Legal:

An influencing factor specified in the REACH legislation that may influence the prioritisation of which draft decisions to focus on (if to many to examine them all) is:

If the dossier is prioritised according to Article 41(5)

- Other:

Examples of factors that may influence the prioritisation of which draft decisions to focus on (if too many to examine them all) are:

- If testing is required, see influencing factors listed for "Examination of testing proposals" above

- If the substance is a so-called "difficult substance" (e.g. low water solubility, highly volatile, ...) which may require specific considerations as regards the interpretation of the data

- If the dossier contain waiving statements

- If the different registrants, in case of a joint submission, have different opinions on how the substance should be classified

- Available non-testing data for a substance, which are considered reliable enough, that indicate a higher toxicity than presented in the dossier

- And of course resources available and country specific political instructions etc. (from government/departments) 
Additional influencing factors identified at the workshop

Additional influencing factors that were recognised to influence the priority for examining draft decisions on compliance checking were:

- information from enforcement and monitoring data;

- non classified high volume substances (for example where use of (Q)SARs or available "self-classification lists" indicate that classifycation is warranted).

Sources of information:

The main source of information for compliance check is the information submitted in the technical dossier or in the CSR. Both will be available to the MSCA via REACH-IT.

Other sources of information that may contain useful information exists, e.g.: the Risk Assessment Reports produced during the Existing Substance Regulation (RARs already published are available in ESIS, the rest has been submitted by the MSCAs as transitional dossiers and will be published later on, according to ECHA), SIAP/SIAR resulting from the OECD HPVchemicals program, WHO- and IARC-substance monographs, criteria documents from the Scientific Committee on Occupational Exposure Limits (SCOEL), priority hazardous substances according to the European Water Framework Directive; chemicals for priority action according to OSPAR and HELCOM, the Domestic Substances List of Environment Canada, the US EPA Priority PBTs, the Washington State PBT list; the Substitute It Now list (from the International Chemical Secretariat), the European Trade Union Confederation priority list for Reach authorisation, and the European Commissions lists of possible chemicals with potential for endocrine disruption. Furthermore, substances frequently detected in monitoring studies (especially from remote areas) could also be considered.

\section{Relation to other processes:}

In general, the three evaluation tasks (testing proposal and compliance check within dossier evaluation, and substance evaluation) are to be considered independently. However, certain links are evident, and results and information obtained in the different tasks should be used and linked in an intelligent manner, particularly to avoid any duplication of work between ECHA and MS CAs.

There is no automatic link between the examination of testing proposals and the compliance check of registrations which are the two parts of the dossier evaluation. In fact examination of testing proposals and compliance check are two separate processes. However, a dossier can be evaluated for testing proposal(s) and also be selected for a compliance check. In addition, the examination of a testing proposal could result in a check on some relevant sections of the CSR or different studies included in the technical report. Hence, all the steps undertaken during the examination of testing proposals 
should be properly documented in order to avoid any duplication of this work if the dossier is selected for a compliance check.

Compliance check and substance evaluation are processes that can in principle start independently, one after the other, or even in parallel. Where a compliance check is carried out first, any information obtained as a result of this evaluation process shall be taken into account by MS CAs in order to conclude whether there is concern that the substance constitutes a risk to human health or the environment. For this reason annotations as proposed in IUCLID 5 should be used. In case of a risk the MS CA shall highlight the substance to ECHA for addition to the Community rolling action plan for further evaluation. Substance evaluation should be based on valid information in order to ensure the quality of the assessment. Therefore a quality check of the relevant dossier(s) is regarded as being a basis for substance evaluation.

Registration dossiers for substances on the Community rolling action plan are, according to Article 41(5)(c), prioritised for compliance check. The highest priority should be given to those dossiers which fulfil at least one of the criteria mentioned in Article 41(5); further priority criteria for dossier selection can be found in the ECHA "Guidance on priority setting for evaluation”. The deadline for both procedures is 12 months. Therefore, a compliance check (by ECHA) and substance evaluation (by the MS CA) can run in parallel and the result of the compliance check may not necessarily be available before the substance evaluation begins. In order to promote that the results of a compliance check are available in a suitable timeframe, ECHA should prioritise the relevant dossier(s) for a compliance check as soon as the substance is known to be put on the draft Community rolling action plan.

The MS CA shall, before formally starting a substance evaluation, get information on the status of the dossier(s) regarding compliance check. Ideally the result of a compliance check should be available during the earliest stage of evaluation and duplication of work should be avoided. ECHA will make available to MS CA's a list of dossiers for which the compliance check has been started (Article 41(2)). However, it may be useful for a Member State to contact ECHA in order to get information on the future time plan. It should be noted that more than one dossier might be available for one substance. If a compliance check(s) of the dossier(s) for the substance is/are not available, and the MS CA concludes that a compliance check should be conducted, they should discuss the procedure with ECHA. Where a MS CA wants to start a substance evaluation and no compliance check is available, the MS CA needs to perform a quality check of the dossiers itself. A compliance check performed by ECHA is not a precondition for starting a substance evaluation by a MS CA. Also, in this case the MS CA and ECHA shall be in dialogue to avoid duplication of work and to ensure consistency. Whereas the main idea behind the substance evaluation is to get appropriate further information to clarify an initial concern, and then consider how to 
use any information obtained for the purpose of restriction, identification of substances of very high concern or harmonised classification and labelling, the compliance check is intended to only check the quality of the dossier. Thus it is stressed that it is not the aim of a compliance check to identify candidates for restriction/authorisation/harmonised classification and labelling, although new information obtained after dossier evaluation may finally be used for that purpose.

\section{References}

The following documents have been used for the compilation of this section on the compliance check process.

- ECHA “Guidance on priority setting for evaluation" (available on http://guidance.echa.europa.eu/)

- ECHA" Guidance on Dossier and Substance Evaluation” (available on http://guidance.echa.europa.eu/)

\subsection{Substance evaluation}

\subsubsection{Process outline and legal context}

Substance evaluation aims to clarify any grounds for considering that a given substance constitutes a risk to human health or the environment. It is a process of data collection and data review, starting with the initial concern and ending with a decision on how to address it, if appropriate. The coordination of this process falls under the responsibility of ECHA. Member State competent authorities (MS CAs) are responsible for carrying out the evaluations.

\section{Substances to be evaluated}

In order to provide a harmonised approach, criteria for prioritising substances for inclusion in the (draft) Community rolling action plan (CORAPlist) shall be developed by ECHA in co-operation with the Member States. Article 44(1) of REACH indicates the considerations for criteria for prioritising substances for inclusion in the (draft) CORAP-list.

ECHA will combine information from registration dossiers and dossier evaluation (when available) with the prioritising criteria to compile a draft CORAP-list which covers a period of three years and specifies substances to be evaluated each year. ECHA submits the first draft CORAP-list to the Member States by 1 December 2011 and adopts the final Community rolling action plan on the basis of an opinion from the Member State Committee. ECHA publishes it on its website. ECHA will submit draft annual updates to the Member States by 28 February each year.

There are two possibilities for a Member State to propose a substance for addition to the CORAP-list to allow for a substance evaluation to be con- 
ducted. The first is during the process of drafting the CORAP-list. The Member State should describe the grounds for considering that the substance constitutes a risk to human health or the environment and argue why (in line with the criteria of Article 44) the substance should be prioritised for addition to the draft CORAP-list (Article 44(2)). Alternatively, a Member State may notify (see Article 45(5)) ECHA at any time of a substance not on the CORAP-list, whenever it is in possession of information which suggests that the substance is of priority for evaluation. ECHA decides whether to add this substance to the CORAP-list on the basis of an opinion from the Member State Committee. It is not possible to withdraw substances from the CORAP-list once it is published.

Only substances that have been registered and appear on the CORAP-list will be subject to the process of substance evaluation by an MS CA.

The only exception would be when read across has been applied. Article 47(1) state that if information on the intrinsic properties has been developed with reference to related substances, then these related substances may form part of the evaluation. This means that if a registrant has derived some of the data on e.g. substance A by read across from others (e.g. substance B and C), then these others ( $B$ and $C$ ) can also be the subject of the evaluation, although substances $\mathrm{B}$ and $\mathrm{C}$ are not included in the Community rolling action plan and possibly not registered themselves. If the MS CA thinks that further information on yet another substance (e.g. substance D) would help to resolve the uncertainties, then they would have to include this substance D on the Community rolling action plan (provided substance $\mathrm{D}$ has been registered) if this substance is not already used in the registration for the main substance. The latter could for instance apply where the registrant had used read-across but with other substances than the one the MS CA wishes to use or where the MS CA considers that the alternative substance will act by the same mode of action, and might be easier to test than the main substance and other alternatives used in the registration by virtue of its properties.

Certain substances are exempted from the substance evaluation: substances included in Annex IV of REACH (substances considered to cause minimum risk because of their intrinsic properties ), substances covered by Annex $\mathrm{V}$ of REACH (substances where registration is deemed inappropriate or unnecessary) and under certain conditions, substances registered, exported and reimported into the Community, substances registered and recovered. In addition, the provisions of REACH concerning evaluation do not apply to the extent that a substance is used in medicinal products for human or veterinary use and in food or feeding stuff (including use as an additive or as flavouring). Moreover, evaluation does not apply for the time to polymers. For on-site isolated intermediates used in strictly controlled conditions, which are not subject to evaluation, the MS CA in whose territory the site is located may however ask for additional information and if necessary recommend any appropriate risk reduction measures; the MS CA must demonstrate in these cases that use of the substance gives rise to a risk equivalent to the level of concern 
arising from the use of substances meeting the criteria for possible inclusion in Annex XIV (substances subject to authorisation).

\section{Allocation of substances to Member States}

The CORAP-list lists the substances to be evaluated each year together with the Member State responsible for the evaluation of the respective substances.

The MS CAs is responsible for carrying out the substance evaluations. However, the only substance evaluation that the MS CA is required to perform, according to REACH, are the ones that the MS CA choose to do. In the event of a substance from the CORAP-list not being chosen by any Member State, ECHA shall ensure that the substance is evaluated (Article 45(1)). It is possible that two or more Member States express an interest in evaluating the same substance. If these Member States cannot agree who should carry out the evaluation, ECHA shall refer the matter to the Member State Committee in order to determine which authority shall be in charge of the evaluation, taking into account the Member State in which the manufacturer(s) or importer(s) is/are located, the respective proportions of total Community gross domestic product, the number of substances already being evaluated by a Member State and the expertise available. If the Member State Committee fails to reach a unanimous agreement, the conflicting opinions are submitted to the Commission, which shall take decision, under the committee procedure, which authority shall be in charge of the evaluation.

If a substance is added to the CORAP-list following a notification by a Member State, the proposing MS, or another MS who agrees, shall evaluate that substance.

In carrying out an evaluation of a substance, the competent authorities may appoint another body to act on their behalf, working under the same conditions as them, including the protection of information that has been agreed to be treated as confidential.

\section{Methodology for substance evaluation}

The assessment carried out by the MS CA involves the collection of information relating to the area of concern, the review of this information and a conclusion on whether there is sufficient information to assess the concern.

The main source of information is the registration dossier(s) for the substance. Results from dossier evaluation - if available - or any previous substance evaluation have also to be used. Note that where a MS CA wants to start a substance evaluation and no compliance check is available, the MS CA needs to perform a quality check of the dossiers itself.

The evaluating MS CA may wish to do a targeted substance evaluation, i.e. focus on only specified parts or choose to do a comprehensive evaluation of the substance. In any case, the substance evaluation has to address all grounds that have been identified for considering a risk to human health and/or the environment. 
If the evaluating MS CA comes to the conclusion that, following the data review, the available information is not sufficient to decide whether an initial concern over the risk can be substantiated, it may request further information, including if appropriate, information not required in annexes VII to $\mathrm{X}$ of REACH. Any information can be requested, if justifiable, and it may address general aspects, intrinsic properties of the substance and exposure characteristics (see Appendix 2).

The MS CA may consider engaging in an informal consultation with the registrant(s) to obtain additional information. This informal and voluntary process may be an efficient way to obtain the missing information. If the MS CA considers that it is better, for whatever reason, not to engage in informal consultation, or if the voluntarily submitted information is still not sufficient to conclude on the concern, the MS CA may proceed with the drafting of a formal request for further information under Article 46. The draft request for further information shall be submitted by the evaluating MS CA to ECHA within 12 months of publication of the Community rolling action plan on ECHAs website. After submission to ECHA the procedures described in Article 50 and 52 shall be followed.

The request for further information can include a request for several tests to be performed consecutively, where the need for each test after the first depends on the result of the preceding test. The conditions and test sequence should be clearly indicated in the request for further information. There is also the possibility to request further data once the new data have been received and evaluated.

Criteria and priorities shall be developed by ECHA (Article 47) in order to ensure a harmonised approach to requests for further information, based on monitoring by ECHA of draft decisions under Article 46. Where appropriate, implementing measures shall be adopted in accordance with the procedure referred to in Article 133(3).

There can be three types of decisions in accordance with Article 51 and 52.

1. The MS CA draft decision (which is not made public)

This decision is sent by the MS CA to ECHA and circulated by

ECHA to the registrant(s) (or downstream user(s)) concerned.

Registrants or downstream users potentially affected by an evaluation decision have the right to comment on the draft decisions being prepared by the MS-CA and to have those comments taken into account (Article 50).

2. ECHAs decision (which will not be made public).

The MS CA shall circulate its draft decision, together with any comments by the registrant(s) or downstream user(s), to ECHA and to the other MS-CA's. Member States have the possibility to comment on (draft) decisions prepared by other MS CA's (Article 51/52). Member States may propose amendments to a draft decision via ECHA and may comment on the (modified) draft decision via the 
MS Committee.

If ECHA does not receive any proposal for amendments, ECHA adopts the decision and notifies it to the MS-CA's and to the registrant(s).

If ECHA receives a proposal for amendment, it may modify the decision and shall refer the decision, together with the amendments proposed to the MS Committee, and communicate any proposal for amendment to the registrant(s) and/or downstream user(s). If the MS Committee reaches unanimous agreement on the draft decision, ECHA shall take the decision accordingly and inform the MS-CAs and the registrant(s).

According to Article 51(8) an appeal may be brought, in accordance with Articles 91, 92 and 93, against ECHAs decision.

3. The Commission decision

If the MS Committee fails to reach unanimous agreement, the Commission shall prepare a draft decision to be taken in the Regulatory Committee according to Article 133(3).

The Article 46 decision of ECHA or the Commission is addressed to registrant(s) and does not need publication in the Official Journal (OJ) in order to enter into force. The prerequisite for entry into force is notification of the relevant parties. This does not mean that they will not be published in the OJ. However, the information on the substance (in accordance with Article 119) may need to be updated as a result of the decision. The decision itself would be subject to Article 118 and interested parties could use the information provided under Article 77(2)(f) to ask for decisions on a particular substance. The merits of each case as regards confidentiality will then have to be considered.

After the registrant(s) has/have performed the testing or gathered the information, the information shall be sent to ECHA by the set deadline. The evaluating MS-CA shall, after receipt of the submitted information from ECHA, examine any information submitted.

The MS-CA should then decide whether the available data are now sufficient to conclude on the concern. If the information is still not sufficient, or the circumstances have changed, e.g. as a result of the newly submitted data, it shall draft any appropriate decision within 12 months of the information being submitted. If however the data are considered to be sufficient to conclude on the concern, the conclusion may be that there still is concern or that the submitted information has removed the concern. If concern remains, the MS-CA shall inform ECHA on the follow-up of the substance evaluation. If the concern has been removed, the results of the evaluation shall be documented in the appropriate format and added to the relevant part of REACH-IT. 


\section{Outcome of the substance evaluation process}

According to Article 48 "Once the substance evaluation has been completed, the competent authority shall consider how to use the information obtained from this evaluation for the purpose of Article 59(3), Article 69(4) and Article 115(1). The competent authority shall inform the Agency of its conclusions as to whether or how to use the information obtained. The Agency shall in turn inform the Commission, the registrant and the competent authorities of other Member States."

Thus, substance evaluation may lead to conclusions such as:

- initial concern has been removed;

- action needs to be taken under the restriction or authorisation procedures;

- there is a need for harmonised classification and labelling;

- information needs to be given to other authorities to take appropriate action under other legislation.

Moreover the information gained through an evaluation process should be used by registrants to manage the risks related to their substances and to update their registration dossiers.

\subsubsection{Work performed at MS CA related to the process}

\section{Role of the MS CA in the process}

The obligations of the individual Member State Competent Authority are to:

- cooperate with ECHA in order to develop criteria for prioritising substances for substance evaluation

- propose substances to be added to the CORAP-list

- conduct a substance evaluation when a substance is on the CORAP-list

- draft decisions under substance evaluation and contribute to the decision making process on requesting further necessary information to be submitted by registrants and, in rare cases, by downstream users

- examine, and if appropriate, to propose amendments on draft decisions resulting from substance evaluations

A detailed description of the tasks and responsibilities of the MS CA for substance evaluation is included in Appendix 3.

\section{Work required throughout the process}

Substance evaluations is not expected to start before 2012 since the first draft rolling action plan is planned to be sent by ECHA to the Member States by 1 December 2011. ECHA will then adopt the final Community rolling action plan on the basis of an opinion from the Member State Committee. This since substance evaluations can only be performed on substances on the CORAP-list. 
Once the development of the criteria for prioritising substances for inclusion on the CORAP-list, together with ECHA, is completed, two types of work will be performed at MS-CA related to substance evaluation. It is the work associated with the substance evaluation of a selected substance and it is the work associated with deriving proposals of substances to include on the CORAP-list.

As regards the substance evaluation, the intensity of the work performed by the MS CA will probably vary during the process with peaks associated with the preparation of potential draft decisions, with requests for further information, and with the preparation of the final conclusion(s).

As regards the deriving of proposal of substances for inclusion on the CORAP-list, the formal expression of concern to ECHA can be done at any point in time, i.e. after an initial concern has been identified, after a first look at the available data, or after a comprehensive data review. The timing of this action is important and the following aspects need to be considered by the Member State:

- How to express the concern to ECHA?

- What is the duration of the procedure to come to inclusion of a substance in the Community rolling action plan? Note that the Community rolling action plan is updated annually and submitted to the Member States by 28 February each year.

- What is the urgency and magnitude of the concern?

- When should the relevant information be available?

- What certainty does the Member State want to have that their request for further information addresses all relevant missing information? Note that any subsequent draft decision requiring further information under Article 46 may be justified only by a change of circumstances or acquired knowledge (Article 47). In other words, it is not possible to ask for further information again and again if the circumstances have not changed. However, a further request can be made after a review of the new information if it did not resolve the issue.

- Is it possible to do the substance evaluation within 12 months after publication of the Community rolling action plan? For example, are sufficient resources available?

- Has testing been proposed by the registrant(s) or is testing underway? Have the testing plans been reviewed? It may be the case that the substance is undergoing testing, for example as proposed in the Technical Dossier. Any such testing should be considered in case it might be of relevance to the evaluation. If the testing is relevant, then it should be considered very carefully whether to proceed or whether to await the result of the testing. If the information on the substance includes testing proposals which have not yet been implemented, these proposals should be examined to determine whether they would be able to address the initial concern identified in the review. 
There is no best practice in these cases as the timing is dependent on the specific case. For example, if a Member State has a great concern over a substance and wants to address this urgently, it may be worthwhile to do a first or targeted review of the available data and propose addition of the substance to the Community rolling action plan as early as possible. On the other hand, if the urgency is less, there are numerous and complex dossiers for a given substance and the Member State is not convinced that it will succeed in getting a clear picture of the need for additional information within twelve months, it may be better to propose addition of the substance to the Community rolling action plan only after a comprehensive review of the available data. A consequence of this may be that the draft request for information can be developed in less than twelve months.

\subsubsection{Influencing factors for the process}

MS-CA will be involved in different types of prioritisation related work which will differ both in time and in how it will be performed. One will be together with ECHA, to develop criteria for prioritising substances for inclusion on the CORAP-list, and another will be to nationally prioritise substances to propose for inclusion on the CORAP-list.

According to Article 44 ECHA shall, in co-operation with the Member States, develop criteria for prioritising substances for inclusion in the Community rolling action plan. The prioritisation shall be based on a risk-based approach. The criteria shall consider:

a) Hazard information, for instance structural similarity of the substance with known substances of concern or with substances which are persistent and liable to bio-accumulate, suggesting that the substance or one or more of its transformation products has properties of concern or is persistent and liable to bio-accumulate;

b) Exposure information;

c) Tonnage, including aggregated tonnage from the registrations submitted by several registrants.

MS-CA has the possibilities to propose substances for inclusion on the CORAP (either via process of drafting the CORAP-list or at any time later (see Article 45(5)). As a basis for the proposal some kind of national prioritisation need to have taken place.

Besides hazard and exposure related data from registration dossiers (including chemical safety reports) any other information indicating that the substance may constitute a risk to human health or the environment may be used to prioritise substances for substance evaluation. Some of these factors will influence both types of prioritisation work mentioned above, others may be more relevant to only one of them. Examples of such parameters may be 
- New hazard data

- New (field/monitoring) data on exposure, accumulation, long-range transport

- Diverging classification or PBT assessment proposed by several registrants

- Additional or diverging classification or PBT assessment of other (national or international) organisations

- Opinion of a MS CA on the validity of data used in the dossier, on classification or PBT assessment deviate from registrants` proposal in the dossier

- Outcome of evaluation of similar substances (not considered in the registration dossier)

- Combined exposure from various uses (belonging to DU chains of different registrants) is anticipated to be substantially higher than assumed in individual registration dossiers

- Suspicions/evidence that there are relevant uses not covered by the registrations

- Different Risk Management Measures (RMM) are proposed by several registrants

\section{Additional influencing factors identified at the workshop}

Additional influencing factors that were recognised to influence the process of substance evaluation were:

- grouping of substances (e.g. information on cumulative effects);

- classified substances, a CSR including exposure assessment and risk characterisation will be available for a substance fulfilling a classification criterion, thus providing a better basis for substance evaluation;

- CMR substances below 10 tpa lacking a CSR could be prioritised to ask for exposure information;

- non-registered hazard and exposure data raising an initial concern;

- the priorities of other countries, and

- the economic factor (remuneration): how much will be paid to MS CA for performing a substance evaluation? The coverage of actual costs influences the number of evaluations that MS CAs will have resources to do.

\subsubsection{Sources of information}

Hazard information (on phys-chem, toxicological and ecotoxicological properties), apart from classification, will be available from the registration dossiers in tonnage dependent quantity and level of relevance (for the assessment of the endpoint concerned). Information on classification may independently of tonnage be available from the Classification and Labelling 
Inventory (available from December 2010). For substances imported or produced in amounts of 10 tonnes or above per registrant the chemical safety assessments / reports will further provide information on DNELs, PNECs and $\mathrm{PBT} / \mathrm{vPvB}$ (like) properties, which is suitable to rank substances on the basis of their hazard potential.

In order to identify substances that are structurally similar to known substances of concern or to those known to be persistent or liable to bioaccumulate the use of chemical grouping (analogue and category approach) appears useful. Similarity of chemicals is context-dependent (there is no absolute measure of similarity) and the search for similarities may therefore require the implementation of many different (and flexible) search routines. An example of a tool that may be useful when performing this task is the OECD (Q)SAR Application Toolbox, which in addition to the purely mathematically similarity indices (e.g. Tanimoto index) also includes several different types of profilers (general mechanistic, endpoint specific, organic functional groups, etc.), which depending on endpoint can be used individually or combined, when searching for relevant analogues.

As regards information on exposure, quantitative information on identified uses and emissions from the different stages in the life cycle (e.g. manufacture, service life, disposal or recycling) will be available for all substances in volumes of 10 or more tones per producer/importer if the substance meets the criteria for classification as dangerous in accordance with Directive 67/548/EEC or is assessed to be a PBT/vPvB (Art. 14(4)). The exposure information that needs to be provided for these substances in the context of the chemical safety assessment/report is laid down in Annex I.

For substances not meeting any of the classification criteria of Directive 67/548/EEC and not being identified as PBTs or vPvBs no exposure assessment is required and therefore the quantitative exposure related information as described above will normally not be available. The same holds true for substances in volumes below 10 tonnes per manufacturer/importer, as for those low tonnages no chemical safety assessment in accordance with Annex I and hence no exposure assessment is required. Only qualitative information on exposure as set out in Annex VI (6) need to be provided.

However, one need to be aware that the automatically retrievable exposure information from the CSRs (when available) will not provide true exposure estimates, but only assess levels that ensure safe use, which underlines the need to use more general and qualitative information on use patterns as proxy for exposure potential. The descriptor system, Sectors of Use (SU) and Product Category (PC), are systematic (i.e. not free-text) use descriptors for which information is required for all registrants and can be used to describe use patterns. One potential way to try to identify substances with "wide dispersive use" could perhaps be to search for many registrants using small volumes and/or substances with many cross links between SU and PC.

Whereas for substances without dangerous properties (including $P$ and $B$ ) the lack of quantitative exposure information may not be relevant because 
there is no need to prioritise them for substance evaluation (as long as there is no concern that the information pertaining to the hazard related properties in the registration dossier might be incorrect) the situation might be considered different with regard to substances in the 1-10 tonnes volume range having dangerous properties.

Other sources of information that may be useful when performing substance evaluations, or when searching for potential substances to include on the CORAP-list, are also available, e.g.: the SIAP/SIAR resulting from the OECD HPV-chemicals program, WHO- and IARC-substance monographs, priority hazardous substances according to the European Water Framework Directive; chemicals for priority action according to OSPAR and HELCOM, the Domestic Substances List of Environment Canada, the US EPA Priority PBTs, the Washington State PBT list; the Substitute It Now list (from the International Chemical Secretariat), the European Trade Union Confederation priority list for Reach authorisation, and the European Commissions lists of possible chemicals with potential for endocrine disruption. Furthermore, substances frequently detected in monitoring studies (especially from remote areas) could also be considered.

\subsubsection{Relation to other processes}

The links that can be made between the examination of testing proposal and compliance check can also be identified between testing proposal and substance evaluation. Indeed, during the stage of testing proposal examination, a partial check of relevant parts of the CSR and/or the technical report might be performed. Consequently, to avoid unnecessary duplication of work, it is important that any remark on the quality of parts of the registration dossier made during the evaluation of testing proposal is reported via annotations in IUCLID 5 and is taken into account by the MS-CAs in their substance evaluation.

Compliance check and substance evaluation are processes that can in principle start independently, one after the other, or even in parallel. Where a compliance check is carried out first, any information obtained as a result of this evaluation process shall be taken into account by MS CAs in order to conclude whether there is concern that the substance constitutes a risk to human health or the environment. For this reason annotations as proposed in IUCLID 5 should be used. In case of a risk the MS CA shall highlight the substance to ECHA for addition to the Community rolling action plan for further evaluation. Substance evaluation should be based on valid information in order to ensure the quality of the assessment. Therefore a quality check of the relevant dossier(s) is regarded as being a basis for substance evaluation.

The main idea behind the substance evaluation is to get appropriate further information to clarify an initial concern, and then consider how to use any information obtained for the purpose of restriction, identification of substances of very high concern or harmonised classification and labelling. The information obtained through evaluation can be used for the preparation of an 
Annex XV dossier (i) to propose and justify the identification of a substance of very high concern and (ii) to propose the restriction of the manufacture, placing on the market or use of a substance within the Community, and/or (iii) to propose a harmonised classification and labelling. For example, hazard or use and release/exposure information can be used as a way to increase the information available for a restriction dossier (one type of Annex XV dossier). As sufficient information has to be obtained before the formal submission of the Annex XV dossier, substance evaluation is the procedure to obtain the relevant data for that dossier from the registrant. However, there is no obligation to do a substance evaluation before the compilation of an Annex XV dossier. Performing a substance evaluation for substances that are already listed in Annex XIV (list of substances subject to authorisation) will only be useful if there is another concern that was not covered before.

Evaluation, restriction, identification of substances of very high concern and harmonised classification and labelling procedures should be regarded as entirely independent of each other. This means that for example a procedure for a harmonised classification and labelling can be directly initiated without a prior evaluation procedure. During the preparation of an Annex XV dossier, it may be concluded that registration dossier(s) are not in compliance with the registration requirements. The Member State should point this out to ECHA to initiate a compliance check. Substance evaluation could be started if a need for more information is recognised during Annex XV dossier preparation.

\subsubsection{References}

The following documents have been used for the compilation of this section on the substance evaluation process.

- ECHA” Guidance on Dossier and Substance Evaluation” (available on http://guidance.echa.europa.eu/)

\subsection{Harmonised Classification and Labelling}

\subsubsection{Process outline and legal context}

CLP (Regulation (EC) No 1272/2008 on the classification, labelling and packaging of substances and mixtures ${ }^{1}$ ) is based on the Globally Harmonised System of Classification and Labelling of Chemicals (GHS, UN 2007) and is implementing the provisions of the GHS within the EU. In principle, this system applies to all chemicals regardless their production volume and in its

\footnotetext{
${ }^{1}$ Regulation (EC) No 1272/2008 of the European Parliament and of the Council on classification, labelling and packaging of substances and mixtures, amending and repealing Directives 67/548/EEC and 1999/45/EC, and amending Regulation (EC) No 1907/2006, ${ }^{\text {OJ }}$ L 353, 31.12.2008, p. 1
} 
scope is comparable with the Directives 67/548/EEC (i.e. Dangerous Substance Directive) and 1999/45/EC (i.e. Dangerous Preparation Directive).

A core principle of CLP is "self-classification" of a substance or mixture by the manufacturer, importer or downstream user, which involves identification of its hazards followed by classification as a result of the comparison of the hazard information with the criteria in CLP. Thus, industry is obliged to self-classify chemicals and to provide appropriate hazard communication information (by labelling and in Safety Data Sheet) to the target populations potentially exposed in order to give information on how the chemicals may be used safely.

In addition to SDS, CLP provides an integrated system of hazard communication elements (hazard pictograms, signal words, hazard statements and precautionary statements) on the label. Provision of this information to the end user is obligatory, irrespective of conditions of use and risk. While the Chemical Safety Assessment (CSA) on a particular substance performed for the purpose of REACH may indicate that the substance will be used under conditions leading to an exposure which has been assessed to be adequately controlled, a situation resulting in unforeseen exposure may occur, such as in an accident. In such a situation, workers, managers and emergency personnel will need information on the hazard profile of the substance, which will be provided by the label and the SDS. These sources of information (together with Exposure Scenarios if required) will also provide useful information to the worker on the safe handling of the chemical.

A network of EU legislation relies on classification in one way or the other. This downstream legislation includes laws protecting consumers and workers, as well as rules on biocides, pesticides and waste. The consequences of classification are therefore greater than just a hazard label or a safety data sheet in that it also has a direct effect on management of associated risks. In addition a simplified procedure aimed at limiting use of CMR substances in consumer products may be used by the Commission.

Manufacturers and importers are required to notify ECHA of the classification and labelling of substance(s) placed on the market. ECHA will then include the information in a classification and labelling inventory in form of a database. Substances placed on the market before 1 December 2010 may be notified before that date while substances placed on the market on or after 1 December 2010 require notification within one month. There is no need to notify the information if a registration, containing all required information, for the substance has been submitted under REACH, as the classification and labelling is part of the registration package and will automatically be added to the inventory.

\section{Harmonised classification}

Harmonised classification and labelling is described in Title V of CLP.

The main aim with the harmonised classification and labelling of a substance is to: 
i. provide for a high level of protection of health and the environment, and

ii. provide legal clarity for suppliers and distributors of the same substance of high concern (i.e. manufacturers of substances, importers of substances or mixtures, producers of specific articles, downstream users (including manufacturers of mixtures).

For substances of particular concern or for other substances where Community-wide action is needed, CLP sets out a system for formal harmonisation of classifications at Community level.

All harmonised classifications are provided in Annex VI to CLP. If a substance has a harmonised classification, this classification must always be used by a manufacturer, importer or downstream user, but where some but not all hazard classes or differentiations within hazard classes have been harmonised, the remainder should to be self-classified to complete the classification.

The process of harmonised classification and labelling starts with submission of a proposal to ECHA. Such a proposal should comprise proposals for inclusion in as well as for updating of Annex VI to CLP and should normally be made if that substance fulfils the classification criteria for (CLP Article 36):

- $\quad$ respiratory sensitisation, category 1 ;

- germ cell mutagenicity, categories $1 \mathrm{~A}, 1 \mathrm{~B}$ or 2 ;

- carcinogenicity, categories $1 \mathrm{~A}, 1 \mathrm{~B}$ or 2 ; or

- reproductive toxicity, categories $1 \mathrm{~A}, 1 \mathrm{~B}$ or 2 .

Further to this, proposals relating to other hazard classes or their differentiations may be made, provided that the need for Community-wide action is justified.

In contrast to other substances, active substances in the meaning of Directive 91/414/EEC (plant protection products) or Directive 98/8/EC (biocidal products) shall normally be subject to harmonised classification and labelling for all hazard classes and labelling elements.

A Competent Authority of a Member State as well as a manufacturer, importer and downstream user of a substance may submit a proposal to ECHA for the harmonised classification and labelling of a substance (CLP Article $37^{2}$ ). A Competent Authority may make such a proposal even for a hazard for which harmonised classification and labelling already exists for that substance. In contrast, a manufacturer, importer or downstream user cannot make such a proposal for a hazard for which harmonised classification and labelling already exists for that substance; on the other hand, if he has new information which may lead to a change in the harmonized classification and labelling of a substance; he must contact the Competent Authority in one of the Member States in which the substance is placed on the mar-

\footnotetext{
${ }^{2}$ Please note that for active substances used in plant protection or biocidal products, only Member State competent authorities can submit proposals, but not companies.
} 
ket and submit a proposal to it (CLP Article 37(6)). If the proposal of the Competent Authority or the manufacturer, importer or downstream user pertains to other hazard classes than CMR or respiratory sensitizers, a justification demonstrating the need for action at Community level is required.

Once submitted, all parties concerned will be given the opportunity to comment on the proposal. The opportunity to comment will be provided on the ECHA website, where comments can be introduced by a specified deadline.

The Committee for Risk Assessment of ECHA will form an opinion on a proposal for the harmonised classification and labelling of a substance within eighteen months (CLP Article 37(4)), and ECHA will then forward this opinion to the Commission. Should the Commission find that the proposal and justification are appropriate, it will propose to include the substance in Table $3.1^{3}$ of Annex VI to CLP, listing substances with harmonised classification and labelling, together with the relevant classification and labelling elements and, where appropriate, the specific concentration limits and M-factors. The procedure to include a substance in Annex VI is called "comitology with scrutiny", leading to a Commission decision.

\subsubsection{Work performed at MS CA related to the process}

\section{Role of the MS CA in the process}

It is still a question of interpretation of the CLP regulation to understand what the obligations of the MSCA are. E.g. what is meant by Art. 36 stating that CMR properties should normally be subject to harmonised classification while Art. 37 points out that both MS and industry may (not should) submit a proposal for harmonised classification to ECHA?

The legislation is however clear when it comes to an obligation for manufacturers, importers and downstream users. According to Article 37.6 these actors have to send to a MSCA in the country of their operation a proposal for updating a harmonised classification and labelling if they become aware of new information on the substance. In this situation, according to our interpretation, the MSCA should proceed with this proposal if it finds the new information altering the current classification. It means that the MSCA takes over the case from the industry and writes a new proposal for the updating of the harmonised classification of the substance and submits it to ECHA.

There may where harmonised classification is required although not explicitly requested by legal acts. E.g in the course of the evaluation of active substances and plant protection products various Guidance Documents have been developed (non-legally binding). In at least one Guidance Document used for substance evaluation, i.e. in the "Guidance Document on the Assessment of the Relevance of Metabolites in Groundwater of Substances Regulated under Council Directive 91/414/EEC”, a direct reference to hazard classifications can be found, i.e. the classification as Very Toxic, Toxic

\footnotetext{
${ }^{3}$ Until 31 May 2015, a corresponding entry shall also be included in Table 3.2 of Annex VI to CLP.
} 
and CMR of the parent molecule (which is the active substance) could trigger testing of the metabolite(s). Thus, although not requested by law, the harmonised classification of these endpoints would be necessary to achieve in order to finalise the evaluation process of these substances.

\section{Work required throughout the process}

According to CLP, an opinion on a proposal for harmonised classification and labelling should be agreed by RAC within 18 months, which is from the day of the beginning of the public consultation to the day a final opinion on the substance classification proposal has been agreed by RAC. The time of 18 moths does not cover the time needed for inclusion of the substance into CLP Annex VI.

In order to make a first estimation of work needed to be performed by the Authority in the process of harmonised classification and labelling, a complexity in terms of number of steps to be performed in the process is described below. This complexity depends on the role of CA:

i. As a submitter of a proposal the CA has to allocate resources for:

a) Writing a dossier, which after the accordance check may be further improved based on the comments received (according to Swedish experiences completing a dossier for harmonised classification and labelling takes approximately one week by one person).

b) Responding to the comments (RCOM) received during the public consultation (within 45 calendar days). The CA is also supposed to integrate the comments, where relevant into the Background Document (BD).

c) Taking part in a discussion on the substance at RAC, if relevant.

ii. As receiver of a proposal from industry on updating of an existing entry in CLP Annex VI the following steps would be necessary to complete:

a) Assessing the proposal submitted by the industry by checking whether the new information amends the existing classification of the substance. If yes, all the steps described in (i) have to follow. If not the process stops here.

iii. Involvement of MSCA providing support for a RAC rapporteur starts with an accordance check of a proposed C\&L dossier and follows the obligation of the rapporteur in the whole process, which includes:

a) Drafting an opinion on the proposed harmonised classification and labelling of that substance, taking into account comments received from concerned parties, the MSCAs, and responses to the comments from the dossier submitter;

b) Considering and preparing responses to comments (ORCOM) received from other RAC members on the first draft opinion; 
c) Revising the draft opinion(s), based on the comments received from RAC, and prepare the final RAC opinion;

d) Discussing the classification at a plenary session of RAC, if necessary

e) Modifying, where necessary, the draft BD that supports the scientific basis for the classification and labelling in the RAC opinion.

iv. Commenting of a dossier for harmonised $C \& L$ within a public consultation would require from MSCA allocation of resources for that task only (the commenting period is foreseen for 45 calendar days). If a substance is prioritised by a MSCA further work may be performed in order to support MSCA member in RAC in his/her work on the substance in the Committee.

\subsubsection{Influencing factors for the process}

\section{Submitting MSCA}

- Since (i) active substances in PPP and BP should normally get all hazard classes harmonised and (ii) only MSCA may propose harmonised classification for PPP and BP this implies that MSCArapporteur should consider proposing to ECHA CLH for its substances.

- Since industry is obliged to send a proposal for updating of an existing entry in CLP Annex VI to a MSCA in a country of its operation, the chosen MSCA may decide to proceed with this proposal if it finds that the new information would indeed amend the current harmonised classification.

- Although not required by REACH but following a procedure agreed by the Member State Committee substances for which a MSCA considers preparing an Annex XV due to their CMR properties, should have classification for these properties harmonised before starting the process leading to identification of a substance as a SVHC. Thus as a first step, the MSCA should send a proposal for CLH to ECHA and after the substance has been included into Annex VI to CLP continue the process by submitting an Annex XV dossier for SVHC.

- Commission may propose by application of a simplified procedure, restrictions in use of substances with CMR properties in consumer products (Reach Art. 68.2). This provision may be used by MSCA to reduce risks of a certain substance(s) which poses risk to consumers. For this type of substances MSCA should submit proposal for harmonised classification and labelling to ECHA.

- Due to downstream legislation certain classifications (mainly, but not only CMR) are regulated by other legal acts. Detailed knowledge on these regulations may guide in selection of an appropriate option for a substance to control the risks (for a detailed description of the downstream legislation see Appendix 3). 
MSCA commenting proposal within public consultation

- Prioritising substances (i.e. industrial chemicals) that are important from the authorisation point of view?

- For PPP proved to leak to groundwater the classification of a mother compound is needed in order to proceed (within a limited period of time) with evaluation of the degradation products.

- PPP and BP prioritised by PPP and BP people on grounds other than specified above.

\section{MSCA supporting RAC rapporteur}

- Prioritising substances (i.e. industrial chemicals) that are important from the authorisation point of view?

- Prioritising substances that have different classification on the Inventory

- Prioritising substances from the CORAP list?

Other factors

- Outcome of substance evaluation (i.e. when harmonised classification has been chosen as an appropriate measure to limit the identified risks )

- By 1 December 2010 the industry has to inform ECHA about classification of their substances according to CLP. This information would be included in the Inventory. From that date information on many substances will be made available for the Authorities. The classifications may also be changed with time as Reach goes by and produces new information that would be than used in classification of substances (especially for substances that have to be register at the later stages).

- The inventory could potentially reveal substances that have been selfclassified as CMR as well as substances that have different classifications.

- A new regulation for PPP is foreseen to come into force at the end of year 2010/beginning of 2011. According to the proposal PPP heaving CMR properties would not be allowed for sale at the European market. The decision on non-inclusion of a substance onto a list of accepted active substances would be based on a harmonised classification, which means that the decision on classification would be necessary to finalise the evaluation process of these substances.

Additional influencing factors identified at the workshop

- Current policies of MS

- Exposure to substances (the lesser exposure the lower priority)

- Borderline cases receive higher priority

- Substances whose classification may influence PBT assessment of the substance as well as substances with self-classifications for T, Tx, R5053 with $\mathrm{M}>10$ that diverge between industry should be prioritised 


\subsubsection{Sources of information}

In addition to the sources specified in section 2.4.4 information on substances already assessed as having CMR properties may be also found in Publications of IARC, in publications from the Committee on Carcinogenicity of Chemicals in Food, Consumer Products and the Environment: http://www.iacoc.org.uk/; Committee on Mutagenicity of Chemicals in Food, Consumer Products and the Environment: http://www.iacom.org.uk/,; in lists showing classification of substances according to GHS (performed by other countries that have implemented GHS) as well as from The ECHA Inventory (after December 2010).

\subsubsection{Relation to other processes}

- Due to a number of legal acts that refer to the list of harmonised classifications, C\&LH should also be seen as a risk management measure. Depending on the objective (and a type of downstream legislation) C\&L may be an optimal instrument to achieve certain effects, e.g. worker protection.

- Identification of SVHC, candidates to Annex XIV, is among others based on harmonised classification of their CMR properties.

- REACH foresees a simplified procedure for the introduction of restrictions regarding risks from substances that meet the criteria for classification as carcinogenic, mutagenic, or toxic for reproduction, category 1 or 2 , related to consumer users ${ }^{4}$. The simplified procedure significantly reduces the resources and time needed to restrict such uses as it does not require the preparation of an Annex XV dossier, the opening of public consultations, or the opinion of the RAC and SEAC.

\subsubsection{References}

The following documents have been used for the compilation of this section on the C\&L process.

- $\quad$ Module 1 of RIP 3.6

- $\quad$ Introduction to module 2 of RIP 3.6

Please note that both these sources are available on ECHA website (link: http://www.echa.europa.eu/classification/clp_guidance_en.asp)

\footnotetext{
${ }^{4}$ See Article 68(2).
} 


\subsection{Identification of Substances of Very High Concern (SVHC) for the candidate list}

\subsubsection{Process outline and legal context}

According to Article 59(1) in REACH a candidate list should be established to identify substances of very high concern (SVHC), i.e. substances meeting the criteria referred to in Article 57 (CMR 1 or 2 substances, PBT substances, $\mathrm{vPvB}$ substances, or substances with probable serious effects which give rise to an equivalent level of concern). The first candidate list, containing 15 substances, was published in October 2008. The list will be regularly updated when more substances are identified as SVHC.

There are several reasons to identify SVHCs for the candidate list; the listing in the candidate list may lead to the eventual inclusion of the substance into Annex XIV; the candidate list is a tool for the official identification of SVHCs particularly of PBT/vPvB; the listing of substances in the candidate list is a way to promote their replacement by alternative substances/technologies; and the candidate list is a tool to gather information on uses in articles and the listing is a way to provide information on SVHCs in articles to recipients and consumers.

SVHCs can be identified by MS CAs or by ECHA (on behalf of the Commission) by preparing an Annex XV dossier ${ }^{5}$. This dossier must conform to the requirements set out in Section 2 of Annex XV of REACH. REACH does not specifically foresee a process for the verification by ECHA that the dossier submitted is in line with Section 2 of Annex XV. In case of substances that are classified in accordance with Part 3 of Annex VI to the Regulation No 1272/2008, the dossier may be limited to a reference to that entry if appropriate. For all other cases, the dossier must justify that the intrinsic properties of the substance meet one of the conditions in Article 57. In addition, it is recommended that the dossier include any available information on uses, emissions, and exposures.

ECHA shall make the dossier available to other MS CAs within 30 days of receipt, and any comments (by other MS CAs or by ECHA) shall be made within 60 days of circulation. If ECHA does not receive or make any comments, it shall include the substance on the candidate list. If ECHA receives or makes any comments, it shall refer the dossier to the Member State Committee (MSC) within 15 days of the end of the 60-day circulation. If, within 30 days of referral, the MSC reaches a unanimous agreement on the identification, ECHA shall include the substance in the candidate list. If not, the Commission has three months to prepare a decision, which must be adopted under a comitology procedure ${ }^{6}$. As soon as a decision has been

\footnotetext{
${ }^{5}$ See Article 59(2) and Article 59(3) or REACH.

${ }^{6}$ Although the time needed for the Commission to adopt a decision under the comitology process vary depending on the complexity of the dossier but in general a minimum of 4 months are required in the case of the regulatory procedure which applies in this case.
} 
taken to include a substance on the candidate list, ECHA shall update the candidate list on its website.

When a substance has been included on the candidate list, ECHA may consider prioritising the substance for inclusion in Annex XIV. Priority shall normally be given to substances with: $\mathrm{PBT}$ or $\mathrm{VPvB}$ properties; or wide dispersive us; or high volumes ${ }^{7}$.

When a substance has been included on the candidate list companies may have legal obligations from the date of inclusion. These obligations are linked to the listed substances on their own, in preparations, and in articles:

Suppliers of articles which contain substances listed on the candidate list (in a concentration $>0.1 \%(\mathrm{w} / \mathrm{w})$ ) have to provide their customers with sufficient information, available to the supplier, to allow safe use of the article (as a minimum, the substance name should be included). This information shall also be provided to consumers up on request within 45 days of receipt of the request ${ }^{8}$.

Suppliers of substances included on the candidate list have to provide their customers with a safety data sheet. Suppliers of preparations containing at least one substance listed on the candidate list (in a concentration $>0.1 \%$ (w/w), or $0.2 \%$ by volume for gaseous preparations) have to provide the recipients, at their request, with a safety data sheet ${ }^{9}$.

Producers or importers of articles have to notify to ECHA if their article contains a substance listed on the candidate list in a concentration $>0.1 \%$ $\mathrm{w} / \mathrm{w}$, and if its quantities in the article are above 1 tonne in total per year per company ${ }^{10}$. This obligation applies from 2011.

\subsubsection{Work performed at MS CA related to the process}

The role for MS CAs in the process is to submit own Annex XV dossiers and to participate in the preparation of dossiers submitted by other MS CAs. The initial work load to submit an Annex XV dossier is relatively low. However, the resources and time needed are dependent on the amount of available information. When a MS initiates an Annex XV dossier (be it to trigger the authorisation or the restriction process), it has to bear such costs. There will be no income for the MS in terms of fees to be paid by economic operators.

The MS CAs are involved in the decision making on inclusion of a substance on the candidate list either trough the MSC or trough the comitology procedure.

\footnotetext{
${ }^{7}$ See Article 58(3) of REACH.

${ }^{8}$ See Article 33 of REACH.

${ }^{9}$ See Article 31 of REACH.

${ }^{10}$ See Article 7(2) of REACH.
} 


\subsubsection{Influencing factors for the process}

\section{- Legal:}

Basically, any substance fulfilling the SVHC criteria could be identified and included in the candidate list. As the number of substances with identified defined properties of very high concern is expected to be relatively high, it is, however, necessary to prioritise the progressive inclusion of identified substances into the system.

- Other:

There may be several reasons for listing substances in the candidate list and some reasons/ implications were agreed on at the workshop on The Candidate List and Authorisation as Risk Management Instruments, held in January 2009. These reasons are listed in Table 1 below together with the influencing factors for the prioritisation of substances that may follow.

Table 1. Reasons/implications for listing a substance in the candidate list and influencing factors for the prioritisation of substances that may follow.

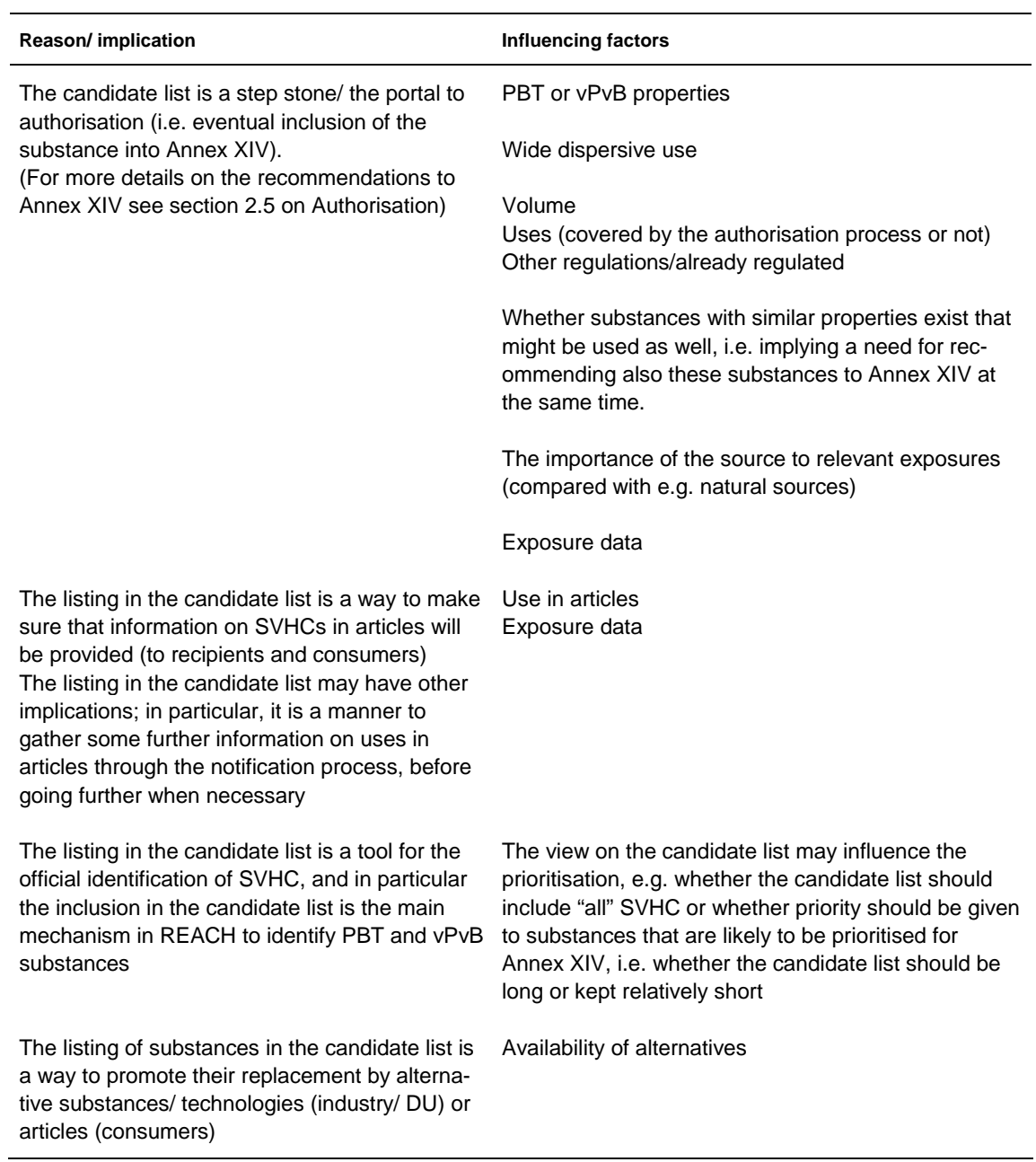


Additional influencing factors identified at the workshop Intrinsic properties are the most important influencing factors according to the workshop participants. The participants also suggested that substances that are extremely persistent and extremely toxic (ePeT) should be considered as SVHC and that the prioritisation should not be affected by the availability of alternatives.

\section{Experiences drawn by the MS CAs informal expert group}

One of the recommendations from the workshop in January, mentioned above, was that MS CAs should initiate an informal expert group to propose a method and timelines for the pre-screening of potential SVHC for inclusion in the candidate list. Such a group has been established, and participating countries are; The Netherlands, Germany, Austria, France, Denmark, and Sweden. The aim of the group is to develop a simple, manageable process on the identification of SVHCs. The results of the group are to be presented at the CARACAL meeting in June 2009.

The substances considered by the group are CMR substances included in Annex I of the Dangerous Substances Directive 67/548/EC (now in Part 3 of Annex VI to the Regulation No 1272/2008), and PBT substances identified by the PBT-working group (subgroup of the Technical Committee of New and Existing Chemical Substances).

Especially the CMR-substances are so many that the number has to be reduced before a prioritisation can be made. Initial ideas for de-prioritisation arguments that were suggested at the ECHA workshop in January were:

- substances which are (solely) used as intermediates;

- substances for which the use is outside the scope of authorisation (e.g. pesticides, biocides);

- substances where (all) uses are known to be already well controlled;

- petroleum streams.

Due to limited information only a few of these de-prioritisation criteria have been taken into account by the group.

Some prioritisation criteria have further been considered by the group, e.g.:

- Use

- Volume

- "Critical" use pattern, i.e. widespread use and use in articles

- Potential for exposure for

- Occupational

- Consumer

- Environment

- Intrinsic properties 
The sources of information that have been used are e.g. IUCLID data for volume; information from products registers and pre-registration data for use pattern; the register of RAPEX notifications and the EIS-ChemRisk database for occurrence in consumer products; and monitoring data collected within the Water Framework Directive for environmental exposure.

Several other prioritisation criteria have been discussed by the group. However, the lack of easily available information at this time has precluded the possibility to search for information for such a large number of substances. For most of these substances (the CMRs category 1 and 2) more information will, however, become available when the registration dossiers for these substances become available at the end of 2010.

In a follow-up step of the project interested MS CAs will be invited to choose substances from the pre-screened list. The interested MS CA may either place the substance directly on the ROI together with the desired date of delivery, or alternatively, may screen the substance on the basis of selection criteria developed by the MS CA to decide its placing on the ROI.

\section{Influence of time}

The time needed to prepare an Annex XV SVHC dossier is dependent on the status of the substance in REACH. It is expected that a lot of information that can be used for the identification of substances as SVHC will have been provided by industry at the first registration deadline by 1 December 2010 for

- phase-in substances above 1000 tpa, and

- phase-in substances with CMR properties above 1 tpa, and

- phase-in substances classified as dangerous to the environment ( $\mathrm{R}$ 50/53) above 100 tpa

By the same deadline of 1 December 2010 industry will also have made notifications to ECHA of classifications for all substances regardless of volume.

\subsubsection{Sources of information}

Several sources, apart from those mentioned above, exist with information on potential SVHC substances. Some examples are, e.g.: priority hazardous substances according to the European Water Framework Directive; chemicals for priority action according to OSPAR and HELCOM; the Domestic Substances List of Environment Canada; the US EPA Priority PBTs; the Washington State PBT list; the Substitute It Now list (from the International Chemical Secretariat); the European Trade Union Confederation priority list for REACH authorisation; European Commissions lists of possible chemicals with potential for endocrine disruption. Furthermore, substances frequently detected in monitoring studies (especially from remote areas) could also be considered. 
The main source of information on substances under REACH is the registration dossier. For a substance manufactured or imported in an annual quantity of ten tonnes or more per year the registration dossier will include a CSR with a PBT/vPvB assessment for the substance. Further information may be requested through a substance evaluation (see below).

\subsubsection{Relation to other processes}

Substances on the candidate list may be prioritized for inclusion in Annex XIV and therewith be subject to authorisation, as described above (see also the section on Authorisation). The notification process on uses in articles may give information that eventually lead to other risk management options (e.g. restriction), when necessary (see section on Restriction). It is recommended to propose and achieve an entry for harmonised classification in Annex VI to CLP before a CMR substance is proposed to be identified for inclusion in the candidate list.

In cases where the data are not sufficient to prepare an Annex XV dossier, but where there are still concerns that the substance may meet the criteria for identification and Community wide action needed, a substance evaluation could be initiated in order to generate information to clarify the concerns.

\subsubsection{References}

- ECHA "Guidance for the preparation of an Annex XV dossier on the identification of substances of very high concern" (available on http://guidance.echa.europa.eu/docs/guidance_document/svhc_en.pdf)

- Workshop on the candidate list and authorisation as risk management instruments, ECHA, 21-22 January 2009. Draft Report.

\subsection{Authorisation}

\subsubsection{Process outline and legal context}

The REACH Regulation sets up a system under which the use of SVHCs and their placing on the market may be made subject to authorisation. The aim of authorisation, besides ensuring the functioning of the internal market through an equal treatment of such substances, is to ensure that risks from SVHCs are properly controlled and that these substances are progressively replaced by suitable alternative substances or technologies, where these are economically and technically viable. To this end all manufacturers, importers and downstream users applying for authorisations shall analyse the availability of alternatives, consider their risks, and the technical and economic feasibility of substitution. 
The substances that may be included in the authorisation system have intrinsic hazardous properties of such concern that the Community needs to decide about the adequacy of the control of the risks arising from their uses or whether the socio-economic benefits of the uses of such substances outweigh the risks arising from their use.

Substances that are included in Annex XIV are subject to authorisation. This means that, after the sunset date set for each substance in that Annex, they may not be used or placed on the EU market as substances, in products or be incorporated in articles without an authorisation; they may, however, continue to be manufactured in the EU for export without authorisation.

\section{Trigger of the process}

The authorisation process can be triggered by a Member State preparing an Annex $X V$ dossier proposing to identify a Substance of Very High Concern and submitting that dossier to ECHA, or by the preparation of an Annex XV dossier by ECHA at the request of the Commission ${ }^{11}$ (see the section on Substances of Very High Concern for further details on this process and further considerations on priority setting).

After the substance is included in the candidate list of substances meeting the criteria in article 57 a number of obligations on industry apply ${ }^{12}$ (see section on SVHCs for further details), and the substance becomes eligible for inclusion in Annex XIV. Specifically, ECHA shall prioritise among the candidates and make a recommendation to the Commission as to which substances it recommends for inclusion in Annex XIV. Priority shall normally be given to substances with $\mathrm{PBT}$ or $\mathrm{vPvB}$ properties, or with wide dispersive uses or high volumes. In recommending substances, ECHA must take into account its ability to handle applications for authorisation within the deadlines provided by $\mathrm{REACH}^{13}$. Before submitting its recommendation to the Commission, ECHA must hold a public consultation ${ }^{14}$, and take the opinion of the Member State Committee into account ${ }^{15}$.

The first ECHA recommendation for Annex XIV shall be made by 1 June 2009 and further recommendations at least every second year. In the report from the ECHA "Workshop on the Candidate list and Authorisation as Risk Management Instruments" held in January 2009, it was foreseen that the frequency of preparing a draft recommendation should not be more often than once a year. The decision between updating once a year and the minimum of every two years could be taken case by case. Criteria could e.g. be: number of "new" substances on the candidate list, availability of new relevant information for "old" candidate substances, new substances added to the candidate list that could be grouped with "old" ones etc...

\footnotetext{
${ }^{11}$ See Article 59(2) and Article 59(3) of REACH.

${ }^{12}$ See Articles 7(2), 31(1) and 33(2) of REACH.

${ }^{13}$ See Article 58(3).

${ }^{14}$ See Article 58(4) of REACH.

${ }^{15}$ See Article 58(3) of REACH.
} 
The final decision to include a substance in Annex XIV is taken by the Commission under a comitology procedure ${ }^{16}$. The entry in Annex XIV may provide for specific exemption of uses.

\section{Application and granting of an authorisation}

Each operator that uses or manufactures the substance must seek an authorisation for the use or placing on the market of a substance that is included in Annex XIV (unless the use and/or placing on the market of the substance stops after the sunset date or the use category or uses are exempted from the authorisation requirements in accordance with Article 58(1)(e)). Joint applications are possible but not mandatory. A fee has to be paid for each application.

The application must include a chemical safety report covering risk related to those properties that caused the substance to be included in the authorisation system, and an analysis of possible alternative substances or technologies including, where appropriate, information on research and development foreseen or already in progress to develop such alternatives. Where the analysis of alternatives reveals that there is a suitable alternative, any application via the adequate control route must include a substitution plan, explaining how the applicant intends to replace the substance by the alternative. In cases where the applicant cannot demonstrate adequate control of risks a socio-economic analysis must be included in the application.

The decision to grant or refuse an authorisation is taken by the Commission under a comitology procedure. The Commission is to prepare its draft decision taking into consideration the opinion of the Committee for Risk Assessment ("RAC") and the Committee for Socio-economic Analysis ("SEAC"). The two Committees must prepare their draft opinions within 10 months after the date of receipt of the application ${ }^{17}$. Within these 10 months, there must be a public consultation ${ }^{18}$ and particularly the SEAC should take into account the comments received regarding socio-economic factors and the availability of suitable alternatives.

Before ECHA submits the opinions of the Committees to the Commission, it must give the applicant the opportunity to comment ${ }^{19}$. If the applicant wishes to comment, the process will last approximately 5 additional months.

The Commission must prepare a proposal for a decision to grant or refuse the authorisation within 3 months after receiving the opinions from the Committees $^{20}$. However, there is no deadline by which the decision must be adopted. As a minimum, 4 months are required for the adoption of the deci-

\footnotetext{
${ }^{16}$ Although the time needed for the Commission to adopt a decision under the comitology process vary depending on the complexity of the dossier but in general a minimum of 6 months are required in the case of the regulatory procedure with scrutiny which applies in this case.

${ }^{17}$ If the application refers to parts of a previous application in accordance with Article 63(2), the Committees must deliver the opinion within five months (see Article 64(10) of REACH.)

${ }^{18}$ See Article 64(2) of REACH.

${ }^{19}$ See Article 64(5) of REACH.

${ }^{20}$ See Article 64(8) of REACH.
} 
sion but more time will be required if there are divergent views in the REACH committee.

Authorisation decisions are applicant specific, but an application may also cover the uses of the applicant's downstream users. The authorisation decision is subject to a review period and may also be subject to conditions. The duration of the review period will be decided on a case-by-case basis taking account of all relevant information including the risks posed, the socioeconomic implications, the availability of alternatives and information on the risks of alternatives, as appropriate. A holder of an authorisation must submit a review report at least 18 months before the expiry of the timelimited review period. During the review the Commission may decide to amend or withdraw the authorisation if circumstances have changed including situations where suitable alternatives have now been identified.

\section{Consequences}

The inclusion of a substance in the Annex XIV means that no operator can use it or place it on the market without an authorisation after the sunset date - except for uses that are exempted. In particular, it should be noted that:

- before the sunset date, the substance may be used or placed on the market; and

- after the sunset date, the substance can be used or placed on the market if an authorisation is granted or if the Commission has not yet adopted a decision, provided that the application for an authorisation had been submitted before the relevant deadline set in Annex XIV ${ }^{21}$.

The presence of the substance listed in Annex XIV in articles manufactured outside the EU and placed on the market in the EU is not affected by the authorisation process, but can be addressed through restriction.

\subsubsection{Work performed at MS CA related to the process}

Role of the MS CA in the process

The role of the individual Member State Competent Authority is to contribute to the prioritisation of relevant substances for Annex XIV by participating in the work of the Member State Committee and the comitology procedure for Annex XIV. Furthermore, MS CAs will be involved in the processes of assessing applications for authorisation in the Risk Assessment Committee and the Socio-Economic Committee and the comitology procedure for granting authorisations. MS CA may also be involved in preparing Annex XV dossier proposing SVHC, but this is primarily covered in section 2.4 on identification of SVHCs for the candidate list.

\footnotetext{
${ }^{21}$ See Article 5(c ) of REACH
} 


\section{Work required throughout the process}

When considering the workload for Member State CAs in relation to the authorisation process, all phases of the processes from the development of the Annex XV dossier until final decision(s) and enforcement of these decisions) need to be considered (see Table 2 below).

The overall resource requirements for the operation and management of the authorisation process may be considerable. This is because the process requires separate Commission decisions per applicant (and also multiple public consultations and multiple opinions of the SEAC and the RAC). In addition, the authorisation process also involves a mandatory review process.

Table 2. Main tasks of the MS authorities in different phases of the authorisation process.

\begin{tabular}{|c|c|}
\hline Phase & Tasks \\
\hline $\begin{array}{l}\text { Preparation of an Annex } \\
\text { XV dossier }\end{array}$ & $\begin{array}{l}\text { primarily hazard information } \\
\text { (information on uses emissions and exposures needed for prioritisation } \\
\text { for inclusion in Annex XIV is not obligatory, but if not provided may lead } \\
\text { to non-prioritisation) }\end{array}$ \\
\hline $\begin{array}{l}\text { Providing comments on } \\
\text { and input to the Annex } \\
\mathrm{XV} \text { dossier submitted by } \\
\text { other MSs (or prepared } \\
\text { by ECHA at COM re- } \\
\text { quest) }\end{array}$ & $\begin{array}{l}\text { the Annex XV dossier } \\
\text { Where a substance is prioritised for inclusion in Annex XIV: } \\
\text { the draft Annex XIV recommendation } \\
\text { the basis of broad information on uses applied for }\end{array}$ \\
\hline $\begin{array}{l}\text { Preparation of responses } \\
\text { to comments received }\end{array}$ & $\begin{array}{l}\text { hazard information } \\
\text { (information on uses emissions and exposures needed for prioritisation } \\
\text { for inclusion in Annex XIV if provided) }\end{array}$ \\
\hline $\begin{array}{l}\text { Providing support to } \\
\text { rapporteur(s) and to the } \\
\text { Committee members in } \\
\text { preparing and adopting } \\
\text { the opinions on }\end{array}$ & $\begin{array}{l}\text { identification of a substance as SVHC (MSC) } \\
\text { prioritisation of substances and Annex XIV recommendation (MSC) } \\
\text { authorisation applications (number of application per substance can vary } \\
\text { from } 0 \text { to hundreds) (RAC and SEAC) }\end{array}$ \\
\hline $\begin{array}{l}\text { Decision making in } \\
\text { Comitology committee }\end{array}$ & $\begin{array}{l}\text { identification of a substance as SVHC (if no unanimity achieved in MSC) } \\
\text { the Annex XIV recommendation } \\
\text { authorisation applications (number of applications per substance can } \\
\text { vary from } 0 \text { to hundreds) }\end{array}$ \\
\hline Enforcement & $\begin{array}{l}\text { compliance with sunset date (application submitted, authorisation } \\
\text { granted to the relevant actor in the supply-chain or no placing on the } \\
\text { market / use) } \\
\text { compliance with authorisation decisions (conditions and review periods) } \\
\text { NB possibly different conditions in different decisions }\end{array}$ \\
\hline
\end{tabular}

\subsubsection{Influencing factors for the process}

There are a number of influencing factors that should be taken into account when assessing whether to prepare an Annex XV dossier with a view to trigger the authorisation process (see also section 2.4 on identification of SVHCs), and when assessing whether to recommend a substance for inclusion in Annex XIV. 
- Legal:

There are legal factors for considerations in so far as the authorisation process has a limited scope. Authorisation only applies to substances fulfilling the criteria of substances of very high concern (SVHC). A number of uses are exempted from authorisation under REACH.

It should be noted that the authorisation requirement will concern all uses that are not exempted according to REACH or for which there is no substance specific derogation in Annex XIV. Substance specific derogations can be set in Annex XIV only when the conditions provided by Art 58(2) ${ }^{22}$ are fulfilled. It is also necessary to consider upfront whether using the authorisation process will affect the possibilities of using other risk management instruments and/or affect their effectiveness (see section 2.5.4 on Relation to other processes).

- Other:

The choice between the authorisation process and other risk management options, such as the restriction process or other EU legislation, is also influenced by a number of other factors such as the availability of information on different aspects such as uses, emissions, exposure, risks, alternatives, socioeconomic information, etc, at the point in time when this decision is taken.

Furthermore, the processes have different possibilities and obligations for different parties to fill in the information gaps in different phases of the procedure which could be an aspect to consider when selecting the process. However, to a large extent the same aspects will be taken into account during the process leading to decisions on granting or refusing the authorisations and, for example, in the process leading to the decision whether to impose a restriction.

In order to give a basis for discussion we have included some indications on when authorisation could be a preferred risk management option in the sections below. These are excerpted from an ECHA document prepared for the January 2009 Workshop. In that document it was emphasized that it should be noted that the bullet points give intentionally a simplistic picture on how different aspects could be considered and are presented here only to initiate discussion. This list of aspects is not exhaustive and there can be more important substance specific factors. Not all these aspects are relevant or applicable to all cases. None of these aspects should be used alone but a holistic view on the benefits and drawbacks is needed. Furthermore the aspects can be overlapping and/or inter-dependent.

\footnotetext{
${ }^{22}$ Art 58(2): 'Uses and categories of uses may be exempted from the authorisation requirement provided that, on the basis of the existing specific Community legislation imposing minimum requirements relating to the protection of human health or the environment, the risk is properly controlled....'
} 


\section{Consideration of the type of risk that is targeted}

The authorisation process can only be applied to risks emanating from the properties identified in Article 57 of REACH, which are considered as the properties of highest concern, i.e.:

- substances meeting the criteria for classification as carcinogenic, mutagenic or toxic for reproduction, category 1 or 2;

- substances that are PBTs or vPvBs; or

- substances for which there is scientific evidence of probable serious effects to human health or the environment which give rise to an equivalent level of concern to the above.

Furthermore, Article 58(3) of REACH provides that priority for recommendation for inclusion in Annex XIV shall normally be given to substances with:

- PBT or vPvB properties; or

- wide dispersive use; or

- high volumes.

Authorisation could be the preferred option if:

- There is a lack of knowledge on risks (arising out of the properties identified in Article 57)

- Benefits seem currently to outweigh the risks but the review system built into the authorisation process is regarded as a useful tool to ensure that authorities get use-specific updates, e.g., because there are indications that the situation is changing fairly rapidly

Consideration of the type of use

It should be noted that the authorisation process is only addressing the placing on the market and the use of a substance and cannot cover risks arising from the manufacturing process of the substance ${ }^{23}$.

A number of uses are exempted from authorisation under REACH. Specifically, the authorisation process cannot be used to target the following uses:

- Research and development ${ }^{24}$;

- Intermediates ${ }^{25}$;

- Medicinal products within the scope of the Community legislation on medicines ${ }^{26}$;

\footnotetext{
${ }^{23}$ In accordance with Article 56(1) of REACH, the authorisation process only covers the placing on the market and the use.

${ }^{24}$ See Article 56(3) of REACH.

${ }^{25}$ See Article 2(8) (b) of REACH. I should be noted also that non-isolated intermediates are exempted from all the provisions of REACH (see Article 2(1) (c) of REACH.

${ }^{26}$ See Article 2(5) (a) of REACH.
} 
- Food and feeding stuffs within the scope of the relevant Community legislation ${ }^{27}$;

- Cosmetic products within the scope of the relevant Community legislation - the exemption only applies to the extent that the substance is selected for the authorisation process on account of CMR (category 1 or 2) properties or because it is a substance of equivalent concern for human health ${ }^{28}$;

- Food contact materials within the scope of the relevant Community legislation - the exemption only applies to the extend that the substance is selected for the authorisation process on account of CMR (category 1 or 2) properties or because it is a substance of equivalent concern for human health ${ }^{29}$;

- Medical devices within the scope of the relevant Community legislation - the exemption only applies to risks for human health ${ }^{30}$;

- Biocides and pesticides within the scope of the relevant Community legislation $^{31}$; and

- Motor fuels within the scope of the Community legislation on quality of petrol and diesel fuels and certain fuels used in closed systems ${ }^{32}$.

- Use of substance in preparations below certain concentration limits ${ }^{33}$

Although consumer uses may be covered by the authorisation process, this always requires starting a full process (from the inclusion in the candidate list to the decision on the authorisation application). In contrast, there is a simplified procedure to address risks arising from substances that meet the criteria for classification as carcinogenic, mutagenic, or toxic to reproduction (category 1 or 2 ) in consumer uses through the restrictions process.

- Use in articles:

The actual incorporation of a substance in an article is covered by the authorisation process. However, risks arising from articles manufactured in third countries that are placed on the EU market are excluded from the authorisation process ${ }^{34}$. In addition, REACH requires ECHA to consider (after the sunset date set in Annex XIV) whether a use of a substance in an article poses a risk to human health or the environment that is not adequately controlled. In the affirmative, ECHA is required to prepare an Annex XV dossier with a view to impose a restriction ${ }^{35}$. This means that the use of the authorisation process for risks that are mainly related to substances in arti-

\footnotetext{
${ }^{27}$ See Article 2(5) (b) of REACH.

${ }^{28}$ See Article 56(5) (a) of REACH.

${ }^{29}$ See Article 56(5) (b) of REACH.

${ }^{30}$ See Article 60(2) of REACH.

${ }^{31}$ See Article 56(4) (a) and (b) of REACH.

${ }^{32}$ See Article 56(4) (c) and (d) of REACH.

${ }^{33}$ See Article 56(6) (a)and (b) of REACH.

${ }^{34}$ See Article 56(1). It should be noted also that the incorporation of a substance into an article is a "use". However, the placing on the market of an article is not a use and placing on the market of substances in articles is not covered by Article 56(1).

${ }^{35}$ See Article 69(2) of REACH.
} 
cles could lead to duplication of work as ECHA could be required to deal with potential requests from companies for authorisation of the use of the substances in articles and could be required to prepare an Annex XV dossier with a view to start a restriction process. In both processes the opinions of the Risk Assessment Committee (RAC) and Socio-Economic Analysis Committee (SEAC) would be required.

Authorisation could be a preferred option if:

- There is little knowledge on uses, or a lot of uncertainty on the types of uses or in the details of the uses.

- Users of the substance have specific use conditions or supply to actors with specific requirements and use conditions. Authorisation can be justified for certain users under tailor-made authorisation conditions.

- There is a strong supply-chain co-operation

\section{Consideration of the existence of alternatives}

An Annex XV dossier intended to propose the inclusion of a substance in the candidate list does not specifically have to consider the existence of suitable alternatives.

The lack of suitable alternatives is taken into account in the authorisation decision. Time limited review periods are defined in the decisions and the review involves a requirement to update the analysis of alternatives which includes the identification of the potential alternatives and their assessment in terms of technical and economic feasibility for the applicant and capacity to reduce the risks. By that the obligation on industry to generate information on alternatives and provide that to the authorities is built into the authorisation process.

In the absence of suitable alternatives or information regarding the availability or development of alternatives the authorisation can be granted (provided that all the conditions of Article 60 are met) and the authorisation will be subject to review. In cases where there are suitable alternatives, the authorisation can be granted also if the applicant demonstrates adequate control; in all other cases, the authorisation cannot be granted and, hence, the substance would have to be replaced.

To ensure regulatory coherence it is useful to consider also other substances than the substance under attention. If the substance belongs to a group of substances with similar intrinsic properties (e.g. salts of a metal) and which can easily be replaced by each other, it may be worthwhile to consider the need and possibilities to address all these substances at the same time and in a similar way.

Authorisation could be a preferred option if:

- There is a lack of knowledge on alternatives and on their development.

- Feasible alternatives seem not to be currently available. 


\section{Influence of time}

There are no requirements for registration or evaluation before a substance can be introduced in the authorisation system.

However, it is expected that a lot of information that can be used for identification of substances as SVHC and subsequent recommendation for authorisation will have been provided by industry at the first registration deadline by 1 December 2010 for

- phase-in substances above 1000 tpa, and

- phase-in substances with CMR properties above 1 tpa, and

- phase-in substances classified as dangerous to the environment (R 50/53) above 100 tpa

By the same deadline of 1 December 2010 industry will also have made notifications to ECHA of classifications for all substances regardless of volume.

\subsubsection{Sources of information}

Several sources, apart from those mentioned above, exist with information on potential SVHC substances. Some examples are, e.g.: priority hazardous substances according to the European Water Framework Directive; chemicals for priority action according to OSPAR and HELCOM; the Domestic Substances List of Environment Canada; the US EPA Priority PBTs; the Washington State PBT list; the Substitute It Now list (from the International Chemical Secretariat); the European Trade Union Confederation priority list for REACH authorisation; European Commissions lists of possible chemicals with potential for endocrine disruption. Furthermore, substances frequently detected in monitoring studies (especially from remote areas) could also be considered.

The main source of information on substances under REACH is the registration dossier. For a substance manufactured or imported in an annual quantity of ten tonnes or more per year the registration dossier will include a CSR with a PBT/vPvB assessment for the substance. Further information may be requested through a substance evaluation.

\subsubsection{Relation to other processes and legislation}

The relation to other REACH processes and existing legal requirements needs to be considered in the authorisation process. 
Use of the restriction process after a substance

has been included in Annex XIV

If a substance is included in Annex XIV of REACH, no new restrictions arising from the properties identified in Annex XIV may be imposed ${ }^{36}$. As an exception to this principle, REACH allows for the introduction of new restrictions to address the risks arising from the presence of that substance in articles $^{37}$. This means that, if a substance has been included in Annex XIV because of its carcinogenic profile, it will not be possible to later initiate a restriction process to address the risks derived from the carcinogenic properties of that substance, with the exception of a restriction on the presence of that substance in articles.

The restriction process could, of course, be used to address risks other than those identified in Annex XIV. For instance, if a substance is included in Annex XIV because of its carcinogenic profile, it would be possible to use the restriction process to cover risks to the aquatic environment.

\section{Use of the authorisation process after a substance}

has been included in Annex XVII

The use of the restriction process limits the ability to use the authorisation process for the same substance. It is not possible to use the authorisation process for substances for which all uses have been prohibited (either in Annex XVII or by means of other Community legislation) ${ }^{38}$. For substances for which not all uses have been restricted, resort to the authorisation process regarding restricted uses is only possible if the authorisation does not lead to a relaxation of the restriction ${ }^{39}$. However, uses exempted from restrictions may be subject to authorisation requirements.

\section{Existing legal requirements}

The authorisation requirement will concern all uses that are not exempted according to REACH or for which there is no substance specific derogation in Annex XIV. Substance specific derogations can be set in Annex XIV only when the conditions on proper control of risks through existing specific Community legislation imposing minimum requirements related to the protection of human health and the environment, provided by Art $58(2)^{40}$, are fulfilled.

Special attention should be given to cases where a specific use of a substance is already covered by specific Community legislation. In that case it is useful to consider the possibilities to reduce the risks by better implementation and enforcement of existing legislation. If that does not seem to en-

\footnotetext{
${ }^{36}$ See Article 58(5) of REACH.

${ }^{37}$ See Article 58(6) of REACH.

${ }^{38}$ See Article 58(7).

${ }^{39}$ Article 60(6).

${ }^{40}$ Art 58(2): 'Uses and categories of uses may be exempted from the authorisation requirement provided that, on the basis of the existing specific Community legislation imposing minimum requirements relating to the protection of human health or the environment, the risk is properly controlled....'
} 
sure the proper control of risks, it is worthwhile to consider the reasons why the existing legislation was not effective or enforceable and take these reasons into account when selecting the new instrument and defining the exact conditions in the new rules.

\section{Interface with the POPs Regulation}

The Commission is required to withdraw the authorisation for uses that are restricted under Regulation 850/2004 Persistent Organic Pollutants Regulation (POPs Regulation) $^{41}$. In light of the principle of proportionality and better regulation, to the extent that it can be reasonably foreseen that the manufacture, import and/or use of a specific substance is going to be banned with possible (time limited) exemptions under the POPs Regulation, it should only be considered to be included in Annex XIV for the exempted uses.

\subsubsection{References}

The following documents have been used for the compilation of this section on the Authorisation process.

- Authorisation vs restrictions: which aspects to consider when deciding on the most appropriate instrument, Background paper for the workshop on the Candidate List and Authorisation and Risk Management Instruments.

- Authorisation and Restriction Processes under REACH: A Comparative Analysis

- Workshop on the Candidate list and Authorisation as Risk Management Instruments. Workshop proceedings. Helsinki, 21-22 January 2009

\subsection{Restriction}

\subsubsection{Process outline and legal context}

The Restriction procedure is described in Title VIII, articles 67-73. Annex XVII of the REACH Regulation contains the list of all restricted substances, specifying which uses are restricted. The existing restrictions set out in the Marketing and Use Directive (76/769/EEC), e.g. the ban on asbestos and restrictions on the uses of certain azo-dyes, were carried over to REACH.

$\mathrm{REACH}$ foresees a restriction process to regulate the manufacture, placing on the market or use of certain substances within the EU territory if they pose an unacceptable risk to health or the environment. Such activities may be limited or even banned, if necessary. The restriction is designed as a "safety net" to manage risks that are not addressed by the other REACH processes.

\footnotetext{
${ }^{41}$ See Article 61(6) of REACH.
} 
Any substance on its own, in a preparation or in an article may be subject to restrictions if it is demonstrated that risks need to be addressed on a Community-wide basis. Restrictions of a substance can apply to all uses or to specific uses. There is no tonnage threshold for a substance to be subject to restriction.

Proposals for restrictions will be prepared by Member States or by ECHA on request of the Commission in the form of an Annex XV Dossier. The Annex XV dossier should demonstrate that there is a risk to human health or the environment that needs to be addressed at Community level and should identify the most appropriate set of risk reduction measures. Interested parties will have an opportunity to comment and ECHA will provide opinions on any proposed restriction.

\section{Trigger of the process}

The restriction process can be triggered by a Member State that submits an Annex XV dossier to ECHA or by the preparation of an Annex XV dossier by ECHA at the request of the Commission ${ }^{42}$. This dossier must conform to the requirements set out in Section 3 of Annex XV of REACH, including identification of the risks, evidence that the risk management measures already implemented are not sufficient, available information on alternatives, and a justification that a restriction is the most appropriate measure. The socio-economic impact may be analysed with reference to Annex XVI.

Before a Member State starts preparing an Annex XV dossier with a view to trigger a restriction process, it must notify its intention to ECHA. ECHA must keep a list of substances for which an Annex XV dossier is planned or is being prepared and, in so far as a substance is in this list, no other Annex XV dossier can be prepared ${ }^{43}$. Accordingly, REACH requires that the dossier must be submitted to ECHA at the latest 12 months after the notification of the intention to prepare such dossier ${ }^{44}$. It should be noted, however, that preparing an Annex XV with a view to trigger a restriction process requires significant input.

Following the submission of the dossier (or the finalisation of the dossier by ECHA), the RAC and SEAC must verify that the dossier complies with the requirements of Section 3 of Annex XV (30 days). If it does not, it must be brought into conformity within 60 days after receiving the reasons from the Committees; otherwise the procedure shall be terminated ${ }^{45}$.

All conforming Annex XV dossiers are made public by ECHA and there is a public consultation (six months) ${ }^{46}$.

\footnotetext{
${ }^{42}$ See Article 69(4) and Article 69(1) and Article 69(5) of REACH.

${ }^{43}$ See Article 69(5) of REACH.

${ }^{44}$ See Article 69(4) of REACH. The same deadline applies to ECHA in cases where the Commission requests it to prepare a dossier (see Article 69(3) of REACH).

${ }^{45}$ See Article 69(4) of REACH.

${ }^{46}$ See Article 69(6)
} 


\section{Adoption of a restriction}

The decision to impose a restriction is adopted by the Commission under a comitology procedure. The Commission is to prepare its draft decision taking into consideration the opinions of the RAC and the SEAC. The opinion of the RAC must be prepared within 9 months after the Annex XV dossier is published by ECHA and the opinion of the SEAC within 12 months (the period for the SEAC is longer because it is required to run a second public consultation on its draft opinion ${ }^{47}$ and the opinion of the RAC may also be relevant to the opinion of the SEAC); the Committees must take into consideration the comments received in the public consultation(s).

While REACH foresees the possibility for the Commission to adopt a restriction decision when the Committees do not deliver their opinion within the deadlines above referred ${ }^{48}$, it should be noted that it would be very difficult for the Commission to adopt a proposal for a restriction in absence of the Committees opinion. It follows that the failure of the Committees to adopt opinions might even lead to a situation that the Commission will be unable to conclude that the conditions of Article 68 for adopting a restriction are fulfilled.

It should be noted that REACH envisages a simplified procedure for the introduction of restrictions on consumer uses regarding substances that meet the criteria for classification as CMRs (category 1 or 2$)^{49}$, This does not require the preparation of an Annex XV dossier, the opening of public consultations or the opinion of RAC and SEAC.

\section{Consequences}

A restriction can take the form of a total ban of the substance but this is rare in practice. In most cases, the restriction process is used to ban or put conditions on specific uses or use categories.

After a restriction enters into force, all economic operators manufacturing, importing, using, or placing on the EU market that substance or preparations or articles containing it (if these are part of the restriction) are required to comply with the restriction.

\subsubsection{Work performed at MS CA related to the process}

Role of the MS CA in the process

- Prepare Annex XV Restrictions dossier

- Input to Annex XV Restrictions dossiers submitted by other MS (or prepared by ECHA)

- Support to the rapporteur and committee members in preparing and adopting opinions

\footnotetext{
${ }^{47}$ See Article 71(1) of REACH. Where the opinion of the RAC diverges from the restrictions originally suggested, the deadline for the opinion of the SEAC may be postponed by 90 days (Article 71(3).

${ }^{48}$ See Article 73(1) of REACH.

${ }^{49}$ See Article 68(2) of REACH.
} 


\section{Work required throughout the process}

When considering the workload for Member State authorities in relation to the restrictions process, not only the work needed to prepare an Annex XV dossier should be considered but also later phases of the processes until final decision(s) and enforcement of these decision(s) (see the Table 3 below).

Table 3. Main tasks of the MS authorities in different phases of the restriction process.

\begin{tabular}{ll}
\hline Phase & Task \\
\hline Preparation of an Annex XV dossier & $\begin{array}{l}\text { more obligatory information compared to Annex XV SVHC } \\
\text { dossier } \\
\text { covers already many aspects which are filled in later in the } \\
\text { authorisation process } \\
\text { requires more resources and normally longer time than au- } \\
\text { thorisation }\end{array}$ \\
$\begin{array}{ll}\text { Providing comments on and input to } \\
\text { the Annex XV dossier submitted by } \\
\text { other MSs (or prepared by ECHA at } \\
\text { COM)request) }\end{array}$ & $\begin{array}{l}\text { the Annex XV dossier } \\
\text { the draft opinion of SEAC }\end{array}$ \\
$\begin{array}{ll}\text { Providing support to rapporteur(s) and } \\
\text { to the Committee members in prepar- } \\
\text { ing and adopting the opinions on }\end{array}$ & $\begin{array}{l}\text { SEAC) } \\
\text { restriction proposal (RAC and SEAC) }\end{array}$ \\
$\begin{array}{ll}\text { Decision making in Comitology com- } \\
\text { mittee }\end{array}$ & $\begin{array}{l}\text { restriction proposal } \\
\text { Enforcement }\end{array}$ \\
\hline
\end{tabular}

When a Member State initiates an Annex XV dossier, it has to bear such costs. There will be no income for the Member States in terms of fees to be paid by economic operators.

\subsubsection{Influencing factors for the process}

There are a number of considerations that should be taken into account when assessing whether to prepare an Annex XV dossier with a view to trigger the restrictions process. First, there are legal considerations in so far as the restrictions process has only few exemptions to what kind of risks can be addressed, but it is necessary to show that the risk is unacceptable and that here is a need for community wide action. Second, there are practical considerations that should be considered to use the resources in the most efficient manner.

In order to give a basis for discussion we have included some indications on when restriction could be a preferred risk management option in the sections below. These are excerpted from an ECHA document prepared for the January 2009 Workshop. In that document it was emphasized that it should be noted that the bullet points give intentionally a simplistic picture on how different aspects could be considered and are presented here only to initiate discussion. This list of aspects is not exhaustive and there can be more im- 
portant substance specific factors. Not all these aspects are relevant or applicable to all cases. None of these aspects should be used alone but a holistic view on the benefits and drawbacks is needed. Furthermore the aspects can be overlapping and/or inter-dependent.

The restrictions process can be triggered with regard to risks emanating from almost any specific hazards. In addition, it can cover the manufacturing process of the substance concerned as well as substances in articles. The only risks that are exempted by REACH from the restriction process are:

- risks arising from research and development activities ${ }^{50}$;

- risks arising from on-site isolated intermediates ${ }^{51}$;

- risks for human health arising from uses in cosmetic products within the scope of the relevant Community legislation ${ }^{52}$;

Thus, restriction can be utilised also when other intrinsic properties of the substance cause concern than those covered by Article 57.

However, it is necessary to show two cumulative elements: (1) that there is an unacceptable risk to human health or the environment, and (2) that the risk needs to be addressed on a Community-wide basis. In addition, the initiator of an Annex XV dossier with a view to propose a restriction also has to demonstrate that a restriction is the most appropriate Community-wide measure in accordance with the criteria, i.e.: (i) effectiveness, (ii) practicality (in terms of implementation, management, and enforcement), and (iii) monitorability of the results.

Any substance on its own, in a preparation or in an article may be subject to restrictions if it is demonstrated that risks need to be addressed on a Community-wide basis. Restrictions of a substance can apply to all uses or to specific uses. There is no tonnage threshold for a substance to be subject to restriction.

The restrictions process may cover risks arising from any substance that is contained in any article that is placed on the EU market regardless of whether the article incorporating the substance is produced within the EU or outside.

Finally, REACH foresees a simplified procedure for the introduction of restrictions regarding risks from substances that meet the criteria for classification as carcinogenic, mutagenic, or toxic for reproduction, category 1 or 2 , related to consumer users ${ }^{53}$. The simplified procedure significantly reduces the resources and time needed to restrict such uses as it does not require the preparation of an Annex XV dossier, the opening of public consultations, or the opinion of the RAC and SEAC.

\footnotetext{
${ }^{50}$ See Article 67(1) of REACH.

${ }^{51}$ See Article 68(1) of REACH.

${ }^{52}$ See Article 67(2) of REACH.

${ }^{53}$ See Article 68(2).
} 
Thus, restriction could be a preferred option if:

- $\quad$ The (main) risks are related to:

o manufacturing

0 the use as intermediates

0 the use in articles or

o other uses exempted from Title VII

- There is reasonable knowledge on the types of uses and on the main use conditions

- A large number of actors use the substance under similar conditions, thereby enabling sector organisations and/or national authorities to provide support and guidance

- A total ban of all uses (including in articles) is the objective

- There is reasonable knowledge on the availability and feasibility of alternatives, and on their development

An Annex XV dossier intended to propose the restriction of a substance shall include available information about the existence of suitable alternatives, including information on the risks to human health and the environment related to the manufacture or use of the alternatives, availability (including the time scale) and the technical and economical feasibility ${ }^{54}$. It should also be noted that, when the Commission takes the decision whether or not to amend Annex XVII in order to restrict the manufacture, placing on the market or use of a substance, it is required to take into account the socioeconomic impact of the restriction and, in particular, the availability of alternatives.

In the restriction process the availability of alternatives is taken into account: the MS (or ECHA on the request from the COM) is required to document the available information on alternatives in the Annex XV report and the Commission has to take into account the availability of alternatives before adopting a restriction. In Annex XVII it is possible to set case-bycase time-limited derogations for the uses for which transfer to alternatives within the normal implementation period is not regarded as feasible and also to set requirements on the industry, e.g., to report on the status of the development of alternatives.

In the restriction process enforceability is one criterion against which the authority preparing the Annex XV restriction dossier has to assess the proposed restriction. Furthermore the Forum has a possibility to give its view on the enforceability of the proposed restriction.

Restriction sets out the same requirements and same timelines on all similar actors throughout the EU.

\footnotetext{
${ }^{54}$ See Section 3 of Annex XV.
} 


\section{Additional influencing factors identified at the workshop}

Additional influencing factors that were considered important for the prioritisation were:

- monitoring data from remote areas;

- information on vulnerable groups;

- information on cumulative effects;

- possibilities for grouping of substances (including different approaches, e.g. based on inherent properties or uses (e.g. alternatives));

- complexity of the supply chain (which may influence MS CAs workload for example by presenting a challenge in terms of obtaining information and assessing socioeconomic implications);

- the timing perspective in relation to substance evaluation which most likely will not provide results for use in restriction dossiers until 2013 (first draft CORAP-list from ECHA by 1 December 2011);

- early identification whether it would be better to regulate a certain "targeted risk" under another legislative framework.

\subsubsection{Influence of time}

The Restrictions title in REACH will enter into force on 1 June 2009.

There are no requirements for registration or evaluation before a substance can be introduced in the restriction system.

However, it is expected that a lot of useful information will have been provided by industry at the first registration deadline by 1 December 2010 . In particular registration dossiers containing exposure scenarios will be valuable sources of information for identifying risks associated with certain uses of substances.

By the same deadline of 1 December 2010 industry will also have made notifications to ECHA of classifications for all substances regardless of volume.

By the end of 2012 (approximately) it can be expected that the outcome of substance evaluations will provide further information for restrictions of certain evaluated substances.

\subsubsection{Sources of information}

Several sources, apart from those mentioned above, exist with information on potential risks associated with the use of substances. Some examples are, e.g.: priority hazardous substances according to the European Water Framework Directive; chemicals for priority action according to OSPAR and HELCOM; the Domestic Substances List of Environment Canada; the US EPA Priority PBTs; the Washington State PBT list; the Substitute It Now list (from the International Chemical Secretariat); the European Trade Union Confederation priority list for REACH authorisation; European Commissions lists of possible chemicals with potential for endocrine disruption. 
Furthermore, substances frequently detected in monitoring studies (especially from remote areas) could also be considered.

Information on the use of substances is critical in order to identify risks. The main source of information on substances under REACH is the registration dossier. The exposure scenarios will provide information on the use of substances. Other sources are for example the Nordic Product Registers. Further information may be requested through a substance evaluation.

\subsubsection{Relation to other processes}

Use of the authorisation process after a substance has been included in Annex XVII

The use of the restriction process limits the ability to use the authorisation process for the same substance. In particular, it is not possible to use the authorisation process for substances for which all uses have been prohibited (either in Annex XVII or by means of other Community legislation) ${ }^{55}$.

For substances for which not all uses have been restricted, resort to the authorisation process regarding restricted uses is only possible if the authorisation does not lead to a relaxation of the restriction ${ }^{56}$.

Use of the restriction process after a substance has been included in Annex XIV

If a substance is included in Annex XIV of REACH, no new restrictions arising from the properties identified in Annex XIV may be imposed ${ }^{57}$. As an exception to this principle, REACH allows for the introduction of new restrictions to address the risks arising from the presence of that substance in articles ${ }^{58}$. This means that, if a substance has been included in Annex XIV because of its carcinogenic profile, it will not be possible to later initiate a restriction process to address the risks derived from the carcinogenic properties of that substance, with the exception of a restriction on the presence of that substance in articles.

The restriction process could, of course, be used to address risks other than those identified in Annex XIV. For instance, if a substance is included in Annex XIV because of its carcinogenic profile, it would be possible to use the restriction process to cover risks to the aquatic environment.

\footnotetext{
${ }^{55}$ See Article 58(7).

${ }^{56}$ Article 60(6).

${ }^{57}$ See Article 58(5) of REACH.

${ }^{58}$ See Article 58(6) of REACH.
} 


\subsubsection{References}

The following documents have been used for the compilation of this section on the restriction process.

- http://guidance.echa.europa.eu/restriction_en.htm

- Authorisation vs. restrictions: which aspects to consider when deciding on the most appropriate instrument, Background paper for the workshop on the Candidate List and Authorisation and Risk Management Instruments.

- Authorisation and Restriction Processes under REACH: A Comparative Analysis 



\section{Considerations of different risk management options}

A workshop was organised by ECHA in January 2009 "Workshop on the Candidate List and Authorisation as Risk Management Instruments". This section includes summaries of selected sections from the workshop as presented by ECHA and the Commission. The summaries are intended to provide a basis for further discussions on the different risk management options of Reach and other legislation.

\subsection{Generic policy evaluation criteria and principles}

There are normally several different options to achieve a policy objective. Generic policy evaluation criteria and principles can be used in order to support the choice in a specific case. Although the exact wordings used, grouping of issues and description of different criteria may vary, often such generic criteria include ${ }^{59}$, e.g.

- Effectiveness:

The extent to which options can be expected to achieve the objectives set out; how well the options can be targeted to the effects or exposure concerned; the extent to which new adverse effects/risks can be avoided; which measure seems to be more cost-effective to the society as a whole;

- Proportionality:

Whether the (administrative and compliance) costs are proportionate to the benefits of the reduced risks

- Practicality:

Clarity of the obligations placed on the industry and administration; implementability (for concerned administration and actors); enforceability; possibility to monitor whether or not the objectives are achieved

\footnotetext{
${ }^{59}$ Such generic criteria can be found, for instance, the Treaties (Art 5 and Protocol 2, http://europa. eu/lisbon_treaty/full_text/index_en.htm), the Commission Impact Assessment Guidelines (http://ec. europa.eu/governance/impact/index_en.htm), section 3 of Annex XV of REACH, national policy documents (e.g. http://www.betterregulation.ie/)
} 
- Consistency:

Are/will similar cases be handled in a consistent manner; predictability of the rules; legal certainty for actors; the extent to which options are likely to limit trade-offs across the economic, social and environmental domain (e.g. between different social and economic groups, regions etc.)

\subsection{Authorisation vs. Restrictions, deciding on the route}

The participants of the "Workshop on the Candidate list and Authorisation as Risk Management Instruments" held in ECHA in January 2009 came to the conclusion that there is a need for a common framework to analyse the best Risk Management Option (RMO) applying to chemicals (authorisation under REACH, restriction under REACH, or any other Risk Management Option or combinations of them). This framework should promote an early discussion, and eventually cooperation, between the authorities.

Even if the assessment of the best RMO for a certain substance should remain a case-by-case exercise, it should preferably be carried out according to a common (stepwise) approach, using a minimum set of standard parameters. In particular, the analysis of the necessary (human) resources should, if possible, cover the whole process from the initiation and development of the necessary documentation to the actual implementation and enforcement of the new risk management measure(s).

It was also agreed that the analysis of the best Risk Management Option should preferably be conducted as early as possible in the development process of any new Annex XV dossier, and shared with the other authorities, even if not entirely finalised.

According to the participants in the workshop, this approach would reduce the risk of having to take another direction in terms of Risk Management Option at a later stage in the process. Even if this would need an upfront investment, it will in the end probably save scarce resources.

The participants agreed that:

- a certain flexibility should remain in the conduction of the analysis, with in particular no formal requirement nor strict format,

- the analysis would mainly be a comparative assessment based on the available information, a full (quantitative) analysis not being recommended nor probably feasible,

- the exact mechanism and best timing to conduct and share the analysis with the other authorities still needs to be discussed and agreed

A recommendation from the January workshop was: To further develop a common "framework" for the analysis of the best RMO option (authorisation, restriction, other RMO, or combination). 
According to the document "Workshop proceedings" it was proposed that ECHA develops a first proposal, on the basis of the background documents developed for the workshop and the discussions that took place.

This proposal will be presented to the next CA meeting (June 2009) for a general agreement before it can serve as a basis for the authorities in charge of initiating the development of Community-wide risk management measures in the field of chemicals. This framework should also include proposals for appropriate mechanisms and timing for sharing and discussing the analyses between authorities, as well as suggestions on how to submit these with/as part of the Annex XV dossiers.

(Short summary of presentation by ECHA)

A well informed decision on the process authorisation or restriction should be based on systematic consideration of advantages and drawbacks to ensure:

- effective prevention and control of risks

o defined case-specific objectives to be achieved

o cost-effective use of resources throughout the process

- consistent regulation of substances

Before deciding between Authorisation and Restrictions examples of prestep considerations are:

- Is a Community-wide action needed/justified? (subsidiarity)

o objective could not be sufficiently achieved by national action (the necessity test)

o objective could be better achieved by Community-wide action (the added-value test)

- Is other Community legislation more appropriate than restriction or authorisation under REACH?

o Occupational health, consumer and/or environmental legislation

o Sector / issue specific legislation

The main steps for initiating an authorisation or restriction process for a substance are described in the figure below. 


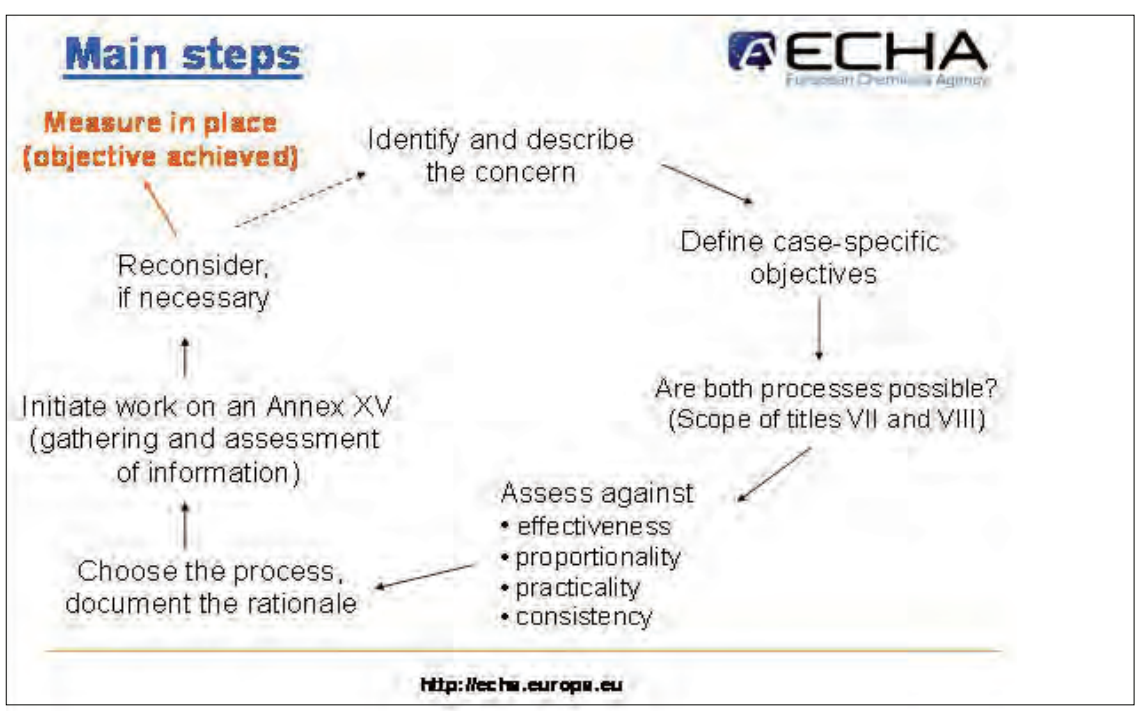

Conclusions

- Systematic consideration of advantages and drawbacks can give a better basis for the selection of the process

- Use of available information, identify and take into account uncertainties

- Holistic view

- The whole process, all actors, all relevant aspects

- Reconsideration if necessary

- Documentation of the consideration

\subsection{Other community legislation}

As presented by the European Commission at the January Workshop.

In the context of discussions on authorisation and restrictions of substances in REACH, possible risk management options (RMOs) provided by other Community legislation should be kept in mind. The consideration of possible RMOs is part of the process of preparing restrictions proposals as elaborated in the Guidance for the preparation of Annex XV dossiers for restrictions.

When preparing a restrictions proposal, it should be assessed what is the best way to manage the risks. Next to the option of a restriction under REACH, RMOs in the framework of other Community legislation may be considered as appropriate. Attached is a non-exhaustive list from the guidance document of EU legislation that the Authority may consider. In addition there may be sector or use specific legislation that can be used (e.g. directive on fuel quality where the risk arises from the use of a substance as additive in petrol). The aim of the identification of other RMOs is to find those that have potential to reduce the identified risk, i.e. their scope cover the use(s) in question and requirements under them can address the relevant exposure. 
It should be noted that the identified risks may in some cases best be addressed by a combination of RMOs. This could particularly be the case when a substance evaluation has been carried out, which would normally evaluate any risks resulting from the manufacturing and uses of the substance and, on the basis of the information obtained, identify the need for further measures. Such a combination of measures may also include a restriction under REACH for certain uses. In that case, the Authority should submit to ECHA an Annex $\mathrm{XV}$ dossier proposing a restriction for these uses and document the need for other Community wide measures for the rest of the uses.

The identified RMOs need to be shortly described for further comparison with the proposed restriction. It is also useful to give an overview on how the possible RMOs would address the identified risks.

See annex 5 for a brief description of examples of existing Community legislation under which substance-specific conditions are set. 



\section{Outcome of workshop}

The structure of the workshop followed the agenda as provided in Annex 6. A list of participants is given in Annex 7. The first half-day of the workshop was devoted to introductory presentations describing the different REACH processes (dossier evaluation, substance evaluation, harmonised classification and labelling, SVHC for the candidate list, authorisation, and restrictions). In between the respective presentations, time was allotted for questions and clarifying discussions. After the introductions the participants were invited to discussions in sub-groups leading up to conclusions and recommendations that were reported and discussed in the next day's plenary session.

The background document and the presentations prepared by the preparatory group from the Swedish Chemicals Agency were provided to serve as the basis for the discussions. The groups were instructed to focus their discussions on the issues described in Annex 1 and to follow the instructions given in Annex 8. Each group focused its discussions on two of the REACH processes (major) and one additional process was discussed (minor) if time was available.

\subsection{Reports from breakout groups}

The reports from the discussions in the four breakout groups are shown below.

\subsubsection{Group 1}

The processes discussed in group 1 were substance evaluation and dossier evaluation (major), and harmonised classification and labelling (minor). The participants in this group were; Marie Holmer (DK), Jaana Heiskanen (rapporteur) and Riita Leinonen (Finland), Joke Herremans (the Netherlands), Marianne van der Hagen (Norway), and Jörgen Henriksson (co-rapporteur) and Katarina Lundberg (Sweden). 


\begin{abstract}
Substance evaluation
- Aim \& Objectives of the process

- Aim and objective: clarify concern, OK

- Long procedure, time consuming

- How much/little should/do I need to do before CORAP, because of no payment?

- Process may not need to end up by asking for testing/monitoring only review/evaluation

- Targeting: if you target for one concern $(\mathrm{HH})$, is it possible to target later the same substance for
\end{abstract} CORAP for another concern (ENV)?

\author{
Substance evaluation \\ - Influencing factors (2) \\ - Exposure based waiving - need to \\ check carefully \\ - Substances with high political \\ focus \\ - Difficult to rank different prioritisa- \\ tion factors
}

Dossier evaluation - testing proposals

- Aim \& Influencing factors

- Aim: OK

- Some endpoint more interesting than the others

- Use of the substance in respective country via product register data (e.g. Norway "Exposure Index") - Non standard test vs standard test: not clear case (for some endpoints non standard preferred)

- Substances with high political focus (e.g. In DK endocrine disrupting substances)

Dossier evaluation - compliance check

- Aim \& Objectives of the process

- Aim: ECHA may check part of registration, but not necessarily check all points - MSs aims are different - clarification of wording (replace "and" with "or")

- How to influence 1) on ECHA on the choice of the dossiers and 2) if $\mathrm{ECHA}$ agrees with the registrant? Use of Art. 41(6) - third party to provide info

- ECHA can re-evaluate the same dossier

- C\&L part of compliance check as risk management measures are mentioned
Substance evaluation

- Influencing factors (1)

- Use descriptors: info on wide dispersive use

- Concern for C\&L gives initiative for substance evaluation

- Economic factor (remuneration): how much will be paid to

the CA?

- Grouping under substance evaluation

- Number of registrations per substance

- aggregation of tonnages/combined exposure

Substance evaluation

- Additional issues

- (Nordic) cooperation

- Product register - Exposure Index project ongoing (publicly available end of year in SPIN)

- ECHA's CASPAR-prioritisation tool being developed more information needed

- Using non-testing/(Q)SAR method for prioritisation; yes, for example in classification (different classifications between registrants?)

Dossier evaluation - testing proposals

- Additional issues

- Prioritisation of CA work:

- Share of burden between countries in checking testing proposals, like in OECD program, based on different expertise in different countries, fast procedure needed

- ECHA could organize the work, good experience from new substances

Dossier evaluation - compliance check

Influencing factors \& Additional issues

- Prioritisation factors for MSs:

- Enforcement and monitoring data

- C\&L (not classified and high volume) are priority factors

- Waiving, exposure info/use descriptors

- Sharing of burden - is it possible to divide the work between MSs in advance?

- Use of QSARs: yeas (if you use ready self-classification list for non classified substances; SPIN.....) 


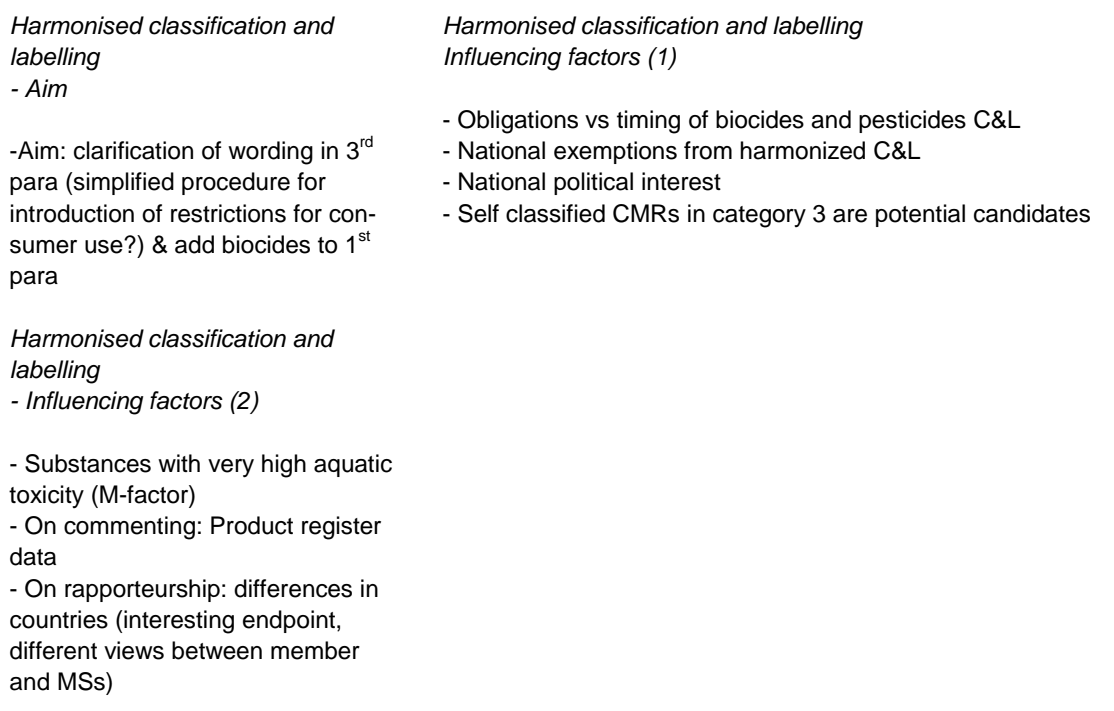

\subsubsection{Group 2}

The processes discussed in group 2 were harmonised classification and labelling and SVHC for the candidate list (major). The participants in this group were; Henrik Tyle (rapporteur) (Denmark), Kirsi Annola (Finland), André Muller (the Netherlands), Heidi Morka (Norway), and Alicja Andersson (co-rapporteur) and Sten Flodström (Sweden).

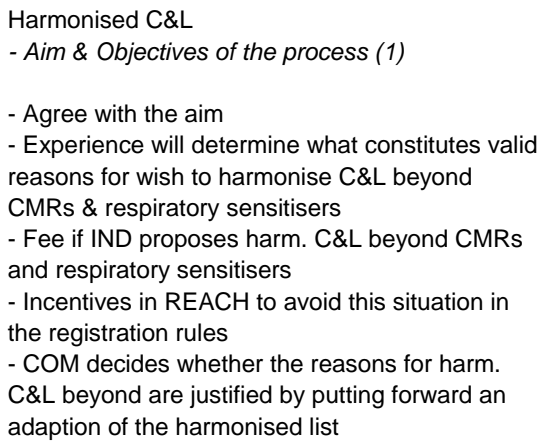

Harmonised C\&L

- Aim \& Objectives of the process (2)

- IND has to change the self-classification according to Art 22.1 REACH (f) if there is information leading to "any change in the classification and labelling of the substance"; = CLP art 15 (MS have no obligations here) - No legal requirement to have harm. CMR adopted before SVHC can be proposed for the Candidate List - but in practice this will take effect

- REACH has extended the possibility of prohibition of consumer use to also articles using on simplified procedure based on harm, CMR C\&L

Harmonised C\&L

Influencing factors (2)

- Substances for harm. C\&L except those being PPP, BP and substances for the Candidate list (SVHC): good reasons for equal protection leve by the labelling and by the downstream consequences of the harm C\&L

- Other effect of importance for harm. C\&L: skin sensitisers, R48 (even for PBT), T, Tx, N;R5053 (especially if $M \geq 10$ ), high exposure potential - all those especially when diverging selfclassified by IND

- The appropriateness of proposals should be screened/the scrutiny will also be somewhat based on experience with the submitter 
Harmonised C\&L

- Influencing factors (3)

- Priority will also reflect the current policies of MS (particular hazardous endpoints may be especially "popular"), higher priority for MSCA when a lower $C \& L$ is proposed \& the more knowledge on a substance/group of substances the higher priority

- The way communication goes with IND is also dependent of the administrative/regulatory set up - The lesser exposure potential the lesser priority - Borderline cases receives higher priority

\section{Harmonised C\&L}

Additional issues (2)

- OECD QSAR TG use may over time as people get more knowledge in non testing approaches pave the way for greater but still science based positivism towards use of non test methods (grouping \& QSARs)

- Interaction with ECHA staff at the technical level will be very important because $\mathrm{ECHA}$ will be a key player - some concerns expressed with the bureaucratic set up which may inhibit that efforts will succeed

SVHC Candidate list

- Aim \& Objectives of the process (2)

- MSCA: When preparing CANDI-list proposals consider quickly to propose the restriction possibility - to prevent ECHA/COM from proposing the substance for the Authorisation List which would open up for the possibility that even certain very problematic uses of the SVHC may be granted later on

- Discussions of the case with DEHP, DBP and $\mathrm{BBP}$ - is the placing on the Authorisation list really what we want? - Future experience may inform

\section{SVHC Candidate list}

- Influencing factors (2)

- Often desired technical properties goes hand in hand with undesired hazardous properties - but sometimes shift in nature of undesired property (see above rockwool/HBCDD ex.)

- Difficult for MSCA to go too much into actual promoting certain alternatives - must stay at IND because otherwise CAs take over the IND responsibility (against the spirit of $\mathrm{REACH}$ )
Harmonised C\&L

Additional issues (1)

- Non test results should be - especially for certain endpoint - important for triggering testing (not our agenda), priority setting for C\&L or directly in some cases for regulatory decisions in relation to C\&L (and PBT assessment) - Cooperation between MSCA based on their competence in various fields important (to avoid duplication of work)

- How will the update of the DK EPA Advisory Self-classification list be used when IND under $\mathrm{REACH}$ is promoted to agree on their selfclassification

SVHC Candidate list Aim \& Objectives of the process (1)

- CANDI-list is stigmatising chemicals and gives incentives in itself to substitute to better alternatives

- Placing the CAND-list substances eventually on the Authorisation list signalizes that certain uses may be allowed- but this may not be what is warranted

- Open mind for using the restriction option or mixed approach for different applications/uses - View: Not all substances in the list should with that perspective be sent from CANDI-list to Annex XIV

- Indicate clearly why a substance is proposed placed on the CANDI-list

SVHC Candidate list - Influencing factors (1)

- Agree to many of the issues listed but - For CMRs potency matters in the priority setting

- Revise the wording regarding source of emission compared with e.g. natural sources- relate to such sources leading to relevant exposure pattern

- Evaluation of the suitability of alternatives. Includes ALSO in practice a large fraction of non scientific based value judgements on what types of concerns deserves interven-

tion/prevention (e.g. mineral fibres versus use of HBCDD - comparing is more difficult than comparing apples and pears; which are similar fruits)

SVHC Candidate list - Influencing factors (3)

- Long/short CANDI-list?: irrelevant: content (SVHCs incl.) must be rational - CMR generally (as stipulated by REACH art 58 ) of lesser priority than PBTs because harmonised $C \& L$ of the former assures a range of downstream regulation \& $\mathrm{RM}$

- SELCs may be at least as concerning as PBTs (especially if the PBT criteria is not being updated - need for better screening \& definitive "criteria" in REACH, WoE and scientific expert interpretation of information anyway essential because in many cases not easy to decide in a simplistic way on even costly definitive types of data) 
SVHC Candidate list

- Influencing factors (4)

- P mother of concern - ("to be or not to be")

- Extremely persistent and extremely toxic

substances (ePeT) should also be considered as

SVHC

- Added value of putting CMRs into Candidate

list: (trivial but anyway): better info on use in articles, further stigmatising these nasty chemicals, on the route for substitution (only mentioned here under REACH) because candidate for authorisation (on the other hand where granting of certain uses may take place even based on only SEA nor RA). Warning to lower volume chemicals to not become HPVC

SVHC Candidate list

Additional issues (2)

- Grouping is very important

- may however not be straightforward (e.g.

where are the borders?)

- concerns not only information requirements

but also hazard and risk (when they occur simultaneously they act additively - conc./dose addi-

tion).

- grouping across all regulatory end-

points/concern areas may not be war-

ranted/scientifically justified because these differ in relation to the descriptors defining the type of grouping used

- Grouping is VERY important both for (harmonised) C\&L and later if deciding proposals for the candidate list to avoid replacement of SVHC with similar "alternatives"
SVHC Candidate list

- Additional issues (1)

- Quality of registration (exposure scenarios) very important for whether further action under $\mathrm{REACH}$ (candidate list, restriction, authorization) would be warranted for CMRs

\subsubsection{Group 3}

The processes discussed in group 3 were restrictions and substance evaluation (major). The participants in this group were; Frank Jensen (Denmark), Marianne Hänninen (Finland), Jon Birger Aarnes (rapporteur) and Ingunn Myhre (Norway), and Elisabeth Karlsson (co-rapporteur) and Ivar Lundbergh (Sweden).

\begin{tabular}{ll}
\hline $\begin{array}{l}\text { Restrictions } \\
\text { - Aim and Objectives of the process }\end{array}$ & $\begin{array}{l}\text { Restrictions } \\
\text { - Influencing factors (1) }\end{array}$ \\
-Is it a safety net? & - Availability of information on Cumulative effects \\
- Unclear what is meant by "safety net" & and exposure \\
- Yes, for other effects than SVHC (neurotoxic, & - Not able to request info from registrant \\
sensitizers etc.) and for imported articles & - Multiple substances in e.g. one article \\
- IND show safe use, catch those that fall & - Multiple exposure to one substance from \\
through & different sources \\
- Timing perspective & - Demonstrate that restrictions is most appropri- \\
- Restriction proposal based on evaluated & ate community-wide measure, including consid- \\
substance from CORAP-list (first in 2013- & eration of other community-wide regulations
\end{tabular}

2014?)

- Need to start with substances not evaluated,

with enough data 
Restrictions

- Influencing factors (2)

-Sequential order of influencing factors?

- How do we choose? What is the trigger?

- Initial concern (newspaper, monitoring, scientific data)

- Political influence/priority

- Identify unacceptable risk

- Availability of information - differs before and after potential substance evaluation

Restrictions

- Issues for discussion (2)

- Number of actors in the supply chain and size of industry sector may influence priority setting - Does not change the severity of the problem but might influence priority setting

- Workload for MSCA

- Long supply chain, challenge to obtain information

- Socioeconomic implications

Substance evaluation

- Aim and objectives of the process

- In general we agree

- Concern about outcome of substance evaluation What about commenting on the conclu-

sions?

- REACH says - the next step is up to MS CA

- No community conclusion - information can be

used in a later stage

- Consider procedures for after substance evaluation

- Commenting from other MS

- Check/support each others conclusions

- Develop a system for discussion?

Substance evaluation

- Priority setting in the context of listing sub-

stances on the CORAP

- What do other countries prioritize?

- Discussion with ECHA and other MS

- New hazard data -= non-registrated data?

- New data indicating that use is not safe

- Hazard information indicating other effects

than in registration of substance

- QSAR data - but CA wants to see real data

- Breakdown products - which give rise to

concern

- Information may be retrievable from literature search, monitoring data etc.
Restrictions

- Issues for discussion (1)

- Grouping

- Case by case

- Alternatives

- Substances easily substituted - can be reason

to group

- Availability of less harmful alternatives may

facilitate restriction (socioeconomic implications)

- QSAR may be used to assess alternatives

- E.g. PFOS, Azo-dyes, MCCPs?

- Need to identify the different substances/CAS

- Same risk identified, could be addressed

togethe

- E.g. phthalates in eraser

Restrictions

- Issues for discussion (3)

- Relationship with other legislations

- Consider restriction under other legislations covering specific use e.g. RoHS, toys

- Is the risk in scope of another legislation?

- Is risk already regulated?

- Example; Concern for use in toys?

Need to early identify if a "targeted" risk is better regulated in other legislation framework

Substance evaluation

- Development of criteria

- Hazard information

- Substance fulfils classification criteria - exposure assessment included in the CSA

- Endocrine disruptors - political focus

- Exposure information

- Same use, but different exposure levels or

different risk management measures

- Tonnage

- No CSA for substances $<10$ tonnes

- Substance is e.g. a CMR - ask for exposure scenario/information

- Brief general description of use can give initial concern

Connections between Restriction and - Substance evaluation (1)

- What prompts a restriction dossier?

- Triggers that may lead an MS to propose a substance to the CORAP-list in order to request data required for a restriction proposal

- ECHA may include the substance on CORAP

- may trigger a restriction proposal

- Substance evaluation necessary?

- Substance may or may not be of concern

based on sum of exposures

- Some cases with enough info, other sub-

stances not 
Connections between Restriction and Substance evaluation (2)

- Difficult for enforcement to control scenarios - Restriction an option - do not believe CSA and exposure scenario

- Work on that single dossier - start with compliance check

- MS CA gets paid for substance evaluation

- Consider if use/risk should be covered by authorization scheme
(Nordic) cooperation

- Restrictions - Nordic networking

- Mail coordination - need for focal point

- Exchange intention/ideas of pre-Rol

- Network on restriction procedure

- Intention of co-operation should be specified

- E.g. avoid duplication of work and facilitate

process

- Not just for restriction

- NORAP coordination?

\subsubsection{Group 4}

The processes discussed in group 4 were SVHC for the candidate list and authorisation (major), and restrictions (minor). The participants in this group were; Bent Horn Andersen (Denmark), Outi Tunnela (Finland), Angelika Baumbusch and Marianne Tvermyr Holmen (Norway), and Lars Gustafsson (rapporteur), Lolo Heijkenskjöld, and Anna Wik (co-rapporteur) (Sweden).

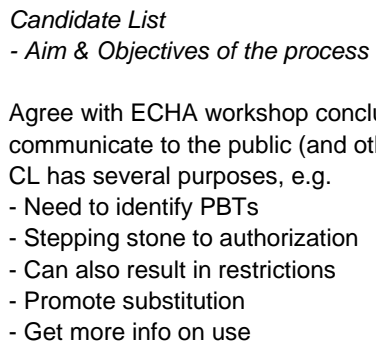
CL has several purposes, e.g.

- Need to identify PBTs

- Stepping stone to authorization

- Can also result in restrictions

- Promote substitution

- Get more info on use communicate to the public (and others) that the
Candidate List

- Influencing factors

Some further ideas on prioritisation - C potency? (T 25 system, a method for ranking)

- Non-threshold versus threshold C/M?

- CMR higher score if also nearly P or B, or PBT and endocrine disrupters?

- Properties are most important for the prioritisation, but better use of indications on use/exposures should be used for better prioritisation;

- SELCs: save for future work to find such (when more information is available)?

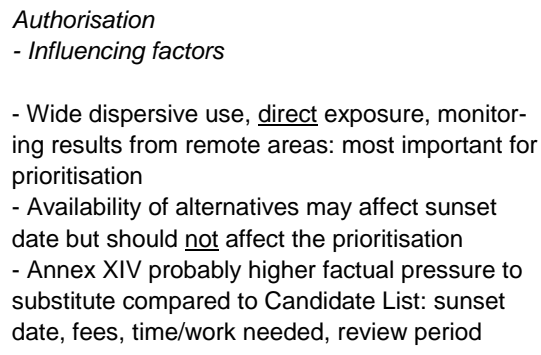
ing results from remote areas: most important for prioritisation

- Availability of alternatives may affect sunset date but should not affect the prioritisation - Annex XIV probably higher factual pressure to substitute compared to Candidate List: sunset date, fees, time/work needed, review period

Choice authorisation/restrictions

- Difficult, case dependant

- Need for checklist, remind ECHA

- Flowchart?

- Better pre-Rol (or informal chat-site?)

- Document considerations, learn from experi-

ence individual substances ( $1^{\text {st }}$ Annex XIV)
Restrictions

- Influencing factors

- If dossier proposes restrictions via other legislation?

- Avoid prio if other legislation may disturb?

- More difficult now to make bans in other legislation?

Prio criteria:

- Good availability of information, identified risk

- Vulnerable groups, direct exposure

- Wide dispersive use

- Monitoring results from remote areas

- Comparatively little work, politically sensitive?

Nordic Co-operation

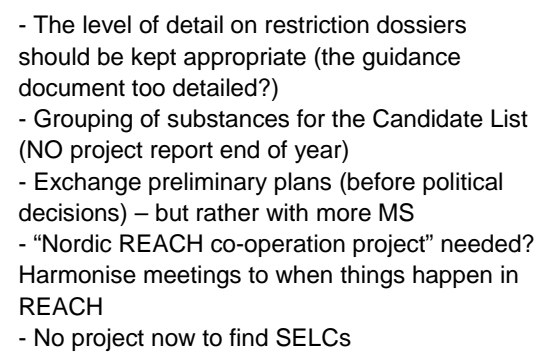




\subsection{Workshop conclusions and recommendations}

The conclusions on aims of the processes and proposals for factors influencing the priority setting and recommendations for further consideration and/or action given in this section are based upon the reports from the four breakout groups and the plenary discussions held on the second day of the workshop. However, the plenary discussions on the breakout group reports were not given sufficient time and were not set up to lead to explicit agreement among the participants regarding all of the additional influencing factors or recommendations proposed.

Therefore, these conclusions and recommendations for each process should be recognised as primarily reflecting the discussions in the breakout groups of the workshop.

\subsubsection{Dossier evaluation}

\section{Aim and objectives of the process}

The participants agreed with the aim of the examination of testing proposals as described in the background document. For the aim of the compliance check the participants agreed but pointed out that ECHA may not necessarily check all parts of a registration.

Influencing factors for the priority setting

Further influencing factors mentioned for testing proposals were for example:

- information on use via product register data;

- substances with high political focus (e.g. endocrine disrupters).

Further factors influencing priority for examining draft decisions on compliance checking were:

- information from enforcement and monitoring data;

- non classified high volume substances (for example where use of (Q)SARs or available "self-classification lists" indicate that classification is warranted).

Regarding the possibilities for the MS CAs to influence which substances ECHA will choose for compliance checking it was concluded that according to REACH article 41(6) any third party may electronically submit information to ECHA relating to substances that have been pre-registered. This information shall be considered by ECHA when checking and selecting dossiers. The participants agreed that this could be an opportunity to be used by MS CAs. 


\section{Recommendations}

A recommendation from the participants was to investigate the possibility for sharing of burden between MSs of the tasks within examination of testing proposals (and possibly compliance checks?), based on MS CAs volunteering to examine a certain test proposal (e.g. thereby taking account of different expertise in different countries). ECHA could be asked to organise the sharing of work on testing proposals in a similar way as is done by the OECD Secretariat when inviting Member Countries to volunteer for examining SIDS documents in the OECD HPVC Program.

\subsubsection{Substance evaluation}

\section{Aim and objectives of the process}

The participants agreed with the aim as described in the background document, but some concern was raised concerning the outcome of the substance evaluation which leaves it up to the MS CA to conclude on any further actions without any opportunity for other MS CAs to comment on the conclusion.

\section{Influencing factors for the priority setting}

The participants agreed with the influencing factors as described in the background document and concluded that it is difficult to rank the factors in order of importance for the priority setting. Some of the additional factors that were recognised to influence the process were:

- grouping of substances (e.g. information on cumulative effects);

- classified substances, a CSR including exposure assessment and risk characterisation will be available for a substance fulfilling a classification criterion, thus providing a better basis for substance evaluation;

- CMR substances below 10 tpa lacking a CSR could be prioritised to ask for exposure information;

- non-registered hazard and exposure data raising an initial concern;

- the priorities of other countries, and

- the economic factor (remuneration): how much will be paid to MS CA for performing a substance evaluation? The coverage of actual costs influences the number of evaluations that MS CAs will have resources to do.

\section{Recommendations}

It was suggested to further consider the pros and cons of proposing to ECHA and MS CAs to start developing an informal system for exchanging comments and discussion of the MS CA rapporteur's conclusions regarding whether and how to use the information obtained from the substance evaluation process. 
Further Nordic cooperation was recommended for producing background material that could be used as input to the development of criteria for prioritising substances for substance evaluation. These criteria will be developed by ECHA in cooperation with the Member States according to article 44 of REACH.

Further information should be sought about the prioritizations tool CASPAR being developed by ECHA.

Results from the currently ongoing Nordic Exposure Index project, using product registry information, may be useful in priority setting. Results will be publicly available via SPIN by the end of 2009 .

Non-testing ((Q)SAR) methods could be useful for priority setting in substance evaluation

\subsubsection{Harmonised classification and labelling}

Aim and objectives of the process

The participants agreed with the aim as described in the background document. It was pointed out that there is no legal requirement to have a harmonised classification for CMRs before these can be proposed for the candidate list but this will, in practice, be the case since the ECHA Member State Committee responsible for the candidate list is expected to ask the RAC for the classification. It was also pointed out that the simplified procedure for the introduction of restrictions regarding risks from CMRs to consumers also applies to articles.

\section{Influencing factors for the priority setting}

Additional factors that were recognised to influence the prioritisation of substances were:

- self classified CMRs in category 3;

- $\quad$ skin sensitisation, R48 (even for PBT), T, Tx, NR50-53 (especially if $M>10),-$ all those especially when diverging self-classification by IND;

- $\quad$ non-testing/(Q)SARs indicating C\&L;

- grouping of substances often very important for harmonised C\&L (and subsequently for the candidate list and authorisation);

- in general there is a direct relationship between exposure potential and priority for C\&L.

\section{Recommendations}

Clarification should be sought (e.g. with ECHA and the Commission, and nationally with relevant authorities) regarding what legal obligations MS CAs have for the submission of dossiers proposing harmonised classification in the following cases: 
a) where IND provides information to the MS CA proposing amendment of an harmonised classification in Annex VI to CLP;

b) for active substances in pesticides and biocides.

It was suggested that Denmark should share their recent update of the "Danish advisory list for self-classification of dangerous substances" with the MS CAs.

\subsubsection{SVHC for the candidate list}

Aim and objectives of the process

The participants agreed with the aim as described in the background document and it was emphasised that the different purposes for listing substances on the candidate list need to be communicated to the public (and others).

\section{Influencing factors for the priority setting}

The participants agreed with most of the influencing factors given in the background document. Intrinsic properties were considered as the most important influencing factors. The availability of alternatives should not affect the prioritisation according to the participants. Some additional factors not mentioned in the document were:

- consideration of possibilities for grouping of substances is very important, may relate either to inherent properties or technical function, and may not be straightforward;

- CMRs generally of less priority compared to PBT (cf article 58) because harmonised CMRs assures a range of downstream regulation and risk management;

- CMR get higher priority when also fulfilling P or B, PBT criteria or endocrine disruptive properties

- potency was considered important in the prioritisation of carcinogenic substances and the T25 system was mentioned as a method for ranking potency;

- it was also suggested that substances that are extremely persistent and extremely toxic (ePeT) ought to be considered as SVHC.

\section{Recommendations}

It should be further considered in what ways MS CAs preparing Annex XV SVHC dossiers could provide an analysis for what purpose the substance should be listed in the candidate list. 


\subsubsection{Authorisation}

\section{Aim and objectives of the process}

The participants agreed with the aim as described in the background document.

Influencing factors for the priority setting

The influencing factors considered as most important, according to the participants, were; wide dispersive use, direct exposure and monitoring results from remote areas. The availability of alternatives should not affect the prioritisation but may affect the sunset date according to the participants.

\section{Recommendations}

A need for a common framework to assist in the choice between authorisation and restrictions has been identified earlier (ECHA workshop on The Candidate List and Authorisation as Risk Management Instruments, January 2009), and the participants at this workshop further emphasised the need to start developing such a framework. An analysis of the most appropriate risk management options should be prepared and informally discussed between MS.

\subsubsection{Restrictions}

\section{Aim and objectives of the process}

The participants agreed with the aim as described in the background document, although the actual meaning of restrictions as a "safety net" was considered somewhat unclear.

\section{Influencing factors for the priority setting}

The influencing factors given in the background document were agreed by the participants. Special emphasis was given to the need for demonstrating that restriction is the most appropriate community-wide measure. Additional influencing factors that were considered important for the prioritisation were:

- monitoring data from remote areas;

- information on vulnerable groups;

- information on cumulative effects;

- possibilities for grouping of substances (including different approaches, e.g. based on inherent properties or uses (e.g. alternatives));

- complexity of the supply chain (which may influence MS CAs workload for example by presenting a challenge in terms of obtaining information and assessing socioeconomic implications);

- the timing perspective in relation to substance evaluation which most likely will not provide results for use in restriction dossiers until 2013 (first draft CORAP-list from ECHA by 1 December 2011); 
- early identification whether it would be better to regulate a certain "targeted risk" under another legislative framework.

\section{Recommendations}

A recommendation from the participants was to keep the level of detail in the restriction dossiers to an appropriate level and it was questioned whether the level of detail aimed for in the technical guidance document is too high in some cases. Consideration should be given to what is really needed in the dossiers as compared to what would be "nice to have", for example in relation to the procedure for checking the conformity of a restriction dossier with the requirements in Annex XV.

It was recommended to start cooperation between Nordic countries (and with ECHA and other interested MS CAs, as appropriate) on issues related to development of Annex XV dossiers for restriction. The purpose is inter alia to exchange ideas/intentions on substances to be given priority, experiences from dossier development, facilitate the process and avoid duplication of work.

\subsubsection{General}

The need for strategies for grouping of substances was emphasised for several of the processes; substance evaluation, harmonised classification and labelling, SVHC for the candidate list, authorisation, and restriction, but no further recommendations were made on this issue. 



\section{Sammanfattning}

I och med införandet av EU-förordningarna Reach och CLP, har nya förutsättningar för kemikaliearbetet skapats för medlemsländernas behöriga myndigheter. Lagstiftningarna har också medfört nya processer för att reglera och få information om ämnen på marknaden (ex. registrering, kandidatlistan, tillståndssystemet). Dessutom utvecklas nya arbetsformer, för vilket den nya Europeiska kemikaliemyndigheten (ECHA) har fått en central roll. För att uppnå en effektiv kemikaliehantering krävs ett aktivt deltagande av medlemsländerna i de olika Reach/CLP processerna och ett aktivt samarbete med ECHA.

För att utnyttja sina resurser på bästa sätt och för att kunna möta de nya kraven enligt REACH och CLP är det nödvändigt att medlemsländerna gör prioriteringar. Medlemsländerna behöver bl a bestämma vilka ämnen man ska arbeta med och i vilka processer man vill driva dessa ämnen. För denna prioritering behöver man ta hänsyn till en rad faktorer. Både faktorer som uttrycks i lagstiftningen och sådana faktorer som är viktiga för den nationella målsättningen.

För att få bättre kunskap om de faktorer som kan påverka prioriteringen av medlemsländernas arbete, anordnades en workshop om prioritering under Reach/ CLP och ett bakgrundsdokument togs fram. Dokumentet innehåller en beskrivning av de Reach/ CLP processer där medlemsländerna är involverade, de legala förutsättningarna, rollen för de behöriga myndigheterna, hur de påverkar olika arbetsuppgifter och vilka resurser det kräver; faktorer som påverkar prioriteringen av arbetet; hur de olika tidpunkterna för registrering för olika tonnagenivåer påverkar; informationskällor och slutligen sambandet mellan olika processer.

Faktorerna som listats i bakgrundsdokumentet diskuterades på workshopen och listan kompletterades av deltagarna. Slutsatserna och rekommendationerna från workshopen kan användas som en bas för nationell prioritering av arbete under Reach och CLP. 



\section{Annex 1 - Issues for discussion in breakout groups}

\section{Examination of testing protocols}

\section{Issue 1: Aim and objective(s) of the process}

Do we have a common understanding that the aim and objective(s) of the examination of testing proposals could be described as follows?

- "The main objective of the examination of testing proposals is to investigate whether the information requirements according to REACH are fulfilled, and if the proposed studies are appropriate and will increase the knowledge of the dangerous properties of chemicals in order to protect human health and the environment, while at the same time preventing unnecessary animal testing and costs. According to Article 40 all proposals for tests specified in Annexes IX and X submitted as part of registrations or in downstream user reports have to be examined and a decision drafted by the Agency." (Source: ECHA “Guidance on Dossier and Substance Evaluation”, p. 24)

\section{Issue 2: Identification of main influencing factors}

Some factors influencing the prioritisation of the MS-CA work related to examining draft decisions resulting from the ECHA process on examination of test protocols:

- The test is prioritised according to Article 40(1), i.e. “...Priority shall be given to registrations of substances which have or may have PBT, $\mathrm{vPvB}$, sensitising and/or carcinogenic, mutagenic or toxic for reproducetion (CMR) properties, or substances classified as dangerous according to Directive 67/548/EEC above 100 tonnes per year with uses resulting in widespread and diffuse exposure."

- Type of test protocol, standard test or not

- The substance is a so-called "difficult substance" (e.g. low water solubility, highly volatile, ...) which may require specific considerations as regards test design and interpretation of the test results

- The test protocol used may have influence on how other tests may be designed ("setting of precedence") 
Questions for discussion:

- Are the main influencing factors listed above? Are there other important factors that are not addressed here and in the background document?

- Is it possible to easily retrieve information on the influencing factors discussed without starting to examine the test proposal, i.e. are these factors useful in priority setting of which test proposals the MS CA should to look at?

\section{Compliance check}

Issue 1: Aim and objective(s) of the process

Do we have a common understanding that the aim and objective(s) of the compliance check could be described as follows?

- "The purpose of checking a registration dossier for compliance is to ensure that the legal requirements of REACH are fulfilled and that the legal requirements of REACH are fulfilled and the quality of the submitted dossiers is sufficient, the safety assessment is suitably documented in a Chemical Safety Report (CSR) as required in the REACH Regulation, the proposed risk management measures are adequate, and that any explanation to opt out from a joint submission of data has an objective basis."

(Source: ECHA “Guidance on Dossier and Substance Evaluation”, p. 11)

New information obtained after dossier evaluation may finally be used to identify candidates for harmonised classification and labelling/ authorisation/restriction, although the purpose of the process not is to identify such candidates.

\section{Issue 2: Identification of main influencing factors}

Some factors influencing the prioritisation of the MS-CA work related to examining draft decision resulting from compliance check process are:

- The dossier contain waiving statements

- The dossier is for a substance listed on the CORAP-list.

- Testing is required, see influencing factors listed for "Examination of testing proposals" above

- The different registrants, in case of a joint submission, have different opinions on how the substance should be classified

- Available non-testing data for a substance, which are considered reliable enough, that indicate a higher toxicity than presented in the dossier 
Questions for discussion:

- Are the main influencing factors listed above? Are there other important factors that are not addressed here and in the background document?

- Is it possible to easily retrieve information on the influencing factors discussed without starting to examine the draft decision or dossier, i.e. are these factors useful in priority setting of which draft decisions the MS CA should look at?

\section{Substance evaluation}

\section{Issue 1: Aim and objective(s) of the process}

Do we have a common understanding that the aim and objective(s) of the substance evaluation could be described as follows?

- "Substance evaluation aims at the clarification of a concern for human health or the environment. The substance evaluation process provides a mechanism for MS-CA, where necessary, to require (the) registrant(s) to obtain and submit additional information to address the initial concern. The outcome of a substance evaluation shall be to decide whether sufficient information is available to clarify the concern and, where further information is required, results in a formal decision that is drafted by the MS-CA and finally taken by the Agency.

Following substance evaluation, the MS-CA may come to the conclusion that action should be taken under the authorisation, restriction or classification and labelling procedures in REACH, that information should be passed to other authorities responsible for relevant legislation, or that no further action is needed. The common feature of these regulatory activities is that they are based on reliable data. The substance evaluation process will ensure that such data are provided by (the) registrant(s) and made available to the relevant bodies by the Agency. Last but not least, the registrant(s) should update their registrations, including chemical safety reports, with any additional information obtained.

(Source: ECHA “Guidance on Dossier and Substance Evaluation", p. 57)

If sufficient information already is available, e.g. to write an Annex XV dossier for restriction, then there is no need to perform a substance evaluation.

Issue 2: Identification of main influencing factors

MS-CA will be involved in different types of prioritisation related work which will differ both in time and in purpose and which will, thus, also re- 
quire prioritisation. One task, which will be done together with ECHA, is to develop criteria for prioritising substances for inclusion on the CORAP-list, and another will be to nationally prioritise substances to propose for inclusion on the CORAP-list.

- Development of criteria for Substance evaluation According to Article 44 "In order to ensure a harmonised approach, the Agency shall in cooperation with the Member States develop criteria for prioritising substances with a view to further evaluation. Prioritisation shall be on a risk-based approach. The criteria shall consider:

a. Hazard information, for instance structural similarity of the substance with known substances of concern or with substances which are persistent and liable to bioaccumulate, suggesting that the substance or one or more of its transformation products has properties of concern or is persistent and liable to bio-accumulate;

b. Exposure information;

c. Tonnage, including aggregated tonnage from the registrations submitted by several registrants.

Some influencing factors related to a) - c) above are:

a) Hazard information

- Diverging classification or PBT assessment proposed be several registrants

- Additional or diverging classification or PBT assessment of other (national or international) organisations

b) Exposure information

- Use patterns (resulting in wide dispersive use?). Note that only "safe use levels" are reported in the CSR

- Suspicions/evidence that there are relevant uses not covered by the registration

c) Tonnage

- Combined exposure from various uses (belonging to DU chains of different registrants) that is anticipated to be substantially higher than assumed in individual registration dossiers

There are connections between substance evaluation and restriction which can be noted in the text below taken from the ECHA "Guidance for the preparation of an Annex XV dossier for restrictions" ${ }^{60}$, section 3 "What prompts a restriction dossier?" The section presents some examples of situations which may prompt a Member State or the Commission to consider a restrictions proposal. Some of these triggers may lead a Member State to propose the

\footnotetext{
${ }^{60}$ http://guidance.echa.europa.eu/docs/guidance_document/restriction_en.pdf?vers=19_09_08
} 
substance for substance evaluation in order to request the data required for the restriction proposal. The Agency may then include such a substance on the Community rolling action plan for substance evaluation. The result of the substance evaluation may then trigger a restriction proposal.

- Where there are a number of available Chemical Safety Reports (CSRs) for one substance, even if each CSR demonstrates that the risks related to the activities covered by each registration are adequately controlled, the aggregation of the exposure related to all of the activities covered by the CSRs may lead to risks which may not be adequately controlled.

- There may be combined exposure due to the formation of the substance of concern through degradation of another substance(s).

- A registered substance (or substances) breaks down to give a product which is not produced or imported (and therefore is not subject to registration) or to a product which is not yet subject to registration (due to tonnage) and which may give rise to concern.

- A single registration is available; there may still be cases where there is a need for a Community-wide restriction. However, in these cases the preliminary work before proceeding with preparing an Annex XV dossier is important to ensure that identified risks are addressed with an appropriate action.

- A restriction under REACH may be an appropriate measure in cases where the proper implementation and enforcement of risk management measures under other REACH processes or under other legislation is not possible to achieve. Such cases may include:

0 substances having a wide range of uses associated with multiple exposures;

o substances which may be widely used by consumers in several applications and for which the conditions of safe use cannot be ensured."

Questions for discussion:

- Are the main influencing factors listed above? Are there other important factors that are not addressed here and in the background document?

- How can they be used and how do they connect to a) - c)?

- Is it possible to easily retrieve information on the influencing factors discussed?

Priority setting in the context of listing substances on the CORAP

As regards the national activities of prioritising substances for inclusion on the CORAP-list, besides the criteria developed as a result of Article 44, a few additional influencing factors are listed below: 
- New hazard data

- New (field/monitoring) data on exposure, accumulation, long-transport

- Outcome of evaluation of similar substances (not considered in the registration dossier

Questions for discussion:

- Do you think that the listed factors can be useful in the national prioritisation work?

- Are there other important factors that are not addressed here and in the background document?

- Is it possible to easily retrieve information on these influencing factors?

\section{Harmonised classification and labelling}

\section{Issue 1: Aim and objective(s) of the process}

Do we have a common understanding that the aim and objective(s) of harmonised classification and labelling could be described as follows?

- The main aim of harmonised C\&L is to provide for a high level of protection of health and the environment by providing legal clarity for suppliers of the same substance of high concern (i.e. manufacturers of substances, importers of substances or mixtures, producers of specific articles, downstream users (including manufacturers of mixtures) and distributors. For industrial chemicals this provision means harmonisation of respiratory sensitisation- and CMR properties, while for pesticides this concept includes harmonisation of all hazardous properties.

- Substances to be proposed for Annex XV (SVHC) based on their CMR effects should first have harmonised classification of these properties.

- REACH foresees a simplified procedure for the introduction of restrictions regarding risks from substances that meet the criteria for classification as carcinogenic, mutagenic, or toxic for reproduction, category 1 or 2 , related to consumer users ${ }^{61}$. The simplified procedure significantly reduces the resources and time needed to restrict such uses as it does not require the preparation of an Annex $\mathrm{XV}$ dossier, the opening of public consultations, or the opinion of the RAC and SEAC.

Issue 2: Identification of main influencing factors

Some proposals of factors influencing the process of priority setting substances for harmonised classification and labelling (depending on the role the MSCA has to play) are provided in the report in section 2.3.3. Different roles that

\footnotetext{
${ }^{61}$ See Article 68(2).
} 
MSCA may play in the process are: (i) submitter of a classification and labelling proposal; (ii) commentator of a proposal within public consultation and (iii) provider for a MSCA RAC member in his/her rapporteurship. Having those in mind are there any other main factors that have been omitted? In order to identify them the following questions are proposed for further discussion:

- Based on the section 2.3.3 in the report do you have the same understanding of MSCA obligations or do you interpret the provisions in the CLP differently?

- Since according to CLP MSCA have a number of obligations (cf. the previous issue) the question is whether MSCA would have resources to propose CLH for other industrial chemicals than those intended for Annex XV (SVHC). If so what industrial chemicals should be prioritised for CLH?

- According to CLP proposals for harmonised classification of other effects than CMR and respiratory sensitisation may also be submitted provided that this is justified as a Community-wide action. What are the examples of Community-wide action that justify harmonised classification of other effects?

- What substances should be prioritised for (i) commenting on C\&LH proposals within the remits of public consultation and (ii) selecting for rapporteurship to be carried out by MSCA RAC member with the support from the MSCA (see also section 2.3.3 in the report).

\section{SVHC - Candidate List}

\section{Issue 1: Aim and objective(s) of the process}

Several purposes for listing substances on the candidate list were agreed on at the workshop on The Candidate List and Authorisation as Risk Management Instruments held in January, 2009:

- the candidate list is a step stone/ the portal to authorisation (i.e. eventual inclusion of the substance into Annex XIV);

- the listing in the candidate list is a way to make sure that information on SVHCs in articles will be provided (to recipients and consumers);

- the listing in the candidate list may have other implications; in particular, it is a manner to gather some further information on uses in articles through the notification process, before going further when necessary;

- the listing in the candidate list is a tool for the official identification of SVHC, and in particular the inclusion in the candidate list is the main mechanism in REACH to identify PBT and vPvB substances;

- the listing of substances in the candidate list is a way to promote their replacement by alternative substances/ technologies (industry/DU) or articles (consumers). 
- Is this a common interpretation, or are there other views?

- Should the reason why to propose the identification of a substance as SVHC be communicated, and how can this be done?

Issue 2: Identification of main influencing factors

Influencing factors for the prioritisation of substances to write Annex XV SVHC dossiers for

- Depending on the purpose for identifying a substance as SVHC there might be different factors that influence the prioritisation of substances. Some factors that we have identified are listed in the background document (Table 1 in section 2.4); i.e. intrinsic properties, use pattern e.g. wide dispersive use and use in articles, exposure, volume, other regulations, availability of alternatives, the relative importance of the source to emissions (compared with e.g. natural sources), the view on the candidate list.

Questions for discussion:

- Are the main influencing factors listed above? Are there other important factors that are not addressed here and in the background document?

- Is it possible to easily retrieve information on the influencing factors discussed?

The view on the candidate list

- Should the candidate list include "all” SVHCs, or should priority be given to substances that are likely to also be prioritised for Annex XIV, i.e. should the candidate list be long or kept relatively short?

Official identification of SVHC

- How can the prioritisation between CMR-, PBT-, vPvB substances, and substances of equivalent level of concern be done? How could Article 57(f) be used and what could be regarded as equivalent level of concern?

- What is the added value of listing already classified CMR substances on the candidate list?

\section{Authorisation}

Issue 1: Aim and objective(s) of the process

Do we have a common understanding that the aim and objective(s) of the authorisation process could be described as follows?

The aim of authorisation, besides ensuring the functioning of the internal market through an equal treatment of SVHCs, is to ensure that risks from 
such substances are properly controlled and that they are progressively replaced by suitable alternative substances or technologies, where these are economically and technically viable. To this end all manufacturers, importers and downstream users applying for authorisations shall analyse the availability of alternatives, consider their risks, and the technical and economic feasibility of substitution.

The substances that may be included in the authorisation system have intrinsic hazardous properties of such concern that the Community needs to decide about the adequacy of the control of the risks arising from their uses or whether the socio-economic benefits of the uses of such substances outweigh the risks arising from their use.

\section{Issue 2: Identification of main influencing factors}

Are the main influencing factors listed below? Are there other important factors that are not addressed here and/or in the background document?

- Existing legislation already in place to regulate the substance

- The legal criteria for inclusion in Annex XIV, that normally shall be applied according to article 58(3), i.e.:

o PBT or vPvB properties, or

o wide dispersive use, or

o high volume.

- Availability of information on other factors such as

o type of risks (e.g. SVHC properties required)

o type of uses

0 risks in different uses (potentially including info on emissions, exposures)

o alternatives

o socioeconomic implications

Issue 3: Issues for discussion

- What influence will knowledge on the number of actors in the supply chain, maturity or size of the industry sector have on priority setting?

- What influence will information on available alternatives and on development of alternatives have on priority setting?

- What influence will the term "wide dispersive use" have on priority setting? What could be covered by the term?

- Do we have a common perception of how the authorisation and restriction procedures work together? How could these legal instruments be combined?

- What possibilities do we see for the development and the practical implementation of a common "framework" to support the authorities in their analysis of the best Risk Management Option to be applied to a substance? See section 3.2 of the background document where this outcome of the ECHA WS in January 2009 is briefly described. 
o How can information be shared between MS CAs in relation to such a framework? How can the informal Registry of Intent be used?

Note: According to ECHA's report from the January 2009 workshop a proposal for such a framework will be presented to CARACAL in June 2009 .

- How could groups of substances be prioritised in this process? What groupings could be relevant and useful, e.g. in terms of intrinsic hazardous properties and uses? Can substances with similar properties and uses be prioritised together, so that also potential replacement substances are covered? Could grouping approaches be useful both at the stage of Annex XV dossier preparations and when recommending for Annex XIV?

\section{Restriction}

Issue 1: Aim and objective(s) of the process

Aim (from Guidance for the preparation of an Annex XV dossier for restrictions)

The restrictions procedure is a safety net to address unacceptable risks to human health or the environment, arising from the manufacture, use or placing on the market of substances, which need to be addressed on a Communitywide basis. Restriction means any condition for or prohibition of the manufacture, use or placing on the market of substances. Any substance on its own, in a preparation or in an article may be subject, where justified, to restrictions.

The Annex XV dossier for a restriction shall include information on hazards and risks, available information on alternatives and a justification for restrictions at Community level. In addition the Annex XV may include a socio-economic assessment. The Annex XV dossier will provide the ground for any decision taken by the Commission. If the Commission proposes restrictions to consumer use of a CMR substance on its own, in preparations or in articles, no Annex XV dossier is required, enabling a faster procedure.

\section{Issue 2: Identification of main influencing factors}

Are the main influencing factors listed below? Are there other important factors that are not addressed here and in the background document?

- Availability of information on:

o Uses

o Risks in different uses

o Alternatives

o Socioeconomic implications

- Identify unacceptable risk

- Possibility to regulate almost any identified risk (hazard and use)

- Justify need for community wide action

- Demonstrate that restrictions is most appropriate community-wide measure 
Questions for discussion:

- Can groups of substances be prioritised in this process? Is grouping in terms of similar intrinsic hazardous properties possible? Can substances with similar properties and uses be prioritised together, so that also potential replacement substances are covered?

- What influence will knowledge on number of actors in the supply chain, maturity or size of the industry sector have on priority setting?

- What is the relation between restrictions under Reach and restrictions under other community legislation, e.g. RoHS? What is the relation between restrictions under Reach and other community legislation aiming for protection of human health and environment, e.g. the IPPC directive?

- In the Guidance for the preparation of an Annex XV dossier for restrictions ${ }^{62}$, section 3 "What prompts a restriction dossier?" presents some examples of situations which may trigger a Member State or the Commission to consider a restrictions proposal. Some of these triggers in the first group may lead a Member State to propose the substance for substance evaluation in order to request the data required for the restriction proposal. The Agency may then include such a substance on the Community rolling action plan for substance evaluation. The result of the substance evaluation may then trigger a restriction proposal.

- In which of the cases listed below could a restriction dossier be prepared and in which cases is it necessary to start with a substance evaluation?

- Where there are a number of available Chemical Safety Reports (CSRs) for one substance, even if each CSR demonstrates that the risks related to the activities covered by each registration are adequately controlled, the aggregation of the exposure related to all of the activities covered by the CSRs may lead to risks which may not be adequately controlled.

- There may be combined exposure due to the formation of the substance of concern through degradation of another substance(s).

- A registered substance (or substances) breaks down to give a product which is not produced or imported (and therefore is not subject to registration) or to a product which is not yet subject to registration (due to tonnage) and which may give rise to concern.

- A single registration is available; there may still be cases where there is a need for a Community-wide restriction. However, in these cases the preliminary work before proceeding with preparing an Annex XV dossier is important to ensure that identified risks are addressed with an appropriate action.

- A restriction under REACH may be an appropriate measure in cases where the proper implementation and enforcement of risk

\footnotetext{
${ }^{62}$ http://guidance.echa.europa.eu/docs/guidance_document/restriction_en.pdf?vers=19_09_08
} 
management measures under other REACH processes or under other legislation is not possible to achieve. Such cases may include:

0 substances having a wide range of uses associated with multiple exposures;

o substances which may be widely used by consumers in several applications and for which the conditions of safe use cannot be ensured.

\section{Triggers resulting from enforcement}

- Substance evaluation or a compliance check of dossiers by ECHA identifies unacceptable risks that may not be dealt with appropriately by proper implementation of other REACH requirements.

- Enforcement shows that the implemented risk management measures are insufficient and that better enforcement cannot reduce the risks to acceptable levels.

Enforcement and monitoring of other legislation provides evidence that controls set at the Community level (for instance, environmental quality standards, emission limit values or occupational exposure limits) cannot adequately manage the risk and a change of these values would not be the right measure to achieve the aim. 


\section{Annex 2 - Examples of further information that can be requested under substance evaluation}

The text in this appendix is taken from Appendix 10 in the ECHA "Guidance on evaluation"

In this Appendix, some examples are presented related to information on intrinsic properties of substances and to information on exposure that could be considered in a request for further information. The list is in random order, is not exhaustive and the types of information needed to address the concern will vary on a case-by-case basis.

- Intrinsic properties

- Annex VII-X or comparable studies

Studies being part of the standard information requirements as specified in Annex VII-X may be requested e.g. if only non-guideline tests are available but the weight-of-evidence is not convincing to the MS-CA to clarify a concern.

- Information on degradation products or metabolites

For example, for substances that are not themselves persistent, but have degradation products or metabolites that have PBT or vPvB properties. Information on degradation of a substance, especially under environmental conditions, may also be relevant in relation to a harmonised classification for effects on the environment.

- Information on impurities

The identity and composition of the impurities in a substance may differ between various registrations for the same substance and thus lead to differences in classification and labelling of such a substance. In these cases, a substance evaluation could be performed to clarify the concern related to the differences in impurities for various registrations of the same substance. The Guidance on substance identification should be taken into account.

- Epidemiological data

When there are indications that a causal relationship may be established between exposure and the occurrence of health effects in certain human populations, it could be considered to ask for an epidemiological survey. This could help in the interpretation of available data e.g. for respiratory sensitisation. Also, if several studies are already available, a meta-analysis of the data could be 
considered. Because of the costs associated with this type of study, a proper justification should be provided.

- Information on the potency to induce specific effects For example, in the case of a group of substances a ranking of the substances based on their potency to exert a given effect may be helpful in the evaluation of the group. Further information could be requested to determine the possible members and/or ranking of the group or to aid in the extrapolation of data of one (or more) compounds to the (rest of the) group of substances.

- Information on the DNELs and/or PNECs Where different registrants have derived different DNEL or PNEC values, and the argumentation provided for the choice of key studies or assessment factors is not clear, the MS-CA may consider asking for further clarification on these issues.

- Information relating to PBT or vPvB properties of a substance The criteria to be used for identification of a substance as a PBT or a vPvB substance are outlined in Annex XIII of REACH. The main types of studies that could be considered are discussed in detail in the Guidance on Annex XV for C\&L, the Guidance on identification of SVHC and the Guidance on Annex XV for restrictions.

- Information related to serious effects to humans or the environment (equivalent concern)

A key part of the definition of equivalent concern relates to their being scientific evidence of probable serious effects to humans or the environment. This can be taken to mean that any effects, should exposure occur, will be at least equivalent to those that could occur from substances included under points (a) to (e) of Article 57, and this will need to be clearly demonstrated. Examples could be substances having endocrine disrupting properties or substances that near-missed the criteria laid down in Annex XIII. Guidance on this issue has been developed in the Guidance on identification of SVHC.

\section{- Exposure}

A request for further information on exposure could include the following elements.

\section{- Production or import tonnage}

Information on the produced or imported tonnage is to be presented in the registration dossiers for the calendar year of the registration. In case the concern is (partly) based on aggregated tonnage from the registrations submitted by several registrants, the MS-CA may wish to request the most recent information on tonnage produced or imported into the relevant markets in the Member States from the individual registrants.

- Details of the uses of the substance 
- Estimates or measurements of exposure to humans resulting from use of the substance.

This should address the assessment of exposure (e.g. occupational exposure, consumer exposure, number of people exposed) under the current situation and conditions (including implemented RMMs as described in the exposure scenarios).

Where the concern relates to a specific activity or a specific exposure situation, then a focussed monitoring programme could be developed. The issues involved in the review of monitoring data, as set out in the CSA guidance, should be taken into account in the planning of such programmes.

- Monitoring data from field studies

Measured data in abiotic and biotic compartments may provide an indication of risks to environment or man and can be considered of superior value to modelled data. For example, measured data in biota provide a clear indicator that the substance is taken up by an organism. The Arctic Monitoring and Assessment Programme (AMAP, 2001) has published recommendations with regard to assessing the quality of monitoring data for use in determining spatial and temporal trends and other types of data interpretations.

Monitoring data for biota in remote regions may provide indications that the substance is both transported long-distances (and so is relatively persistent) and is taken up by organisms (although this is not sufficient to say the substance has a high bioaccumulation potential). However, considering the costs, a request for monitoring data in remote regions would only be made in exceptional cases.

- $\quad$ Time trend data on environmental levels

Time trend data can provide very useful information in terms of whether the levels of the substance are building up over time in the environment, although again the interpretation of such data may not always be straightforward (for example increasing concentrations in the environment may reflect increasing use rather than a high persistence/accumulation potential). Given the anticipated costs for such a monitoring program, a thorough justification of the need for such a program is compulsory.

- Regional concentrations of the substance

It is possible that regional PECs may be based on measured concentrations, which by definition would represent the overall exposures from all relevant sources. These could in principle apply to all registration dossiers, so if they are considered valid then they could be used to replace any calculated values.

- Simulation studies

This type of study could be requested in cases where testing under real life conditions is difficult to perform. 
- Distribution

This could include studies on the distribution of a substance in different environmental compartments.

- Information on Risk Management Measures (RMM)

This could include information on the effectiveness, practicality and monitorability of RMM. Issues like past effectiveness of RMMs and implementation tools and past experience pertaining to the assessment of RMMs could be addressed. Guidance on assessing the effectiveness of implemented RMMs has been developed in the Guidance on Annex XV for restrictions. 


\section{Annex 3 - Detailed tasks and responsibilities of the Member State competent authority (MS CA) for evaluation}

The text in this appendix is taken from Appendix 1 in the ECHA "Guidance on evaluation"

\begin{tabular}{l} 
Responsibility MS competent authority \\
\hline Dossier Evaluation \\
Receipt of registrants' or downstream user's comments on draft deci- \\
sion via Agency. \\
Receipt via Agency of information on former cessation by registrant of \\
manufacture or import for a substance or the production or import of an \\
article, or the downstream user's use subject to a (draft) decision under \\
Art. 40 or 41 . \\
Receipt via Agency of information on cessation of manufacture or \\
import for a substance or the production or import of an article, or the \\
downstream user's use subject to a (draft) decision under Art. 40 or 41 \\
in response to this (draft) decision.
\end{tabular}

REACH text

Receipt via Agency of draft decision together with any comments by registrant(s) or downstream user(s).

Receipt of draft decision together with any comments by registrant(s) from other MS-CAs.

Proposal of amendments to draft decisions under Art. 40 or 41 to Agency within 30 days of circulation.

Art. 50 (1)

Art. $50(2)$

Art. $50(3)$

Using the required information for highlighting a substance for addition to the Community rolling action plan.

Using the required information for preparation of an Annex XV dossier to propose and justify the identification of PBTs, vPvBs or a substance of equivalent concern and the restriction of the manufacture, placing on the market or use of a substance within the Community.

Substance Evaluation

Contribution to the development of criteria for prioritising substances with a view to further evaluation, in co-operation with the Agency.

Receipt of draft Community rolling action plan.

Art. $44(1)$

Prepare an opinion on draft Community rolling action plan, input via MS Committee.

Art. $51(1)$

Art. $51(1)$

Art. $51(2)$

Art. $42(2)$

Art. $42(2)$

If applicable, appoint another body to act on MS behalf in substance evaluation.

Art. $44(2)$

Art. $44(2)$

Art. $45(1)$

Selection of substances from Community rolling action plan with the aim of becoming competent authority for the purpose of Art. 46-48.

Art. $45(2)$ 


\begin{tabular}{|c|}
\hline Responsibility MS competent authority \\
\hline $\begin{array}{l}\text { Adopt substance for evaluation if decided by MS Committee or Com- } \\
\text { mission (under procedure Art. } 45 \text { (3)). }\end{array}$ \\
\hline Evaluation of allocated substances. \\
\hline $\begin{array}{l}\text { Evaluation of proposed substances by MS after addition to Community } \\
\text { rolling action plan. }\end{array}$ \\
\hline $\begin{array}{l}\text { Notify the Agency at any time of a substance not on the Community } \\
\text { rolling action plan, whenever it is in possession of information which } \\
\text { suggests that the substance is a priority for evaluation. }\end{array}$ \\
\hline $\begin{array}{l}\text { Preparation of draft decision with request for further information, if } \\
\text { considered necessary, within } 12 \text { months after publication of Community } \\
\text { rolling action plan (procedure Art. } 50 \text { and 52). }\end{array}$ \\
\hline Send draft decision under Art. 46 to Agency. \\
\hline $\begin{array}{l}\text { Receipt of registrants' or downstream user's comments on draft deci- } \\
\text { sion via Agency. }\end{array}$ \\
\hline $\begin{array}{l}\text { Amendment of draft decision taken under Art. } 46 \text {, if necessary based } \\
\text { on registrants' or downstream user's comments. }\end{array}$ \\
\hline $\begin{array}{l}\text { Receipt via Agency of information on former cessation by registrant of } \\
\text { manufacture or import for a substance or the production or import of an } \\
\text { article, or the downstream user's use subject to a (draft) decision under } \\
\text { Art. } 46 \text {. }\end{array}$ \\
\hline
\end{tabular}

Receipt via Agency of information on cessation of manufacture or import for a substance or the production or import of an article, or the downstream user's use subject to a (draft) decision under Art. 46 in response to this (draft) decision.

Prepare request for information despite notification of cessation of exposure in specific cases.

Circulation of draft decision together with any comments by registrant(s) or downstream user(s) to Agency and other MS-CAs.

Receipt of draft decision together with any comments by registrant(s) or downstream user(s) from other MS-CAs.

Proposal of amendments to draft decisions under Art. 46 (of other Member States) to Agency within 30 days of circulation.

Prepare an opinion on amended draft decision, input via MS Commit-

Receipt and examination of any information submitted by registrant to

Preparation of draft decision, within 12 months after submission of information.

Complete evaluation activities within 12 months of the start of the evaluation of the substance or within 12 mo of the information being submitted under Art. 46(2).

Notify Agency of completed evaluation activity. 


\begin{tabular}{|c|c|}
\hline Responsibility MS competent authority & REACH text \\
\hline $\begin{array}{l}\text { Inform Agency of conclusions as to whether or how to use information } \\
\text { obtained (i.e. follow up activities). }\end{array}$ & Art. 48 \\
\hline Receipt of follow up activities from other Member States via Agency. & Art. 48 \\
\hline $\begin{array}{l}\text { Consider whether risks equivalent to use of substances of very high } \\
\text { concern (Art. 57) arise from use as on-site isolated intermediate are } \\
\text { adequately controlled. }\end{array}$ & Art. 49 \\
\hline $\begin{array}{l}\text { Prepare request for further information (directly related to the risk } \\
\text { identified) to registrant (with written justification) }\end{array}$ & Art.49 \\
\hline $\begin{array}{l}\text { Examine any information submitted and, if necessary, recommend any } \\
\text { appropriate RRM. }\end{array}$ & Art. 49 \\
\hline $\begin{array}{l}\text { Inform Agency of results of evaluation of use as on-site isolated inter- } \\
\text { mediate. }\end{array}$ & Art. 49 \\
\hline $\begin{array}{l}\text { Receipt from Agency of results of evaluation by other MS-CAs of use of } \\
\text { substances as on-site isolated intermediate. }\end{array}$ & Art. 49 \\
\hline
\end{tabular}

Article 52(2) of REACH states "The provisions of Article 51(2) to (8) shall apply mutatis mutandi”. Therefore, in this Table, reference is made to Article 52(2) as well as the corresponding part of Article 51 in italics.

\begin{tabular}{|c|c|}
\hline Responsibility MS Committee & REACH text \\
\hline $\begin{array}{l}\text { Form an opinion on the draft Community rolling action plan presented } \\
\text { by the Agency. }\end{array}$ & Art. $44(2)$ \\
\hline $\begin{array}{l}\text { Decide on who should be the competent authority in cases where two or } \\
\text { more Member States have expressed an interest in evaluating the same } \\
\text { substance and they cannot agree who should be the competent author- } \\
\text { ity, if requested by the Agency. If no unanimous agreement is reached, } \\
\text { matter should be referred to the Commission by the Agency. }\end{array}$ & Art. 45 (3) \\
\hline $\begin{array}{l}\text { Form an opinion on whether or not to add substance (as proposed by } \\
\text { Member States) to the Community rolling action plan. }\end{array}$ & Art. 45 (5) \\
\hline $\begin{array}{l}\text { Form an opinion on draft decision under Art. } 40,41 \text { or } 46 \text {, together with } \\
\text { any amendments proposed, within } 60 \text { days of the referral by the } \\
\text { Agency. (If no unanimous agreement is reached, the matter should be } \\
\text { referred to the Commission by the Agency.) }\end{array}$ & Art. 51 (4), Art. 52 (2) \\
\hline
\end{tabular}





\section{Annex 4 - Downstream legislation to CLP}

(based on Analysis of the Potential Effects of the Proposed GHS Regulation on Its EU Downstream Legislation, Commission Services, August 2006)

Detergents: Regulation (EC) No 648/2004 of 31 March 2004;

Regulation No. 648/2004 mainly serves the purpose to control or restrict those ingredients which are not readily biodegradable.

Eco-label award scheme: Regulation (EC) No 1980/2000 of 17 July 2000;

The eco-label may not be awarded to substances or preparations classified as Very Toxic, Toxic, Dangerous to the environment, Carcinogenic, Toxic for reproduction or Mutagenic in accordance with Council Directive 67/548/EEC(9) or Directive 1999/45/EC of the European Parliament and of the Council(10) nor to goods manufactured by processes which are likely to significantly harm man and/or the environment, or in their normal application could be harmful to the consumer. The aforementioned provisions are modified for particular product groups: (i) all purpose cleaners and cleaners for sanitary facilities, (ii) hand dishwashing detergents, (iii) indoor paints and varnishes), (iv) detergents and dishwashers, (v) laundry detergents

Cosmetic products: Council Directive 76/768/EEC of 27 July 1976;

Article 4(b) prohibits the use in cosmetic products of substances which are classified as carcinogenic, mutagenic or toxic for reproduction, of category 1, 2 and 3, and which are listed in Annex I to Directive 67/548/EEC. These substances have to be listed in Annex II to the Cosmetics Directive ("prohibited substances"). As to substances classified in category 3, these may be used in cosmetic products if they have been evaluated by the SCCNFP and found acceptable for use in cosmetic products.

Toy safety: Council Directive 88/378/EEC of 3 May 1988 as amended by Directive 93/68/EEC;

The interaction between the Community legislation on chemicals and the Toy Safety Directive is manifold. The main link is given by Annex II to the TSD and by a number of European Standards focusing on various aspects of toy safety, e.g. EN 71-2 which focuses on flammable properties of sub- 
stances or materials used in toys. In general, the Toy Safety Directive contains four different approaches with regard to chemical substances in toys, cf. below.

\section{Respect of Directive 76/769/EEC on the restriction of the marketing} and use of certain dangerous substances and preparations, cf. Annex II.II.3.1. It is not possible for European Standards or Notified Bodies to allow toys in the market that do not respect the chemical legislation.

In the context of the Toy Safety Directive, respect of Directive 76/769/EEC means that substances which are classified as CMR category 1 or 2 may not be used in substances or preparations (GHS: mixtures) on the market for sale to the general public. However, the corresponding restrictions do not all refer explicitly to the use in toys. Moreover and most important, there is no corresponding restriction relating to articles in Directive 76/769/EEC, except for certain specific CMRs (e.g. wood preservatives). This means that the gross amount of articles is excluded from the restrictions relating to CMRs.

\section{Specific restrictions for certain chemicals set by the Toys Directive itself.}

These are limit values for the bioavailability resulting from the use of toys for the following substances: antimony, arsenic, barium, cadmium, chromium, lead, mercury and selenium.

3. The so-called "New Approach" for substances and preparations which are not restricted by Directive 76/769/EEC, but which are dangerous in the meaning of Directives 67/548/EEC and 1999/45/EC. The Toy Safety Directive requires:

"Toys must not contain dangerous substances or preparations within the meaning of Directives 67/548/EEC and 88/379/EEC (repealed by Dir 1999/45/EC) in amounts which may harm the health of children using them."

This sentence is the legal basis for the use of the New Approach for chemicals in toys. The

New Approach is to complement the chemical legislation: European Standards and Notified Bodies have to respect the restrictions imposed by Directive 76/769/EEC, but they can impose further restrictions on the use of chemicals classified as dangerous by Directives 67/548/EEC and 1999/45/EC. Recent as well as ongoing standardisation work aims at introducing restrictions related to the use of certain organic chemicals in toys. This work follows a mandate from the Commission to CEN given in 1996. The mandate requested CEN to "prepare one or several European standards concerning the risks associated with the presence of organic chemical compounds in toys ... CEN will have to identify the substances that come within the remit of Directive 67/548/EEC, with the exception of those banned by Directive 76/769/EEC, within the groups of organic chemical products rec- 
ommended by the Toxicology Section of the Scientific Advisory Committee, as well as those of paints and colouring agents.” In the following, CEN elaborated the draft European Standard prEN 71-Y "Safety of toys - Organic chemical compounds - Requirements”. Draft standard prEN-Y addresses the risks by in particular taking into account the potential exposure to and toxicological effects of those substances which are considered to represent the greatest health hazards. It specifies requirements for the most hazardous organic compounds concerning their migration from, or content in, toys and parts of toys which (when used in a foreseeable fashion by children, or as intended) are likely to be mouthed, or which might be ingested; which come into prolonged contact with the skin or into contact with the eyes or which contain organic compounds which might be inhaled.

Draft Standard prEN-Y sets out a table listing the toys and toy components, made from specific listed materials, which may not contain or release the organic compounds associated with them beyond the stipulated amounts. The amounts are also expressed in tables.

On the whole, CEN considered the risks associated with more than 650 organic compounds.

The draft European Standard prEN 71-Y contains restrictions for the use of 90 chemical substances in toys. These restrictions are not the same for all toys, but are linked to at least one of the 18 categories of toys. The organic compounds covered by the draft Standard can be assigned to the following categories: solvents, preservatives, wood preservatives, plasticisers, flame retardants, monomers, primary aromatic amines, processing aids and colouring agents.

However, CEN realised that not all potentially hazardous substances could be addressed. The draft therefore explicitly reiterates that the limitation of the scope to only some hazardous compounds should not reduce the responsibility of toy manufacturers, importers and suppliers to ensure that the use of other substances will not endanger the health of children whilst playing with toys as intended or in a reasonable manner.

4. Prohibition to include dangerous substances and preparations (mixtures) in a toy if they are intended to be used as such while the toy is being used, cf. Annex I.I.3.3.

The potentially affected hazard classifications are listed in Table V.3 of Part I of this study (i.e. almost all hazard classes).

Aerosol dispensers: Council Directive 75/324/EEC of 20 May 1975. CLP Article 14 (2c) takes account of the Aerosols Directive Article 8 (1a);

The Directive on aerosol dispensers derives particular labelling provisions from the classification of its content as 'extremely flammable', 'highly flammable' and 'flammable'. 
Biocidal products: Directive 98/8/EC (BPD) of 16 February 1998;

In the Biocides Directive, most legal obligations are risk-based, i.e. based on a combination of hazard and exposure data. There are only three obligations where decisions are based on hazard and classification alone:

\section{Article 10.1: Inclusion of an active substance in Annex IA}

An active substance cannot be included in Annex IA if it is classified according to Directive 67/548/EEC as:

- carcinogenic,

- mutagenic,

- toxic for reproduction,

- sensitising, or

- is bioaccumulative and does not readily degrade.

With regard to the hazards CMR and sensitisation, it is not expected that the kind and number of substances classified according to the GHS will change or increase compared to the current system, cf. Table V3 of Part I or the analysis of the Cosmetics Directive (Chapter I.3.2).

\section{Article 5.2: Authorisation for marketing or use to the general public}

A biocidal product classified according to Article 20(1) as toxic, very toxic or as a category 1 or 2 carcinogen, or as a category 1 or 2 mutagen or classified as toxic for reproduction category 1 or 2 , shall not be authorised for marketing to, or use by the general public.

\section{Article 2.1 (b) and 2.1 (e): Low-risk biocidal products}

A biocidal product which contains as active substance(s) only one or more of those listed in Annex IA and which does not contain any substance(s) of concern ... This may be any other than the active substance, which has an inherent capacity to cause an adverse effect on humans, animals or the environment and is present or is produced in a biocidal product in sufficient concentration to create such an effect. It would be normally a substance classified as dangerous according to Council Directive 67/548/EEC of 27 June 1967 on the approximation of laws, regulations and administrative provisions relating to the classification, packaging and labelling of dangerous substances, and present in the biocidal product at a concentration leading the product to be regarded as dangerous within the meaning of Article 3 of Council Directive 88/379/EEC of 7 June 1988 on the approximation of the laws, regulations and administrative provisions of the Member States relating to the classification, packaging and labelling of dangerous preparations, as replaced by Directive 1999/45/EC. 
Plant protection products: Council Directive 91/414/EEC (PPPD) of 15 July 1991;

There are some few specific obligations which are related to classification issues:

1. The second sentence of paragraph 2.4.1.3. of Annex VI Part C to Directive 91/414/EEC establishes legal obligations based on hazardous properties only: "Moreover, plant protection products which are classified as very toxic may not be authorized for use by non-professional users."

2. In the course of the evaluation of active substances and plant protection products various Guidance Documents have been developed (non-legally binding). In at least one Guidance Document used for substance evaluation, i.e. in the "Guidance Document on the Assessment of the Relevance of Metabolites in Groundwater of Substances Regulated under Council Directive 91/414/EEC”, a direct reference to hazard classifications can be found, i.e. the classification as Very Toxic, Toxic and CMR of the parent molecule (which is the active substance) could trigger testing of the metabolite(s).

Control of major-accident hazards involving dangerous substances (Seveso II): Council Directive 96/82/EC of 9 December 1996;

The Seveso II Directive sets up rules for the safety of establishments where dangerous substances and mixtures are present above defined threshold quantities. It works both on the basis of a list of explicitly named substances (Part 1 of Annex I) and on the basis of selected categories of danger which are defined according to Directive 67/548/EEC (Part 2 of Annex II).The categories of danger include the classifications Very Toxic, Toxic, Oxidising, Explosive, Extremely Flammable, Highly Flammable, Flammable, Dangerous to the Environment, in addition, further hazards as well as any substance or mixture classified in combination with the R-phrases R14 or R14/15 and R29.

Regulation (EC) No 304/2003 of the European Parliament and of the Council of January 2003 concerning the export and import of dangerous chemicals Export and import of dangerous chemicals: Regulation (EC) No 689/2008 of 17 June 2008;

In general, chemicals which are classified as dangerous and which are intended for export shall be subject to the measures on packaging and labelling according to Directives 67/548/EEC, 1999/45/EC, 91/414/EEC and 1998/8/EC or any other specific Community legislation. The corresponding provisions in Article 16 apply without prejudice to any specific requirements of the importing Party or other country, taking into account relevant international standards (in future: GHS). 
The Regulation is working on the basis of lists of chemicals, with currently only 88 different entries in Part 1, 2 and 3 of Annex I to the Regulation. These chemicals have been severely restricted or banned by other Community legislation or are subject to the international PIC procedure and subsequently been subject to annual export notification, the obligation to obtain explicit consent or the PIC procedure, cf. above. Since the applicability of the Regulation is not triggered by classification as such, but depends on the outcome of evaluation and restriction under other EU legislation or inclusion of the chemical in Annex III of the Convention.

Limitation of emissions of volatile organic compounds: Council Directive 1999/13/EC (VOCD) of 11 March 1999 and Directive 2004/42/EC of 21 April 2004

Directive 1999/13/EC derives the following legal obligations from classification:

i. Substances or preparations (GHS terminology: mixtures) which, because of their content of VOCs classified as carcinogens, mutagens, or toxic to reproduction under Directive 67/548/EEC, are assigned or need to carry the risk phrases R45, R46, R49, R60, R61, shall be replaced, as far as possible and by taking into account the guidance elaborated by the Commission, by less harmful substances or preparations within the shortest possible time (cf. Article 5.6 and 7.1). Stricter emission values are specified for these substances (cf. Article 5.7).

ii. Where a risk assessment is carried out in accordance with EU legislation of any of the substances causing the labelling R40, R60 or R61 which are controlled under this Directive, the Commission shall consider the conclusions of the risk assessment and shall take the necessary measures as appropriate (cf. Article 5.13).

Directive 2004/42/EC does not contain specific legal provisions which are derived from classification and labelling. It is to complement Community provisions on the labelling of chemical substances and preparations as laid down in Directives 67/548/EEC and 1999/45/EC, cf. Recital 12.

Ambient air quality assessment and management: Council Directive 1996/62/EC of 27 September 1996;

In its Annex III, the Ambient Air Quality Directive makes reference to the Dangerous Substances Directive: it uses the classifications from Directive 67/548/EEC as criteria for choosing air pollutants: 
Guidelines for selecting air pollutants for consideration

- Possibility, severity and frequency of effects; with regard to human health and the environment as a whole, the irreversible effects must be of special concern.

- Ubiquity and high concentration of the pollutant in the atmosphere.

- Environmental transformations or metabolic alterations, as these alterations may lead to the production of chemicals with greater toxicity.

- Persistence in the environment, particularly if the pollutant is not biodegradable and can accumulate in humans, the environment or food chains.

- Impact of the pollutant:

- size of exposed population, living resources or ecosystems,

- existence of particularly sensitive targets in the zone concerned.

- Risk-assessment methods may also be used.

The pertinent danger criteria established under Directive 67/548/EEC

(1) and its successive adaptations must be taken into account in the selection of the pollutants.

However, any conclusions are derived from considerations of risk and exposure of humans and the environment to the pollutant of concern. This means that classification as such is not the decisive factor. The GHS which is likely to classify additional chemicals will have minimal effects only in so far as additional air pollutants could be selected for further consideration.

\section{Water Framework Directive}

Directive 2000/60/EC of the European Parliament and of the Council of 23 October 2000 establishing a framework for Community action in the field of water policy

$\square$ Decision No 2455/2001/EC of the European Parliament and of the Council of 20 November 2001 establishing the list of priority substances

In general, legislation on classification and labelling, have no effect on the legal obligations stipulated in the Water Framework Directive. The prevailing approach for defining priority hazardous substances is based on risk and not on hazard - hazardous properties may only serve as basis for selecting defined pollutants for further assessment.

Chemical agents at work: Council Directive 98/24/EC of 7 April 1998;

Council Directive 1998/24/EC (“Chemical Agents Directive”) is based on Article 137 of the Treaty. It lays down minimum requirements for the protection of workers from risks to their safety and health arising, or likely to 
arise, from the effects of chemical agents that are present at the workplace or as a result of any work activity involving chemical agents. The requirements of this Directive apply where hazardous chemical agents are present at the workplace. A hazardous chemical agent is a substance or a mixture which meets the criteria for classification as dangerous according to Directive 67/548/EEC or 1999/45/EC. Any substance or mixture that only meets the criteria for classification as dangerous for the environment is excluded from the scope of Directive 1998/24/EC. Other hazardous chemical agents are defined, namely those which present a risk to the safety and health of workers even if they do not meet the classification criteria.

Carcinogens and mutagens at work: Directive 2004/37/EC 29 April 2004;

Directive 2004/37/EC (“Carcinogens Directive”) is based on Article 137 (2) of the Treaty. It lays down minimum requirements to protect workers against risks arising specifically from exposure to carcinogens and mutagens, to lessen exposure with a view to reducing health risks, to establish exposure limit values and to take preventive measures. Carcinogens and mutagens are defined as substances or preparations (GHS: mixtures) which meet the classification criteria for categories 1 and 2 as set out in Directives 67/548/EEC and 1999/45/EC. Beyond, carcinogens are defined as substances, preparations or processes referred to in Annex I to the Carcinogens Directive as well as substances or preparations released by a process referred to in that Annex.

Young people at work: Council Directive 94/33/EC of 22 June 1994;

Council Directive 1994/33/EC ("Young Workers Directive") is based on Article 118a of the Treaty establishing the European Community. It applies to all young people below 18 years who have an employment contract or an employment relationship defined by the law in force in a Member State and/or subject to the law in force in a Member State.

One of the main objectives of the Directive is to establish minimum requirements to guarantee the health and safety of young workers. It requires the Member States to prohibit the employment of adolescents in defined cases, i.a. when the work involves harmful exposure to agents which are toxic, carcinogenic, cause heritable genetic damage or harm to the unborn child or which in any other way chronically affect human health, cf. Article 7.2(b).

\section{3. Chemical agents}

(a) Substances and preparations classified according to Council Directive 67/548/EEC of 27 June 1967 on the approximation of laws, regulations and administrative provisions relating to the classification, packaging and labelling of dangerous substances (2) with amendments and Council Directive 88/379/EEC6 of 7 June 1988 on the approximation of the laws, regulations 
and administrative provisions of the Member States relating to the classification, packaging and labelling of dangerous preparations (3) as toxic (T), very toxic $(\mathrm{T}+)$, corrosive $(\mathrm{C})$ or explosive $(\mathrm{E})$;

(b) Substances and preparations classified according to Directives 67/548/EEC and 88/379/EEC7 as harmful (Xn) and with one or more of the following risk phrases:

- danger of very serious irreversible effects (R39),

- possible risk of irreversible effects (R40),

- may cause sensitization by inhalation (R42),

- may cause sensitization by skin contact (R43),

- may cause cancer (R45),

- may cause heritable genetic damage (R46),

- danger of serious damage to health by prolonged exposure (R48),

- may impair fertility (R60),

- may cause harm to the unborn child (R61);

(c) Substances and preparations classified according to Directives 67/548/EEC and 88/379/EEC as irritant (Xi) and with one or more of the following risk phrases:

- highly flammable (R12);

- may cause sensitization by inhalation (R42),

- may cause sensitization by skin contact (R43),

(d) Substances and preparations referred to in Article 2(a)(iii) of Directive 2004/37/EC;

(e) Lead and compounds thereof, inasmuch as the agents in question are absorbable by the human organism;

(f) Asbestos and

II. 6. Work with vats, tanks, reservoirs or carboys containing chemical agents referred to in 1.3

Pregnant and breastfeeding women at work: Council Directive 92/85/EEC of 19 October 1992;

This Directive is based on Article 137(2) of the Treaty. Its purpose is to implement measures to encourage improvements in the safety and health at work of pregnant workers and workers who have recently given birth or who are breastfeeding. The provisions of Directive 89/391/EEC, except for Article 2 (2) thereof, shall apply in full without prejudice to any more stringent and/or specific provisions contained in Council Directive 1992/85/EEC.

For all activities liable to involve a specific risk of exposure to agents, processes or working conditions of which a list is given in Annex I, the employer shall assess the nature, degree and duration of exposure, either directly or by way of the protective and preventive services referred to in Article 7 of Directive 89/391/EEC. This shall be done in order to assess any risks to the safety or health and any possible effect on the pregnancy or 
breastfeeding, and to decide what measures should be taken. The Commission shall draw up guidelines on the assessment of the chemical, physical and biological agents and industrial processes considered dangerous for the health and safety of the relevant workers.

Substances listed on Annex I include (a) substances labelled R40, R45, R46 and R478 under Directive 67/548/EEC in so far as they do not appear on Annex II, (b) chemical agents in Annex I to Directive 90/394/EEC (2004/ For the purposes of this analysis, the chemical agents mentioned in Annex I, A.3(a) are relevant:

\section{Chemical agents}

The following chemical agents in so far as it is known that they endanger the health of pregnant women and the unborn child and in so far as they do not yet appear in Annex II:

(a) substances labelled R40, R45, R46, and R47 under Directive 67/548/EEC ( $\left.{ }^{2}\right)$ in so far as they do not yet appear in Annex II;

(b) chemical agents in Annex I to Directive 90/394/EEC (3);

(c) mercury and mercury derivatives;

(d) antimitotic drugs;

(e) carbon monoxide;

(f) chemical agents of known and dangerous percutaneous absorption

Health and safety signs at work: Council Directive 92/58/EEC of 24 June 1992;

Council Directive 1992/58/EEC is based on Article 138 of the EC Treaty and is an individual Directive within the meaning of Article 16 of Directive 89/391/EEC. It requests employers to provide safety and/or health signs as laid down in this Directive where hazards cannot be avoided or risks cannot be adequately reduced by techniques for collective protection or measures, methods or procedures used in the organization of work, or ensure that such signs are in place. In this connection, the employer shall take into account any risk evaluation made in accordance with Article 6(3)(a) of Directive 89/391/EEC. Wherever appropriate, signs used for road, rail, inland waterway, sea and air transport must be installed inside undertakings.

Directive 1992/58/EEC makes reference to the EU legislation on classification and labelling in its Annexes:

- Annex I, General minimum requirements concerning safety and/or health signs at work

12. Areas, rooms or enclosures used for the storage of significant quantities of dangerous substances or preparations must be indicated by a suitable warning sign taken from section 3.2. of Annex II, or marked as provided in section 1 of Annex III, unless the labelling of the individual packages or containers is adequate for this purpose. 
- Annex III, Minimum requirements governing signs on containers and pipes 1. Containers used at work for dangerous substances or preparations defined in Directives 67/548/EEC ( ${ }^{1}$ ) and 88/379/EEC $\left(^{2}\right.$ ) and containers used for the storage of such dangerous substances or preparations, together with the visible pipes containing or transporting dangerous substances and preparations, must be labelled (pictogram or symbol against a coloured background) in accordance with those Directives.

As can be seen any reference to the EU legislation on classification and labelling is confined to labelling: It refers to dangerous substances and preparations classified and labelled according to the provisions as set out in Directives 67/548/EEC and 1999/45/EC only in so far as the visibility of the labelling is concerned. Classification as such is not decisive for the obligations stipulated in Directive 1992/58/EEC. 



\section{Annex 5 - Examples of existing Community legislation under which substance-specific conditions are set}

Annex - Examples of existing Community legislation under which substance-specific conditions are set (from Annex XV guidance on restrictions)

\begin{tabular}{|c|c|c|c|}
\hline Instrument & Coverage & Conditions & Notes \\
\hline \multicolumn{4}{|l|}{ Environment-Water } \\
\hline $\begin{array}{l}\text { Directive } 96 / 61 / E C \\
\text { Integrated Pollution } \\
\text { Prevention and Control } \\
\text { (IPPC) Directive }\end{array}$ & $\begin{array}{l}\text { Industry branches listed } \\
\text { in Annex } 1 \text {, mainly large } \\
\text { industry installations, for } \\
\text { some branches produc- } \\
\text { tion threshold }\end{array}$ & $\begin{array}{l}\text { - Community emission } \\
\text { limit values (not used so } \\
\text { far); and } \\
\text { - in plant by plant } \\
\text { permits emission limit } \\
\text { values or other condi- } \\
\text { tions to control the risk } \\
\text { for the environment. }\end{array}$ & $\begin{array}{l}\text { - BREFs can be used to } \\
\text { support the work of } \\
\text { Member State competent } \\
\text { authorities. }\end{array}$ \\
\hline $\begin{array}{l}\text { Directive } 2000 / 60 / E C \\
\text { Water Framework Direc- } \\
\text { tive (WFD) }\end{array}$ & $\begin{array}{l}\text { Inland surface water, } \\
\text { transitional waters, } \\
\text { coastal waters and } \\
\text { groundwaters }\end{array}$ & $\begin{array}{l}\text { - Community EQS for } \\
\text { substances listed in } \\
\text { Annex X; } \\
\text { - Community wide } \\
\text { emission controls for } \\
\text { point and diffuse sour- } \\
\text { ces of substances listed } \\
\text { in Annex X; and } \\
\text { - river basin measures } \\
\text { to control point and } \\
\text { diffuse source dis- } \\
\text { charges liable to cause } \\
\text { pollution. } \\
\text { - Note however Article } \\
61 \text { (5) (c) (ii) }\end{array}$ & $\begin{array}{l}\text { - Daughter directives for } \\
\text { hazardous substances } \\
\text { listed in Annex X and for } \\
\text { groundwaters under } \\
\text { development; and } \\
\text { - Annex X will be re- } \\
\text { viewed regularly. }\end{array}$ \\
\hline $\begin{array}{l}\text { Directive } 76 / 464 / E E C \\
\text { Dangerous Substances } \\
\text { Directive } \\
\text { Note that this is repealed } \\
\text { and replaced by Directive } \\
\text { 2006/11/EC }\end{array}$ & $\begin{array}{l}\text { Lists I \& II of substances } \\
\text { dangerous to the } \\
\text { aquatic environment }\end{array}$ & $\begin{array}{l}\text { - List I discharges must } \\
\text { be authorised, such } \\
\text { authorisation laying } \\
\text { down emission stan- } \\
\text { dards for discharges to } \\
\text { waters and, where } \\
\text { necessary, to sewers. } \\
\text { Competent authorities } \\
\text { were required to draw } \\
\text { up an inventory of the } \\
\text { discharges; and } \\
\text { - for List II, Member } \\
\text { States must establish } \\
\text { pollution reduction } \\
\text { programmes including } \\
\text { water quality objectives. }\end{array}$ & $\begin{array}{l}\text { - To be integrated into } \\
\text { WFD by } 2013\end{array}$ \\
\hline
\end{tabular}




\begin{tabular}{|c|c|c|c|}
\hline Instrument & Coverage & Conditions & Notes \\
\hline \multicolumn{4}{|l|}{ Environment-Air } \\
\hline $\begin{array}{l}\text { Directive 96/61/EC IPPC } \\
\text { Directive }\end{array}$ & $\begin{array}{l}\text { Industry branches listed } \\
\text { in Annex 1, mainly large } \\
\text { industry installations, for } \\
\text { some branches produc- } \\
\text { tion threshold }\end{array}$ & $\begin{array}{l}\text { - Community emission } \\
\text { limit values (not used so } \\
\text { far); and } \\
\text { - In plant by plant } \\
\text { permits emission limit } \\
\text { values or other condi- } \\
\text { tions to control the risk } \\
\text { for the environment. } \\
\text { - Note however Article } \\
61 \text { (5) (c) (i) }\end{array}$ & $\begin{array}{l}\text { - BREFs can be used to } \\
\text { support the work of } \\
\text { Member State competent } \\
\text { authorities } \\
\text { - Emission control prin- } \\
\text { ciple }\end{array}$ \\
\hline $\begin{array}{l}\text { Directive 1999/13/EC } \\
\text { Volatile Organic Com- } \\
\text { pounds (VOC) Directive }\end{array}$ & $\begin{array}{l}\text { - Activities listed in } \\
\text { Annex I; and } \\
\text { - solvent consumption } \\
\text { thresholds in Annex IIA. }\end{array}$ & $\begin{array}{l}\text { - Emission limit values } \\
\text { (Annex IIA); and } \\
\text { - fugitive emission } \\
\text { values (\% of solvent } \\
\text { input) (Annex IIA). }\end{array}$ & $\begin{array}{l}\text { - Emission limit values } \\
\text { are for the sum of all } \\
\text { VOCs used in the activity } \\
\text { not for individual sub- } \\
\text { stances } \\
\text { - Substances or prepara- } \\
\text { tions which, because of } \\
\text { their content of VOCs } \\
\text { classified as CMRs under } \\
\text { Directive } 67 / 548 / E E C \\
\text { (assigned R45, R46, } \\
\text { R49, R60, R61), shall be } \\
\text { replaced, as far as } \\
\text { possible, by less harmful } \\
\text { substances or prepara- } \\
\text { tions within the shortest } \\
\text { possible time. }\end{array}$ \\
\hline \multicolumn{4}{|l|}{ Environment-Other } \\
\hline $\begin{array}{l}\text { Directive 2002/95/EC } \\
\text { Restriction of Hazardous } \\
\text { Substances (RoHS) } \\
\text { Directive }\end{array}$ & $\begin{array}{l}\text { Electrical and electronic } \\
\text { equipment falling under } \\
\text { categories set in Annex } \\
\text { IA to Directive } \\
2002 / 96 / E C \text { (Waste } \\
\text { Electrical and Electronic } \\
\text { Equipment) }\end{array}$ & $\begin{array}{l}\text { - New equipment may } \\
\text { not contain Pb, Hg, Cd, } \\
\mathrm{Cr}(\mathrm{VI}), \mathrm{PBB}, \mathrm{PBDE} \text {; and } \\
\text { - exempted applications } \\
\text { listed in an Annex. }\end{array}$ & $\begin{array}{l}\text { - Stakeholder consulta- } \\
\text { tion on proposals for } \\
\text { additional exemptions } \\
\text { ongoing }\end{array}$ \\
\hline $\begin{array}{l}\text { Directive 91/157/EEC, } \\
\text { Directive } 98 / 101 / \text { EC } \\
\text { Note that with effect of } \\
26 / 9 / 2008, \text { this will be } \\
\text { repealed and replaced by } \\
\text { Directive } 2006 / 66 / E C\end{array}$ & $\begin{array}{l}\text { Batteries and accumula- } \\
\text { tors }\end{array}$ & $\begin{array}{l}\text { - Marketing of batteries } \\
\text { and accumulators } \\
\text { containing more than } \\
0,00005 \% \text { of } \mathrm{Hg} \text { prohib- } \\
\text { ited (exemption: more } \\
\text { than } 2 \% \text { of } \mathrm{Hg} \text { in button } \\
\text { cells) }\end{array}$ & $\begin{array}{l}\text { - The revision of the } \\
\text { directives is under } \\
\text { preparation }\end{array}$ \\
\hline $\begin{array}{l}\text { Directive } 86 / 278 / \text { EEC } \\
\text { Sewage Sludge Directive }\end{array}$ & $\begin{array}{l}\text { Protection of the envi- } \\
\text { ronment, and in particu- } \\
\text { lar of the soil, when } \\
\text { sewage sludge is used } \\
\text { in agriculture }\end{array}$ & $\begin{array}{l}\text { - Limit values for con- } \\
\text { centrations of heavy } \\
\text { metals in the soil (Annex } \\
\text { IA), in sludge (Annex IB) } \\
\text { and for the maximum } \\
\text { annual quantities of } \\
\text { heavy metals which may } \\
\text { be introduced into the } \\
\text { soil (Annex IC) }\end{array}$ & $\begin{array}{l}\text { - At present, it applies to } \\
\text { metals only. }\end{array}$ \\
\hline $\begin{array}{l}\text { Regulation 850/2004 } \\
\text { Persistent Organic } \\
\text { Pollutants }\end{array}$ & $\begin{array}{l}\text { It implements the } \\
\text { provisions of the Stock- } \\
\text { holm Convention. }\end{array}$ & $\begin{array}{l}\text { - Dioxins, furans and } \\
\text { PCBs are listed as } \\
\text { unintentionally released } \\
\text { POPs for which the } \\
\text { releases should be } \\
\text { continuously and cost- } \\
\text { effectively reduced as } \\
\text { soon as possible. }\end{array}$ & \\
\hline
\end{tabular}




\begin{tabular}{|c|c|c|c|}
\hline Instrument & Coverage & Conditions & Notes \\
\hline \multicolumn{4}{|l|}{ Occupational health } \\
\hline $\begin{array}{l}\text { Dir 98/24/EC Chemical } \\
\text { Agents at Work Directive }\end{array}$ & $\begin{array}{l}\text { Hazardous chemical } \\
\text { agents present at the } \\
\text { workplace }\end{array}$ & $\begin{array}{l}\text { - Community binding } \\
\text { OELs (annex I); } \\
\text { - binding biological limit } \\
\text { values (annex II); and } \\
\text { - prohibitions of the } \\
\text { production, manufacture } \\
\text { or use at work of (cur- } \\
\text { rently 4) substances } \\
\text { listed in Annex III. }\end{array}$ & $\begin{array}{l}\text { - Some indicative OEL } \\
\text { values have been estab- } \\
\text { lished for } 102 \text { substances } \\
\text { by Directives } \\
\text { 91/322/EEC, } \\
\text { 2000/39/EC, and } \\
\text { 2006/15/EC }\end{array}$ \\
\hline $\begin{array}{l}\text { Directive } 2004 / 37 / E C \\
\text { Carcinogens and } \\
\text { Mutagens Directive }\end{array}$ & $\begin{array}{l}\text { - Exposure of workers to } \\
\text { carcinogens and } \\
\text { mutagens; and } \\
\text { - covers also sub- } \\
\text { stances unintentionally } \\
\text { released by processes } \\
\text { listed in Annex I. }\end{array}$ & $\begin{array}{l}\text { - OELs in annex IIIA; } \\
\text { and } \\
\text { - possibility to set other } \\
\text { related provisions in } \\
\text { Annex IIIB (not used so } \\
\text { far). }\end{array}$ & $\begin{array}{l}\text { - Reduction and re- } \\
\text { placement of carcino- } \\
\text { gens and mutagens in so } \\
\text { far as technically possible } \\
\text { - Prevention and reduc- } \\
\text { tion of exposure to } \\
\text { carcinogens and } \\
\text { mutagens via use in } \\
\text { closed systems in so far } \\
\text { as technically possible }\end{array}$ \\
\hline $\begin{array}{l}\text { Directive 92/85/EEC } \\
\text { Pregnant Workers } \\
\text { Directive } \\
\text { including COM(2000) } \\
466 \text { final/2 }\end{array}$ & $\begin{array}{l}\text { - Exposure of pregnant } \\
\text { workers and workers } \\
\text { who have recently given } \\
\text { birth or are breastfeed- } \\
\text { ing; and } \\
\text { - covers carcinogenic } \\
\text { substances, mutagenic } \\
\text { substances and sub- } \\
\text { stances toxic to repro- } \\
\text { duction. }\end{array}$ & $\begin{array}{l}\text { - Employer to assess } \\
\text { the nature, degree and } \\
\text { duration of exposure for } \\
\text { Annex I substances; } \\
\text { and } \\
\text { - exposure to agents } \\
\text { listed in Annex II to be } \\
\text { prohibited. }\end{array}$ & \\
\hline $\begin{array}{l}\text { Directive 94/33/EC } \\
\text { Protection of Young } \\
\text { Workers at the Work- } \\
\text { place Directive }\end{array}$ & $\begin{array}{l}\text { Harmful exposure to the } \\
\text { physical, biological and } \\
\text { chemical agents re- } \\
\text { ferred to in point I of the } \\
\text { Annex }\end{array}$ & $\begin{array}{l}\text { - Article } 7 \text { (2) prohibits } \\
\text { the employment of } \\
\text { young people for work } \\
\text { involving harmful expo- } \\
\text { sure to agents which are } \\
\text { toxic, carcinogenic, } \\
\text { cause heritable genetic } \\
\text { damage, or harm to the } \\
\text { unborn child or which in } \\
\text { any other way chroni- } \\
\text { cally affect human } \\
\text { health. }\end{array}$ & \\
\hline \multicolumn{4}{|l|}{ Consumers } \\
\hline $\begin{array}{l}\text { Directive 98/83/EC } \\
\text { Drinking Water Directive }\end{array}$ & $\begin{array}{l}\text { Water intended for } \\
\text { human consumption }\end{array}$ & $\begin{array}{l}\text { - Minimum limit values } \\
\text { for substances listed in } \\
\text { Annex } 1 \text { part B }\end{array}$ & \\
\hline $\begin{array}{l}\text { Directive 88/378/EEC } \\
\text { Toys Directive }\end{array}$ & $\begin{array}{l}\text { Toys as defined in } \\
\text { Article } 1\end{array}$ & $\begin{array}{l}\text { - Limit values for } \\
\text { bioavailability of metals } \\
\text { resulting from the use of } \\
\text { toys }\end{array}$ & $\begin{array}{l}\text { - Use of certain sub- } \\
\text { stances in toys restricted } \\
\text { by Directive 76/769/EEC }\end{array}$ \\
\hline $\begin{array}{l}\text { Directive 89/197/EEC } \\
\text { Food Additives Directive }\end{array}$ & $\begin{array}{l}\text { Additives to be used in } \\
\text { foodstuffs }\end{array}$ & $\begin{array}{l}\text { - Positive list of sub- } \\
\text { stances (only these to } \\
\text { be used in foodstuffs } \\
\text { and only certain condi- } \\
\text { tions specified therein) }\end{array}$ & \\
\hline
\end{tabular}




\begin{tabular}{|c|c|c|c|}
\hline Instrument & Coverage & Conditions & Notes \\
\hline $\begin{array}{l}\text { Regulation } 726 / 2004 / E C \\
\text { Medicinal Products }\end{array}$ & $\begin{array}{l}\text { - Safety, quality and } \\
\text { efficacy of medicinal } \\
\text { products for humans } \\
\text { and domestic animals; } \\
\text { and } \\
\text { - medicinal products } \\
\text { listed in Annex and } \\
\text { medicinal products } \\
\text { fulfilling requirements } \\
\text { set in article } 3.2 \text { and } 3.3 \\
\text { and the applicant } \\
\text { requests a marketing } \\
\text { authorisation at Com- } \\
\text { munity level. }\end{array}$ & $\begin{array}{l}\text { - Marketing authorisa- } \\
\text { tion of medicinal prod- } \\
\text { ucts for human and } \\
\text { veterinary use in the } \\
\text { centralised procedure at } \\
\text { Community level; } \\
\text { - only authorised me- } \\
\text { dicinal products may be } \\
\text { placed on the market } \\
\text { (authorisation at Com- } \\
\text { munity or national level); } \\
\text { - the authorisation may } \\
\text { include conditions or } \\
\text { restrictions; and } \\
\text { - an application has to } \\
\text { include evaluation of the } \\
\text { potential environmental } \\
\text { risk and specific ar- } \\
\text { rangements to limit the } \\
\text { risk need to be envis- } \\
\text { aged. }\end{array}$ & $\begin{array}{l}\text { - Directive 2001/83/EC } \\
\text { (as last amended by } \\
\text { Directive 2004/27EC) } \\
\text { and Directive } \\
\text { 2001/82/EC (as last } \\
\text { amended by } \\
\text { 2004/28/EC) cover } \\
\text { marketing authorisations } \\
\text { for medicinal products for } \\
\text { human and veterinary } \\
\text { use outside the Centrally } \\
\text { authorisation procedure } \\
\text { (Community authorisa- } \\
\text { tions) }\end{array}$ \\
\hline $\begin{array}{l}\text { Regulation } 648 / 2004 / E C \\
\text { Regulation on Detergents }\end{array}$ & $\begin{array}{l}\text { - Detergents and surfac- } \\
\text { tants to be used in } \\
\text { detergents }\end{array}$ & $\begin{array}{l}\text { - Lays down require- } \\
\text { ments on degradability } \\
\text { of surfactants to be } \\
\text { used in detergents }\end{array}$ & \\
\hline $\begin{array}{l}\text { Framework Regulation } \\
1935 / 2004 \text { and all the } \\
\text { legal instruments deriving } \\
\text { from this, such as Coun- } \\
\text { cil Directive } 78 / 142 / E C \\
\text { on Vinyl chloride } \\
\text { Food contact materials }\end{array}$ & $\begin{array}{l}\text { - Sets up general } \\
\text { requirements for all food } \\
\text { contact materials. }\end{array}$ & $\begin{array}{l}\text { - The different legal } \\
\text { instruments that have } \\
\text { been produced under } \\
\text { this Framework Regula- } \\
\text { tion regulate migration } \\
\text { levels and contents of } \\
\text { different substances in } \\
\text { food contact materials }\end{array}$ & $\begin{array}{l}\text { - Follow this link for } \\
\text { further details: } \\
\text { http://ec.europa.eu/food/f } \\
\text { ood/chemicalsafe- } \\
\text { ty/foodcontact/index_en. } \\
\text { htm }\end{array}$ \\
\hline $\begin{array}{l}\text { Directive 2004/42/EC } \\
\text { VOC Paints Directive }\end{array}$ & $\begin{array}{l}\text { - The use of organic } \\
\text { solvents in certain paints } \\
\text { and varnishes and } \\
\text { vehicle refinishing } \\
\text { products }\end{array}$ & $\begin{array}{l}\text { - For the paints, the } \\
\text { Directive sets up two } \\
\text { sets of limit values for } \\
\text { the maximum contents } \\
\text { of VOCs in g/litre of the } \\
\text { product ready for use. } \\
\text { - For vehicle refinishing } \\
\text { products there is only } \\
\text { one set of limit values } \\
\text { for the VOC contents. } \\
\text { - It also lays down } \\
\text { special labelling provi- } \\
\text { sions. }\end{array}$ & \\
\hline
\end{tabular}




\section{Annex 6 - Workshop Agenda}

Notes; For the division of breakout groups and processes for discussion in each group see the separate paper. 



\section{Annex 7 - Tasks for consideration and discussion in the breakout groups at the Workshop}

\begin{tabular}{ll}
\hline Group number & Processes for discussion \\
\hline 1 & $\begin{array}{l}\text { Substance evaluation } \\
\text { Dossier evaluation } \\
\text { Harmonised classification and labelling (minor) }\end{array}$ \\
& $\begin{array}{l}\text { Harmonised classification and labelling } \\
\text { SVHC for the candidate list } \\
\text { Authorisation (minor) }\end{array}$ \\
& $\begin{array}{l}\text { Restrictions } \\
\text { Substance Evaluation }\end{array}$ \\
& SVHC for the candidate list \\
4 & Authorisation \\
& Restrictions (minor) \\
\hline
\end{tabular}

Tasks

- Discuss the following issues for the processes selected for your group. Processes indicated with "minor" could be discussed in less detail.

o Issue 1: Aim and objective of the process

- Are there any major differences in perception about the aim of the process compared to the description in the background document?

o Issue 2: Identification of main influencing factors

- Are the main influencing factors identified in Annex I? Are there any others not included?

- Are there any factors more/less important? Is it possible to rank the different influencing factors? Are any of them dependent of each other etc?

- Consider relations and links between the processes (and identify links that could influence the priority setting)

o selected for your group,

o if time allows, discuss relations and links to other processes.

- What are the possibilities for (Nordic) cooperation?

- What are the possibilities for using (Q)SARs/non-test methods for prioritisation? 
- The rapporteurs are asked to document and present the outcome of the discussion in the breakout groups by electronic means, e.g. Power Point Presentation. The co-rapporteur will assist the rapporteur with chairing the meeting if necessary. Computers will be available for those rapporteurs that will not bring their laptops. 


\section{Annex 8 - Workshop participants}

\begin{tabular}{|c|c|c|c|}
\hline Group & Processes for discussion & $\begin{array}{l}\text { Rapporteur } \\
\text { Co-rapporteur }\end{array}$ & Participants \\
\hline 1 & $\begin{array}{l}\text { Substance evaluation } \\
\text { Dossier evaluation } \\
\text { Harmonised classification and labelling } \\
\text { (minor) }\end{array}$ & $\begin{array}{l}\text { Jaana Heiskanen } \\
\text { Jörgen Henriksson }\end{array}$ & $\begin{array}{l}\text { Riitta Leinonen } \\
\text { Marie Holmer } \\
\text { Marianne van der Hagen } \\
\text { Joke Herremans } \\
\text { Katarina Lundberg }\end{array}$ \\
\hline 2 & $\begin{array}{l}\text { Harmonised classification and labelling } \\
\text { SVHC for the candidate list } \\
\text { Authorisation (minor) }\end{array}$ & $\begin{array}{l}\text { Henrik Tyle } \\
\text { Alicja Andersson }\end{array}$ & $\begin{array}{l}\text { Kirsi Annola } \\
\text { Heidi Morka } \\
\text { André Muller } \\
\text { Sten Flodström }\end{array}$ \\
\hline 3 & $\begin{array}{l}\text { Restrictions } \\
\text { Substance Evaluation }\end{array}$ & $\begin{array}{l}\text { Jon Birger Aarnes } \\
\text { Elisabeth Karlsson }\end{array}$ & $\begin{array}{l}\text { Marianne Hänninen } \\
\text { Frank Jensen } \\
\text { Ingunn Myhre } \\
\text { Ivar Lundbergh }\end{array}$ \\
\hline 4 & $\begin{array}{l}\text { SVHC for the candidate list } \\
\text { Authorisation } \\
\text { Restrictions (minor) }\end{array}$ & $\begin{array}{l}\text { Anna Wik } \\
\text { Lolo Heijkenskjöld }\end{array}$ & $\begin{array}{l}\text { Outi Tunnela } \\
\text { Bent Horn Andersen } \\
\text { Angelika Baumbusch } \\
\text { Marianne Tvermyr Holmen } \\
\text { Lars Gustafsson }\end{array}$ \\
\hline
\end{tabular}

